\title{
Décadrages Décadrages
}

cinéma, à travers champs Cinéma, à travers champs

40-42 | 2019

Cinéma ethnographique

\section{Par-delà le cinéma ethnographique : John Marshall et le projet Kalahari}

\section{Carolyn Anderson}

Traducteur : François Bovier

\section{OpenEdition \\ Journals}

Édition électronique

URL : https://journals.openedition.org/decadrages/1453

DOI : $10.4000 /$ decadrages. 1453

ISSN : 2297-5977

Éditeur

Association Décadrages

Édition imprimée

Date de publication : 1 novembre 2019

Pagination : 150-225

ISBN : 978-2-9700963-6-8

ISSN : 2235-7823

\section{Référence électronique}

Carolyn Anderson, « Par-delà le cinéma ethnographique : John Marshall et le projet Kalahari », Décadrages [En ligne], 40-42 | 2019, mis en ligne le 01 septembre 2021, consulté le 04 avril 2022. URL : http://journals.openedition.org/decadrages/1453 ; DOI : https://doi.org/10.4000/decadrages.1453 
1 La traduction usuelle en français de «sequence films» est «séquencesévénements» (voir son utilisation systématique dans Paul Henley, «Le récit dans le film ethnographique», trad. Corinne Hewlett, L'Homme, n ${ }^{\circ}$ I98-i99, 20II, pp. I3I-I57). Cette traduction restitue bien le sens de cette notion discutée plus loin par Carolyn Anderson dans son article, mais elle ne permet pas de rendre compte de la distinction entre «sequence films» et «event films». Nous prenons donc ici le parti de transcrire littéralement cette expression en français, malgré son caractère inusité: soit «film(s)-séquence(s)». Sa relation ou son opposition avec l'expression «sequence shot» [plan-séquence] s'en trouve ainsi renforcée. [Note du traducteur.]

2 John Marshall, cité dans Carolyn Anderson et Thomas W. Benson, «Put Down the Camera and Pick Up the Shovel: An Interview with John Marshall», dans Jay Ruby (éd.), The Cinema of John Marshall, Coire, Harwood Academic Publishers, I993, p. I35 [Sauf indication contraire, je traduis les citations - NdT]. Cet entretien est élaboré à partir d'interviews conduites au domicile de Marshall à Peterborough, le 27 décembre I986, et à Cambridge, le 28 décembre i989. Une première version de cet entretien est parue en allemand: « «Setz die Kamera ab und greif zur Schafel.> Ein Interview Mit John Marshall», dans Reinhard Kapfer, Werner Petermann et Ralph Thomas (éd.), Jager und Gejagte: John Marshall und seine Filme, Munich, Trickster Verlag, I99I, pp. I35-r65. J'ai interviewé pour la première fois John Marshall le I3 avril I984 dans son domicile à Cambridge; ma dernière visite remonte au printemps 2004 dans son domicile à Belmont.

\section{Carolyn Anderson}

(traduction de l'américain par François Bovier)

\section{Par-delà le cinéma ethnographique : John Marshall et le projet Kalahari}

Depuis les annéEs i950, LE CinÉAste américain John Marshall est une figure incontournable du cinéma ethnographique; au début du $\mathrm{XXI}^{\mathrm{e}}$ siècle, son influence est toujours aussi présente. Le parcours filmique de Marshall anticipe un tournant majeur dans le cinéma documentaire et ethnographique, interrogeant les relations entre l'observateur et le sujet observé. Il renonce rapidement au style narratif mythique qui caractérise sa démarche au début des années 1950, optant pour le mode d'observation et la clarté caractéristiques du cinéma direct. Documentant diverses interactions sociales en Afrique et aux ÉtatsUnis, Marshall est un pionnier des courts «films-séquences» [sequence films $]^{1}$ dans les années 1960, privilégiant de longues prises de vues, sans intervention de mise en scène ou de montage. En réponse à la crise qui frappe la représentation dans l'anthropologie et le cinéma ethnographique à partir de la fin des années i970, ses films adoptent un tournant réflexif en présentant explicitement les interventions du cinéaste au moment du tournage et leurs effets. Pendant plusieurs décennies, Marshall a développé une forme de cinéma participatif, en privilégiant des productions collaboratives répondant aux nécessités économiques et aux impératifs politiques des sujets qu'il filme. L'impact de Marshall sur le cinéma ethnographique repose sur sa détermination à devenir indissociablement un cinéaste et un citoyen du monde actif.

Lorsqu'on lui pose la question sempiternelle des débuts de sa carrière filmique, John Marshall a coutume de répondre: «Eh bien, j’ai commencé par défaut»; et il poursuit en rapportant une histoire qu'il aime à raconter à propos des expéditions de son père et de sa famille en Afrique $^{2}$. Cette histoire, relative aux débuts d'une carrière qui va devenir exceptionnelle, est en tout point remarquable. 
Le père de John, Laurence Kennedy Marshall, et sa mère, Lorna McLean Marshall, travaillent en tant qu'anthropologues, sans être pour autant des chercheurs formés à cette discipline. Laurence a un diplôme en physique et a travaillé en tant qu'ingénieur; Lorna a un diplôme en littérature anglaise et a enseigné au Mount Holyoke College. L'anthropologue Margaret Mead, qui fait figure de pionnière dans l'utilisation du film dans la recherche ethnographique, a été invitée au domicile familial, près du campus de l'Université de Harvard, à Cambridge (Massachusetts), et «a donné des conseils à propos du travail sur le terrain ${ }^{3}$. Les contacts entre Mead et la famille Marshall se poursuivront sur de nombreuses décennies.

Laurence Marshall cofonde en 1922 l'American Appliance Company, compagnie à succès renommée Raytheon Manufacturing Company en I925; il en est le président de 1928 à $1948^{4}$. En I949, Laurence et Lorna Marshall se rendent en Afrique du Sud dans le cadre d'un voyage d'affaires qui les conduit autour du monde. Raytheon est devenu un leader dans le développement du radar pendant la Seconde Guerre mondiale, et Laurence a le projet de vendre un système de guidage radar pour les ports aux autorités de Cape Town. Alors qu'il est à Cape Town, Laurence achète des cartes d’Afrique du Sud établies par l'armée américaine et est intrigué par la recherche d'une éventuelle cité perdue dans le désert du Kalahari ${ }^{5}$.

Une année plus tard, Laurence se retire de Raytheon pour s'occuper de son fils John, alors âgé de 17 ans ${ }^{6}$. Elizabeth, la sœur de John, a récusé l'histoire régulièrement rapportée de l'origine des expéditions des Marshall:

[Laurence] n’avait pas besoin de dépenser des centaines de milliers de dollars, de s'accaparer plusieurs années de nos vies, et de nous amener dans l'un des territoires sauvages et inexplorés les plus vastes du monde, à des milliers de kilomètres de secours en cas d'urgence. [...] Je suis persuadée que nous n'étions pas partis là-bas simplement pour que notre père apprenne à mieux nous connaître. Nous nous y sommes rendus car il aimait les espaces sauvages. ${ }^{7}$

Quelle que soit sa motivation, Laurence Marshall n'est pas en vacances, mais investi d'une mission. Le président du Peabody Museum d'archéologie et d'ethnologie à l’Université de Harvard, J. O. Brew, a rapporté à Laurence les rumeurs et les conjectures selon lesquelles des
3 Nancie L. Gonzalez, «A Film Argument», dans Jay Ruby (éd.), The Cinema of John Marshall, op.cit., p. 192, note 5. Gonzalez considère que le point de vue de Mead sur le cinéma en tant qu'outil de recherche est «très proche de ce qu'elle a fini par définir comme les principaux enjeux des films de Marshall».

4 Dès I950, Laurence Marshall est devenu riche, à l'opposé de son enfance passée à Sommerville, en tant que «fils unique de parents qui étaient désespérément pauvres». Voir Elizabeth Marshall Thomas, Dreaming of Lions: My Life in the Wild Places, White River Junction, Chelsea Green Publishing, 2013 (réédition en 2016), p. 26. Lorna McLean est née en Arizona (avant que l'Arizona ne devienne un État). Son père était un ingénieur des mines décédé lorsque Lorna avait 7 ans. Jeune adulte, elle a renoncé à une carrière dans le ballet pour voyager à travers le monde avec sa mère, veuve à deux reprises. Voir Douglas Martin, «Lorna Marshall, Early Scholar on Africa's Bushmen", New York Times, 30 juillet 2002. Lorna trouvera par la suite le ciel étoilé des nuits d'Afrique du Sud rassurant, car il lui rappelle son enfance dans le Sud-Ouest américain. (Conversation avec l'auteure.)

5 Un chirurgien de Cape Town, E.van Zyl (ou F.D. du Toit van Zyl), préparait une telle expédition; Laurence a demandé à s'y joindre. Voir Carolyn Anderson et Thomas W. Benson, «Put Down the Camera and Pick Up the Shovel: An Interview with John Marshall», op.cit., pp. 135 -136.

6 Id., p. I35.

7 Elizabeth Marshall Thomas, Dreaming of Lions, op. cit., p. 26. 
8 Carolyn Anderson et Thomas W. Benson, «Put Down the Camera and Pick Up the Shovel», op. cit., p. 136.

9 En 2003, John et Elizabeth ont fait don des journaux, des registres et des notes de travail de leurs parents documentant leurs expéditions entre I95I et I96I en Afrique (voir Peabody Museum 2003.36, Lorna and Laurence Marshall Expeditionary Notebooks and Journals, Peabody Museum of Archaeology and Ethnology, Harvard University). La lettre du Smithsonian Institute est signée par A. Wetmore, secrétaire, et datée du ro mai I950 (Peabody Museum, 2003.36.I.20, n. p.). Laurence a aussi obtenu des lettres d'introduction et de recommandation de J.O. Brew, directeur du Peabody Museum, à l'Université d'Harvard, et de Leonard Carmichael, président du Tufts College (l'alma mater de Laurence).

10 Voir Ilisa Barbash, Where the Roads All End: Photography and Anthropology in the Kalahari, Cambridge, Peabody $\mathrm{Mu}$ seum Press/Harvard University, 20ı6, Appendice A, pp. 20I-206, pour la liste des membres des différentes expéditions, de I950 à I96r. Dans son livre, Barbash s'appuie sur les 40 ooo photographies conservées dans les archives du Peabody pour considérer le rôle crucial joué par la photographie dans le projet des Marshall sur la durée et dans la création d'un imaginaire du Bochiman. Plus de 300 images sont reproduites dans Where the Roads All End. Les photographes professionnels Merl La Voy et Emil Paul Friede ont participé à l'expédition de I950; leurs photographies, et celles de F. D. van Zyl, sont incluses dans la collection du Peabody, parmi des photographies d'autres professionnels prises pendant les expéditions suivantes (id., p. 73).

peuples de chasseurs-cueilleurs vivent au fin fond du désert du Kalahari. Entrer en contact avec un peuple qui peut ouvrir «une fenêtre sur le Pléistocène à laquelle personne n’a osé rêver» fascine tant le père que le fils Marshall ${ }^{8}$. Afin d'obtenir les visas et les permissions nécessaires, Laurence sollicite une lettre d'introduction de la Smithsonian Institution, une institution vénérée à Washington. Ce précieux sésame précise que Laurence et son fils John voyagent dans l'Union d'Afrique du Sud, dans le Sud-Ouest africain et dans le Bechuanaland (à présent le Botswana)
dans le but d'étudier et photographier les gravures rupestres des Bochi- mans. [...] Ils souhaitent aussi photographier les tribus autochtones qui produisent leur forme actuelle d'expression artistique. [...] Monsieur Marshall [Laurence] a développé des techniques spéciales de photogra- phie qui, on le croit, permettront de réaliser des études sur ces sujets dignes d'intérêt et plus précises que celles réalisées jusqu'à aujourd'hui. [...] Le travail envisagé, sous l'autorité de la Smithsonian Institution, est de nature purement scientifique. Toute aide [...] sera hautement appré- ciée par la Smithsonian Institution. ${ }^{9}$

Laurence n'est pas un photographe professionnel. La mention de «techniques spéciales de photographie» renvoie probablement au fait que l'aîné Marshall a utilisé l'un des premiers appareils Polaroid lors de son expédition en 1950. Cet appareil révolutionnaire, récemment inventé par un ami de Laurence, Edwin Land (en I948), n’a pas encore été mis largement en circulation. Dès le départ, la photographie joue un rôle prédominant dans les expéditions des Marshall, Laurence et John étant équipés à la fois de caméras et d’appareils photographiques en i950. Ils ont pris des centaines de photographies ${ }^{10}$. John a aussi tourné des plans, même s'il a déclaré par la suite: «Je ne pense pas avoir tourné un seul mètre de film utilisable. ${ }^{11}$

Il est impossible de déterminer à quel point ces professionnels ont partagé leur expertise avec la famille Marshall.

11 John Marshall, «Filming and Learning», dans Jay Ruby (éd.), The Cinema of John Marshall, op. cit., p. 25. Cet essai de i33 pages constitue le compte rendu le plus exhaustif publié par John Marshall sur le projet de la famille Marshall et sur sa propre carrière de cinéaste. Dans son carnet de i950, Laurence liste les adresses de laboratoires Kodak à Cape Town, à Johannesburg, à Durban, au Caire et en Alexandrie (Peabody $\mathrm{Mu}-$ seum, 2003.36.r.20, n. p.). Certaines indications dans ses carnets permettent d'établir que la plupart des films ont été envoyés et développés aux États-Unis. 
De juin à septembre I950, Laurence et John Marshall traversent les territoires non cartographiés du Kaokoveld du Sud-Ouest africain en prenant part à l'expédition de F. D. van Zyl, un voyage que John décrira plus tard comme "extraordinaire» ${ }^{12}$. Les Marshall ne parviennent pas à situer les villages des Bochimans mais ils rencontrent, à la fin de ce voyage, deux Ju/'hoansi (Ao// et /Qui); ils conçoivent alors le projet d'une expédition l'année suivante, pendant laquelle les Bochimans et les Marshall se rencontreront ${ }^{13}$.

\section{L'expédition de 1951}

Il ne faut pas sous-estimer le fait que les rencontres entre les Marshall et les Bochimans constituent avant tout des événements de familles. À l'été I95ı, l'ensemble de la famille Marshall, c'est-à-dire Laurence, Lorna, John et sa sœur Elizabeth (qui a I9 ans, une année de plus que John), voyagent dans le Sud-Ouest africain. L'expédition de six semaines (financée par Laurence) est sponsorisée par le prestigieux Peabody Museum; assez étonnamment, aucun anthropologue ou étudiant diplômé en anthropologie culturelle de Harvard ou d'ailleurs n'a accepté l'offre de les accompagner, tous frais payés ${ }^{14}$. Néanmoins, un anthropologue physique d'Afrique du Sud, ainsi que des entomologistes d'Afrique du Sud et d'Angola se sont joints au groupe. Les Marshall ont aussi l'obligation d'intégrer un représentant officiel du gouvernement, en l'occurrence Claude McIntyre, au sein de leur équipe de vingt-quatre personnes (comprenant le personnel). McIntyre (qui deviendra par la suite préposé aux Affaires bochimanes dans le Sud-Ouest africain) «les a conduits vers leur principal site de recherche à Nyae Nyae et a déterminé les paramètres de leurs activités » ${ }^{15}$. Avec l'aide d'interprètes, l'équipe de l'expédition est capable de communiquer dans quinze langues différentes.

Le premier contact des Marshall avec les Bochimans à Nyae Nyae dans la région du Sud-Ouest africain est passé par $\neq$ Toma, un «homme talentueux et d'une intelligence remarquable, tenu en grande estime par les siens». Il deviendra l'ami le plus fidèle des Marshall pendant des décennies. Après trois jours d’observation et de discussion (en passant

12 John Marshall, «Filming and Learning», op. cit., p. 25 .
13 Lorna Marshall, The !Kung of Nyae Nyae, Cambridge, Mass., Harvard University Press, 1976, p.3; Carolyn Ander- son et Thomas W. Benson, «Put Down the Camera and Pick Up the Shovel», op. cit., p. I36. Pour une analyse historique lucide de l'utilisation de ces catégories (à partir du XVII ${ }^{\mathrm{e}}$ siècle), voir Mathias Guenther, « «San〉 or «Bushmen〉?», dans Megan Biesele, Robert Gorden et Richard Lee (éd.), The Past and Future of !Kung Ethnography: Critical Reflections and Symbolic Perspectives, Essays in Honour of Lorna Marshall, Hambourg, Helmut Buske Verlag, I986, pp. 27-5I. «Bochiman» est le terme le plus ancien, parfois considéré comme dépréciatif. Le terme «San» a été adopté par le «Groupe de Harvard» en 1973; mais il a aussi des connotations péjoratives. Guenther recommande (avec circonspection) le maintien ou un retour à l'ancienne désignation. Les peuples autochtones auprès de qui la famille Marshall a vécu ne se conçoivent pas comme un groupe unique ou unifié, et ne se désignent pas à travers un nom unique; aussi les concepts de Bochiman ou de San constituent-ils des notions de Blancs ou de colons. La famille Marshall désigne simplement ces personnes comme les !Kung de Naye Naye ou les Ju/wasi (ou les Ju/'hoansi). Les essais recueillis dans The Past and Future of !Kung Ethnography ont été initialement présentés lors d'un Festschrift en l'honneur de Lorna Marshall en 1986.

14 Voir Lorna Marshall, The !Kung of Nyae Nyae, op.cit., p. xiv. Un étudiant de Harvard diplômé en archéologie, Robert Dyson, les a accompagnés pendant l'expédition de I95I (id., p. I). Dyson deviendra par la suite le directeur du Musée d'archéologie et d'anthropologie de l'Université de Pennsylvanie (1982-I994). 15 Voir Ilisa Barbash, Where the Roads All End, op. cit., p. 36. 
16 Toutes les citations de ce paragraphe proviennent de Lorna Marshall, The !Kung of Nyae Nyae, op. cit., p. 3.

17 Id., p. 204, note 3. Elizabeth Marshall précise: "Il n'est pas nécessaire d'être du même sang. [...] Votre place dans un système peut reposer sur le nom que l'on vous attribue.» (Elizabeth Marshall Thomas, Dreaming of Lions: My Life in the Wild Places, op. cit., p. 49).

18 Elizabeth Marshall Thomas, The Old Way: A Story of the First People, New York, Farrar, Straus, Giroux, 2006, p. 62. Par la suite, Elizabeth revient sur le sujet de cette culture matérielle et estime que chaque Ju/'hoan avait au moins dix-neuf ou vingt objets personnels (Dreaming of Lions, op. cit., p. 50).

19 Carolyn Anderson et Thomas W. Benson, "Put Down the Camera and Pick Up the Shovel», op. cit., p. 136.

20 John Marshall, «Filming and Learning», op. cit., p. 48 . par l'intermédiaire d'interprètes) avec les Marshall, ₹Toma, le chef du Groupe I du peuple !Kung, décide de soutenir le but avoué des Marshall: "C'est une bonne chose pour des peuples qui vivent différemment d'apprendre à se connaître mutuellement du mieux qu'ils peuvent.» Lorna a résumé leur séjour de six semaines à travers cette formule: «La chance fut d'emblée de notre côté et ne s'est pas démentie par la suite» ${ }^{16}$.

₹Toma accepte que les Marshall vivent au sein de sa famille et, dans un élan de générosité, il attribue de nouveaux noms de famille aux Marshall: Lorna reçoit le nom de la mère de $\neq$ Toma, Di/ /khao N!a (la Vieille Di//khao), Laurence le nom de son père, Tsamgao N!a, Elizabeth celui de la sœur de sa femme, Dilai, et $\neq$ Toma donne son propre nom à John ${ }^{17}$. Ces noms permettent d'établir des relations de parenté entre les Ju/'hoansi et les Marshall; néanmoins, l'expression «vivre avec» ne se confond pas avec l'expérience «vivre comme». Elizabeth Marshall se souvient, qu'en sus de multiples véhicules,

nous avions des tentes, des lits de camp, des sacs de couchage, des
chaises pliantes et des tables, des cartes, un compas, des caméras, de
la pellicule, des enregistreurs, des livres de référence, des plumes, de
l'encre, des crayons, du désinfectant, un anti-venin contre les morsures
de serpent, du Brandy, une réserve de boîtes de conserve et d'aliments
secs, des assiettes, des casseroles, des poêles, des couteaux, des four-
chettes et des cuillers, des cigarettes et des allumettes, des roues de se-
cours, des chambres à air, des rustines, des crics, des treuils, des pièces
d'automobile de rechange, une boîte à outils, de l'huile de moteur, des bi-
dons d'essence, des réservoirs d'eau, des savons, des serviettes, des gants
de toilette, du dentifrice et des brosses à dents, des vestes, des pulls, des
pantalons, des bottes, des baskets, des chemises, des sous-vêtements,
des chaussettes, des lunettes de lecture, des épingles de sûreté, des ci-
seaux, une boîte de couture, des jumelles, des munitions et des armes.
Les Ju/wasi avaient des bâtons, des peaux, des coquilles d'œufs et de
l'herbe. ${ }^{18}$

Laurence veut un «rapport complet» sur le peuple !Kung qu'il aspire à connaître; et comme l'équipe ne comprend pas d'ethnologues ni de cinéastes formés, le patriarche assigne différents rôles aux membres de sa famille: Lorna occupe la fonction d'ethnographe; Elizabeth doit écrire un livre; John reçoit une caméra avec cette recommandation: «Tourne les films!» ${ }^{19}$. John se souviendra par la suite que «Laurence pensait que personne ne croirait à nos études sans preuves filmiques ${ }^{20}$. Laurence 
assume la logistique; il prend aussi des photographies, qui s'intègreront à une collection de dizaines de milliers de diapositives en couleur et de photographies en noir et blanc, constituant une preuve visible de leurs recherches ${ }^{21}$. Quand les Marshall prennent des polaroïds et présentent le résultat, les !Kung sont «surpris mais jamais mystifiés en se voyant eux-mêmes ou leurs proches » ${ }^{22}$. Parfois, les polaroïds servent de cadeaux, reçus avec plaisir ou provoquant le rejet, comme le note Lorna dans son journal:

Les portraits de paysage étaient accueillis avec des cris d'émerveillement - ce «oooh» aigu qui est si surprenant -, avec sourire, bavardage et excitation. Chaque famille avait un cri qui lui était propre. Jamais aucune expression négative ne s'était manifestée. Mais un homme, /Qui, nous a répondu quand nous lui avons dit qu'il pouvait garder la photographie: «Que voulez-vous que j’en fasse?» ${ }^{23}$

Les !Kung, auprès de qui les Marshall vivent, intègrent rapidement la caméra comme faisant partie de leur vie quotidienne.

En i95I, John n’a aucune connaissance du cinéma. Non seulement il n'a pas suivi de formation professionnelle, mais en plus il ne connaît pas du tout l'histoire du cinéma ethnographique ${ }^{24}$. Au début, l'adolescent s'efforce de suivre les instructions inscrites sur les bobines de pellicule Eastman Kodak de roo pieds que son père a acquises pour lui: à savoir, tourner successivement un plan large, un plan moyen et un gros plan. Il place sa caméra légère Bell and Howell sur un trépied. Comme John n’a

21 Megan Biesele estime leur nombre à 20000 ( $(\mathrm{A}$ Tribute to Lorna Marshall», dans M. Biesele, Robert Gorden et Richard Lee (éd.), The Past and Future of !Kung Ethnography, op. cit., p. I4). La collection complète conservée dans les archives du Peabody Museum avoisine les 40 ooo images, mais ce nombre inclut les travaux de bien d'autres photographes. Suivant le protocole établi par Mead, un catalogue raisonné désigne précisément chaque photographie ou diapositive prise (Ilisa Barbash, Where the Roads All End, op.cit., p.39), mais sans indiquer le nom du photographe. Laurence utilisait un Leica $35 \mathrm{~mm}$ Stereo Realist et une Polaroid Land Camera (id., p. xxix et p. 70).

22 John Marshall, «Filming and Learning», op.cit., p.32. Pendant les expéditions, les polaroïds permettaient aux Marshall d'évaluer les niveaux d'exposition des photographies, d'expérimenter avec la composition du cadre, d'identifier des personnes et de constituer des cadeaux (Ilisa Barbash, Where the Roads All End, op.cit., p. 7o). Par le passé, les Marshall avaient pris une série de photo- graphies anthropomorphiques, mais ils ont vite renoncé à ce type d'images (id., pp. 55-57). Plusieurs entrées dans le journal de Lorna en 195I indiquent son engagement dans les tournages. Elle mentionne une «leçon en stéréo»; elle inclut des notes de tournage, des indications pour différents types de pellicule, des schémas de profondeur de champ, des tables d'exposition, etc.; elle s'interroge sur «la meilleure manière de faire des portraits de visages foncés». Le 2r août, elle écrit: «J'ai tourné un film» dans ses commentaires qui portent sur ce qu'elle prend (à tort) pour une «danse de guerre» (Peabody Museum, 2003.36.r.2, n. p.).

23 Journal de Laurence Marshall, entrée datée du 24 juillet I95I, citée par Ilisa Barbash (Where the Roads All End, op.cit., pp. 70-7I).

24 Dans l'entrée d'avril-mai i95 I de son journal, Laurence mentionne trois livres relatifs au cinéma: Film Technique de V.I. Pudovkin, Basic Film Techniques de Raymond Spottiswoode et Film Strip Guide de Katherine M. Holden, en plus d'un manuel $16 \mathrm{~mm}$ pour professionnels et amateurs. Nous ignorons si ces trois références, qui sont d'ordre théorique ou pratique, ont été consultées par Laurence ou John (ou les deux) avant ou pendant l'expédition de i95I (qui a débuté en septembre). Laurence note aussi le nombre de projecteurs $16 \mathrm{~mm}$ sonores ( Iо० ०००) disponibles dans les écoles (et ailleurs aux États-Unis : 250 ooo), ainsi que l'adresse et un contact à l'Association des bibliothèques du cinéma éducateur (Educational Film Library Association) de New York. Dès ses débuts dans le milieu du cinéma, il semble avoir à l'esprit le réseau de diffusion du cinéma éducateur (Peabody Museum, 2003.36.r.6, n. p.). 


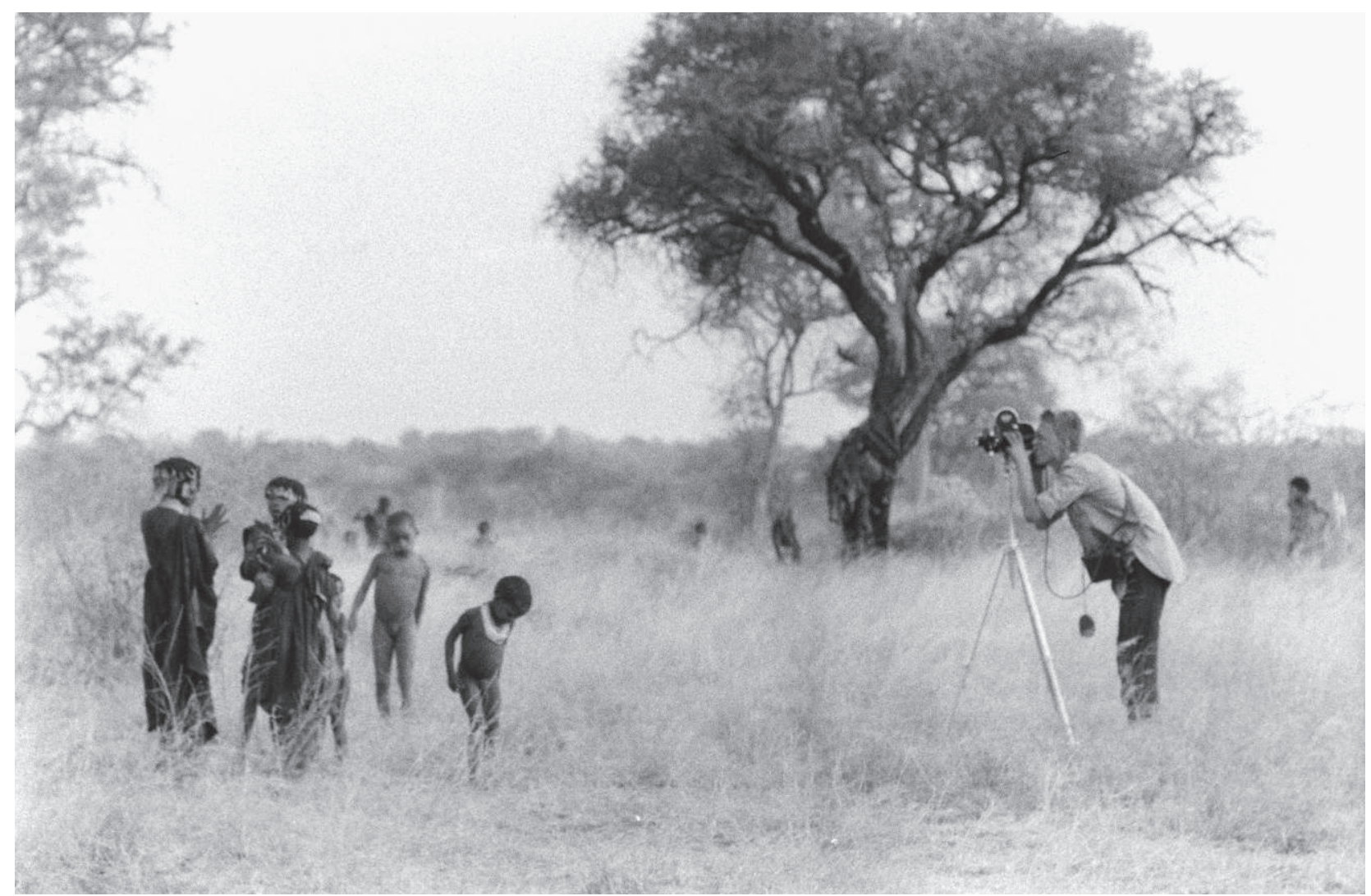


pas la possibilité de voir les rushes, il s'en remet au laboratoire où la pellicule est envoyée pour évaluer la netteté et l'exposition des images; mais il n'a pas de retour sur le contenu ou le rythme des plans. Quand il peut enfin voir les rushes, il s'est «immédiatement rendu compte qu'il avait fait de nombreuses erreurs, le film s'apparentant aux images animées d'une conférence illustrée» ${ }^{25}$.

Malgré l'aspect approximatif des instructions de Laurence Marshall lorsqu'il ordonne à son fils de «tourner», il semble avoir une idée claire de leur finalité. Sa femme précise dans son journal la pensée de Laurence:

D’après moi, Laurence envisage cette expédition comme le moyen de réaliser des films qui pourraient servir de matériaux sources pour l'anthropologie. Il pense que cette discipline ne peut pas se développer sans le point de vue d'une personne compétente sur ces matériaux. Il est convaincu que ces matériaux ne peuvent pas être exploités - ou la vérité apparaître - sans l'implication de nombreux chercheurs. [...] Les images doivent selon lui constituer le principal medium de notre contribution pour I) établir les faits et 2) présenter des matériaux qui permettent de questionner les conclusions auxquelles nous pourrions aboutir. Il projette de consacrer son expérience acquise dans le développement industriel à résoudre ces problèmes. ${ }^{26}$

Laurence et Lorna Marshall reconnaissent qu'ils rencontrent des problèmes de limites des disciplines empruntées et qu'ils doivent développer d'autres méthodes. Mais ils ont confiance en la capacité du cinéma à documenter un changement culturel. En I927, Laurence et Lorna visitent l'Institut technologique de Leningrad pour approfondir leur recherche sur les condensateurs. Sur place, ils prennent connaissance du projet gouvernemental de «filmer la vie quotidienne et le développement de la technique dans les villages à travers toute la Russie». Des décennies plus tard, leur fils avance l'hypothèse que l'intérêt de Laurence pour la documentation de la culture pourrait bien trouver son origine dans ce voyage ${ }^{27}$. La croyance de Laurence dans les potentialités éducatives et informationnelles de la télévision aura été également visionnaire. Alors président de Raytheon, il initie en I944 un réseau de stations de relais et de diffusion à ondes courtes et ultracourtes à l'échelle nationale; et il est à l'origine de la décision de Raytheon d'obtenir les droits de Channel 2 (WGBH), la chaîne éducative de Boston ${ }^{28}$.
25 Carolyn Anderson et Thomas W. Benson, «Put Down the Camera and Pick Up the Shovel», op. cit., pp. I36-I37.

26 Entrée du journal de Lorna Marshall datée du I9 juin I952, citée par Nancie L. Gonzalez, "A Film Argument», dans Jay Ruby (éd.), The Cinema of John Marshall, op. cit., p. I82.

27 John Marshall, «Filming and Learning», op. cit., p. 23.

28 Id., p. 22. La licence pour Channel 2 a été abandonnée après moins de dix ans (id., p. 25). 


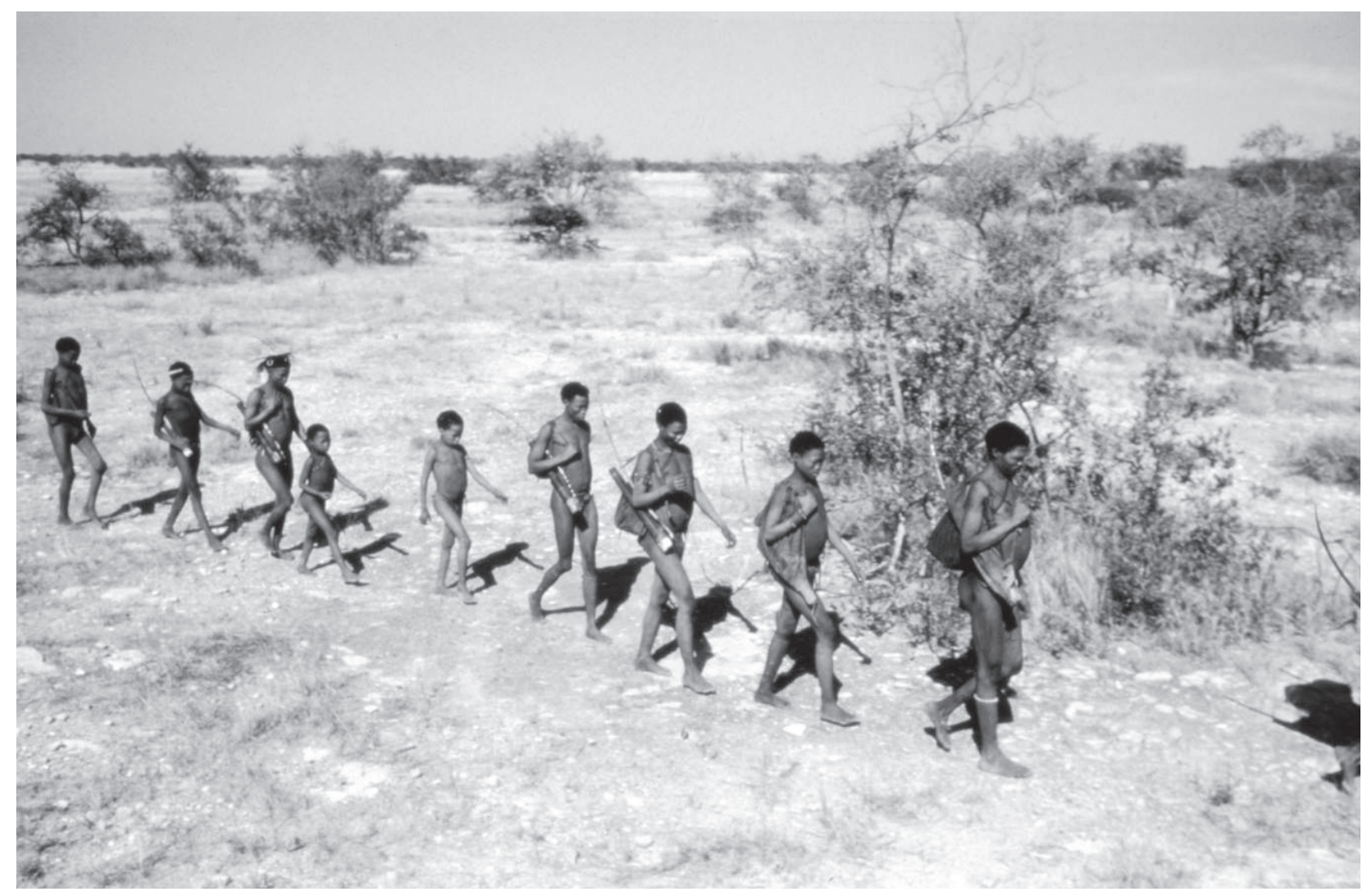




\section{First Film}

Le premier film produit à partir des plans tournés à Nyae Nyae par John et monté par Laurence, Lorna et le cinéaste Jerry Ballantine après leur retour en Nouvelle-Angleterre en I95I, est une affaire de famille. Son titre original était !Kung Bushmen of the Kalahari (I95I ${ }^{29}$. Ce film décisif, qui n'était pas accessible au public pendant plus de quarante ans, ne figure pas dans la filmographie de la série !Kung établie dans The Cinema of John Marshall, ni dans de nombreuses autres filmographies de Marshall. Actuellement intitulé (non sans autoréférentialité) First Film (I95I, I995) et disponible depuis I995 par le biais de DER [Documentary Educational Resources], ce premier documentaire n'est le plus souvent pas mentionné (on le comprend aisément) dans les études sur les films de Marshall ${ }^{30}$.

First Film commence de façon conventionnelle, avec la carte de la région géographique investiguée, une musique indigène et la voix désincarnée d'un narrateur. Cependant, deux caractéristiques insolites apparaissent immédiatement: le film est en couleur (une exception onéreuse pour un documentaire en I95I) et la voix narrative ne correspond pas au ton de baryton d'un homme qui fait autorité (la «voix de Dieu») mais à celle d'une femme qui s'exprime suivant un registre informel et amical ${ }^{31}$.

Lorna Marshall débute son récit avec des commentaires généraux sur «les 200 miles dépourvus d'eau et de route dans le Kalahari» et sur les 38 protagonistes du film, comprenant un groupe de Bochimans de /Gautscha, «le reliquat d'une ancienne race»; mais aussitôt, elle personnalise sa description, nomme des individus et donne des détails à leur sujet. Elle semble bien connaître ces personnes et inviter les spectateurs à faire également leur connaissance. L'utilisation fréquente de pronoms personnels (nous/je/à nous; ils/eux; vous) crée un effet d'intimité et de transparence qui peut paraître naïf ou amateur; mais en fait, elle anticipe une certaine réflexivité ethnographique, position qui sera considérée bien plus tard comme un impératif éthique par différents anthropologues culturels. Ce projet de film souligne la participation active des !Kung («ils nous montrent comment»; «les chasseurs nous montrent comment»), la présence des cinéastes («nous observions»; «au moment

29 Id., p. 30. John inscrit ce film (sous le titre de !Kung Bushmen of the Kalahari) dans sa liste de «films de référence» à la fin de son essai «Filming and Learning» (op. cit.). Dans l'entretien avec Anderson et Benson (Carolyn Anderson et Thomas
W. Benson, «Put Down the Camera and Pick Up the Shovel», op. cit., p. 137), John déclare que sa mère a monté ce film. Ballantine était un cinéaste basé à Boston qui réalisait des publicités pour la télévision et des documentaires. Sur le DVD distribué par Documentary Educational Resources (DER), les crédits pour First Film se limitent à «Raconté et monté par Lorna Marshall». Il n’y a pas de générique sur le film lui-même; cependant, le matériel promotionnel de DER crédite John en tant qu'opérateur. Le DVD distribué actuellement dure 45 minutes, même s'il est annoncé comme un film de 60 minutes - ce qui laisse entendre que le film ı6mm original de r95ı a été monté bien avant sa diffusion en 1995 .

30 Louvrage de Scott MacDonald, American Ethnographic Film and Personal Documentary: The Cambridge Turn (Berkeley, University of California Press, 2013), constitue une exception cruciale par rapport à cette ommission. Dans un chapitre remarquable qu'il intitule sobrement «Lorna and John Marshall», McDonald propose une analyse convaincante de First Film (id., pp. 2023). La perspicacité de MacDonald tout au long de son ouvrage a enrichi considérablement mon essai. Ilisa Barbash (Where the Roads All End, op.cit.) mentionne également brièvement First Film.

31 Bill Nichols a caractérisé de façon influente le mode d'adresse non synchronisé caractéristique du cinéma documentaire comme la «voix de Dieu» (Ideology and the Image: Social Representation in the Cinema and Other Media, Bloomington, Indiana University Press, I98I, p. I83; Representing the Real: Issues and Concepts in Documentary, Bloomington, University of Indiana Press, I99I, pp.34-38). 
32 Ce film, dans sa présentation d'ensemble de la vie des !Kung, semble s'adresser au grand-public; par la suite, de nombreuses activités montrées dans First Film seront au centre de courts «films-séquences» concentrés sur une activité unique et destinés à un public de spécialistes.

33 John se souvient que George P. Murdock avait fourni aux Marshall une «liste d'achats pour anthropologues sur le terrain", et que cette "liste commençait par la technologie» (Carolyn Anderson et Thomas W. Benson, «Put Down the Camera and Pick Up the Shovel», op.cit., p. 137). où nous étions là»; «nous pensons»; «nous comptions»), le public en tant que sujet («vous pouvez voir»; «comme vous le voyez»; «remarquez»; «regardez»), l’acte du tournage ( la caméra avec son objectif de quatre pouces de diamètre») et l'alliage de la narration à l'image dans la postproduction («ce matin de juillet»).

First Film s'ouvre sur des membres du groupe qui construisent des abris; le film se termine sur leur départ pour leur prochaine demeure temporaire. Entre-deux, nous sommes les témoins de la documentation de plus d'une douzaine d'activités, le plus souvent tournées en plan moyen, avec de nombreux gros plans de visages ou de mains au travail. Certaines activités sont différenciées et reliées à des problématiques de genre ou d'âge - des garçons posant des collets; des hommes chassant le gibier; un homme-médecine construisant un arc; des femmes rassemblant la nourriture et préparant les lits; des enfants qui jouent - bref, tout ce qui est présumé «typique» de la part d'autochtones ${ }^{32}$. Comme Laurence a demandé à son fils de «documenter la technologie», il y a beaucoup d'exemples de construction ou d'utilisation d'outils variés ${ }^{33}$.

Nous sommes les témoins d'une vie harmonieuse (la cuisine et le partage de la nourriture; des chants et des danses; des discussions et la consommation de tabac); nous apprenons que les Marshall «n'ont pas constaté de vol ou d'agression [mais] une honnêteté, une coopération et une intégration impressionnantes au sein de ce groupe lointain et indépendant». Les chants et les danses sont présentés comme des «arts»: ils sont «élevés, intenses et extrêmement formalisés». S’adressant avec complicité au public visé, Lorna note que «des mouvements aussi précis, rapides et infimes demandent autant de coordination qu'un ballet». Cette admiration et cette empathie s'appliquent aussi aux enfants, qui sont présentés comme «merveilleux» et «bien élevés» («Pendant toute la durée de notre séjour, nous n’avons vu aucun enfant puni.»). La différence est acceptée et reconnue - par exemple, un homme qui entre en transe devient le centre de l'attention, mais quand il revient à lui il se joint à nouveau au groupe. Une fillette qui danse, N!ai - qui occupera un rôle de plus en plus important dans les films suivants de Marshall - est singularisée et présentée comme une «fille insouciante». Plus tard, elle est décrite comme «intelligente» quand elle trouve un grand tubercule gris qu'elle mange en partie avant d’appliquer le schéma du partage caractéristique des !Kung. D’autres personnages sont nommés et caractérisés: «Ekai est un bon 
chasseur, un artisan, qui a confiance en lui»; Unka, une veuve, «semble parfois esseulée»; Gao «a l'air honnête, humble et responsable»; son épouse est «une femme gaie, qui ne s'en laisse pas imposer». Nous voyons des grands-pères qui «adorent» leurs petits-enfants, des maris qui sont «aimables et attentionnés». La description de qualités reconnaissables et admirables relativise (potentiellement) la distance entre le spectateur visé du Premier Monde et un groupe de personnes qui chassent avec des flèches empoisonnées et pour qui le sang est un met délicat.

Le fait que les Bochimans se déplacent sur 200 miles chaque année, ou tous les deux ans, pour commercer est mentionné (lorsque les pots et les haches confectionnés pour le commerce sont montrés); néanmoins, ces «gens, de petite stature mais forts» sont présentés comme isolés et autosuffisants, respectant les anciennes coutumes «qui développent la cohésion du groupe et non les tensions». Après une chasse fructueuse, quand la viande est distribuée conformément aux privilèges traditionnels décrits par Lorna, nous voyons une personne isolée qui mange. Lorna précise: «Ce doit être une vision séculaire: un homme à la peau foncée accroupi qui ronge un os à moelle.» Le film donne l'impression d'avoir accès à un passé très lointain. Que ce film et ceux qui suivront donnent à voir ou non l'image d'un présent authentique fera l'objet de débats des années plus tard, la controverse portant sur le fait que les Marshall ont idéalisé les Ju/'hoansi pour contrer les préjugés prévalant dans les années i950 sur la sauvagerie et la violence des Bochimans.

Nous ignorons tout du nombre de projections et du public de !Kung Bushmen of the Kalahari en I95I; mais dans son journal, Lorna mentionne que le film a été montré pendant le voyage de la famille sur le bateau African Crescent l'année suivante:

On nous a demandé de montrer notre film en soirée. J'aurais aimé qu'il soit parfait. J'ai honte de ses erreurs de rythmes, et des moments qui témoignent (par la texture de ma voix) que j'étais effrayée. [...] Je ferai mieux la prochaine fois - je redoublerai d'efforts. Mais il n'est pas incroyablement mauvais. ${ }^{34}$

34 Entrée du journal de Lorna Marshall datée du 21 juin I952, citée par Nancie L. Gonzalez («A Film Argument», op. cit., p. I83). Dans l'entretien avec Anderson et Benson, John se souvient d'une scène avec un millier d'habitants de Tsumkwe qui n’apparaît pas dans la version distribuée du film (Carolyn Anderson et Thomas W. Benson, «Put Down the Camera and Pick Up the Shovel», op.cit., p. I37); d'autres arguments encore permettent d'affirmer que le film a été raccourci. Lorsque Lorna parle d'une «prochaine fois», elle sous-entend qu'elle pense s’impliquer comme narratrice dans de futurs projets de films; ce ne sera pas le cas avant des décennies, quand sa voix over est intégrée à la bande son de $A$ Kalahari Family (2002). Dans ses notes de I95I, Lorna renvoie à des « diapositives en couleur pour des conférences», parmi d'autres sujets liés au cinéma (Peabody Museum, 2003.36.I.2, n. p.). Nous ne savons pas non plus quand le commentaire a été rajouté à la bande image, le directeur de DER suggérant que ce n’était pas avant les années I970; John M. Bishop, qui a été engagé pour transférer la collection de films de Marshall en i984, a émis l'hypothèse que les commentaires repris par la suite en voix over ont pu être récités oralement par Lorna dans les années I950 pour accompagner des conférences (Scott MacDonald, American Ethnographic Film and Personal Documentary, op. cit., p. 22). L'entrée du journal de Lorna qui mentionne la «texture de sa voix» laisse penser que la voix over était présente dans le film en i952. Voir John M. Bishop, «Hot Footage/Cold Storage», dans Jay Ruby (éd.), The Cinema of John Marshall, op. cit., p. 22I. "Pendant les expéditions I et II nous utilisions une caméra Kodak (avec des magasins de 50 pieds) et des caméras Bell and Howell Filmo 7oD (avec des magasins de roo pieds); aucune de ces caméras n'avait de viseur, ni de mise au point à travers la lentille. Et leurs moteurs d'enroulement ne supportaient que des prises de vues de trente secondes.» (id., p. 22I). De telles contraintes, et l'absence d'expérience de John, expliquent l'imagerie essentiellement statique de First Film. 
35 Entrée du journal de Lorna Marshall datée du 2 juillet i952, p. 22 (Peabody Museum, 2003.36.4).

36 Nancie L. Gonzalez, "A Film Argument», op. cit., p. 184 .

37 Id., p. I8o.

38 Entrée du journal de Lorna Marshall datée du I8-ı9 juin I952, pp. Io-I4 (Peabody Museum 2003.36.4).
Malgré les appréhensions de Lorna, le film de Marshall a suscité de l'intérêt: lorsque la famille a fait escale à la baie de Walor, «d'autres personnes sont montées à bord pour voir le film » ${ }^{35}$. Le documentaire a par la suite été montré à des représentants du gouvernement et à des notables influents à Windhoek (la capitale du Sud-Ouest africain) qui «l'ont jugé 〈charmant 〉 dans son reflet de la 〈vie autochtone ${ }^{36}$.

\section{L'expédition de 1952-53}

Le is juin 1952, Laurence, Lorna, John et Elizabeth Marshall embarquent sur l'African Crescent à New York pour un voyage de deux semaines et demie à destination du Sud-Ouest africain. Le navire de la Farrell Lines sert à la fois de bateau de passagers et de cargo de ligne. Les Marshall ont rempli les cales de leur cargaison personnelle:

Littéralement des tonnes d'équipement et de fournitures, allant d'une jeep et d'un camion à des cartons de Scotch, des perles de pacotille, de la viande en conserve et une énorme quantité d'équipement de cinéma et de pellicule [...]. ${ }^{37}$

Dans l'entrée du i8 juin de son journal, Lorna note: «nous avons commencé à discuter notre angle d'approche et nos travaux» ${ }^{38}$. Elle précise qu'elle a lu les trois livres de Margaret Mead et qu'elle a envoyé un télégramme à Jo [Brew] pour demander à Mead comment elle se présentait sur le terrain pour justifier sa présence. Lorna relève qu'elle aurait aimé que l'anthropologue chevronnée lui explique «ce qu’elle disait et ce qu'ils disaient. Comment elle faisait pour que ça marche.» John devient cinéaste en bricolant avec les moyens du bord; Lorna et Elizabeth apprennent elles-mêmes sur le terrain le métier d'anthropologue. Lorna l'exprime ainsi: «C’est un pari insensé». Le jour suivant, après une discussion en famille sur le cinéma, Lorna note ses craintes: «Nous avons peut-être placé la barre trop haut, mais cela n’a pas d'importance. Si nous échouons - eh bien quoi?»

La troisième expédition des Marshall constitue pour Laurence, Lorna et Elizabeth leur plus long séjour en Afrique (treize mois) et, selon Lorna, le plus important pour leur travail. Cette expédition est cofinancée par la Smithsonian Institution et le Harvard Peabody Museum. Ces institutions américaines respectées confèrent sérieux et expertise aux expéditions des Marshall; comme Laurence Marshall finance toutes ses expéditions, il en conserve le contrôle sur le plan administratif. L'équipe 


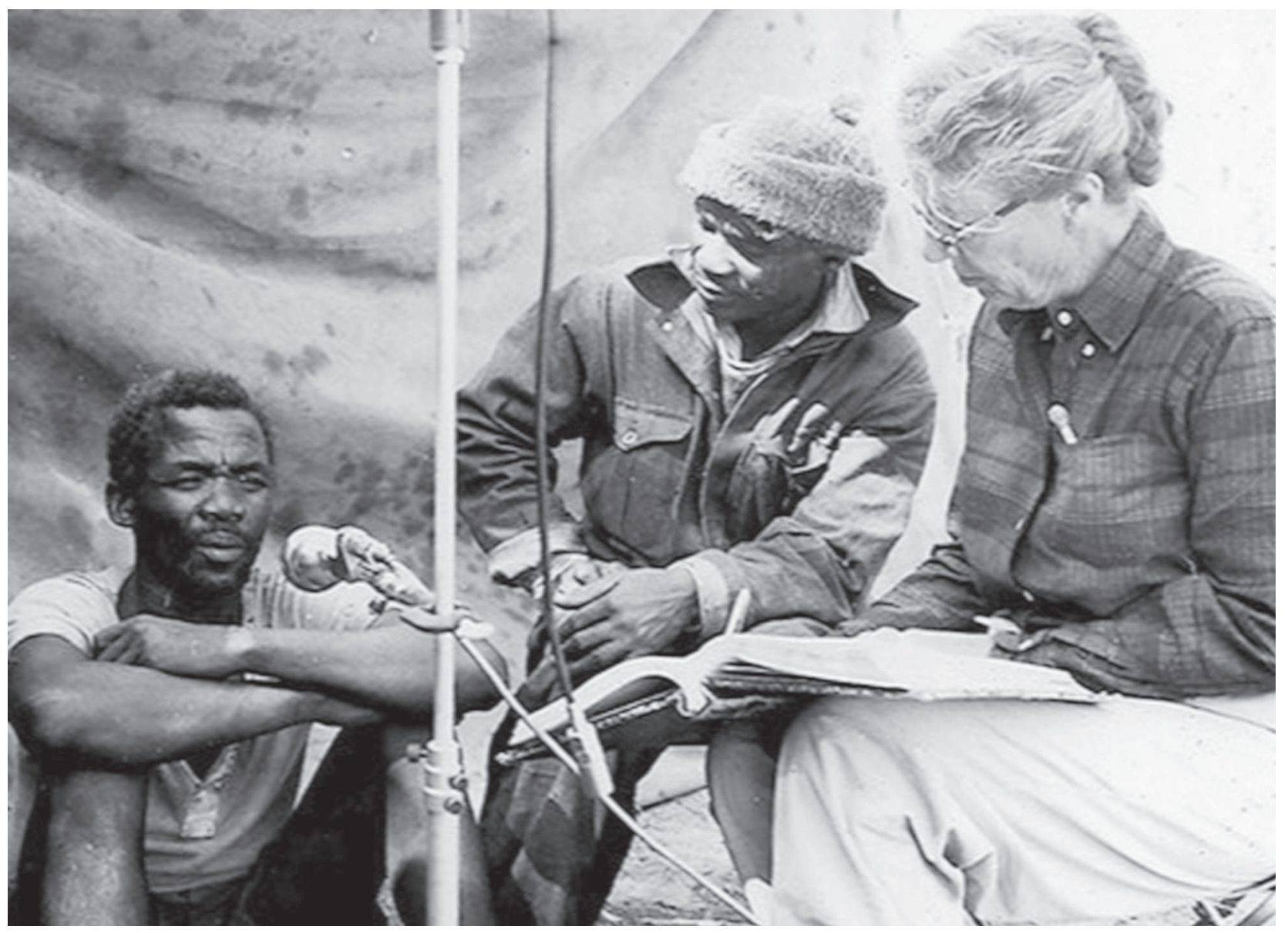


39 Brew était lui-même archéologue; en I952, le Peabody Museum comprenait des collections ethnographiques significatives et il accueillera par la suite la collection des Marshall. Brew tenait un journal qui peut être consulté au Peabody. Pour les noms, les fonctions et les dates de participation des membres de l'expédition de I952-I953, voir Ilisa Barbash, Where the Roads All End, op. cit., pp. 203-204.

40 John M. Bishop, «Hot Footage/Cold Storage», op. cit., p. 22I. Cette troisième expédition est la première qui donne lieu à des tournages en plans continus [shotby-shot logs].

41 Ibid.

42 Carolyn Anderson et Thomas W. Benson, "Put Down the Camera and Pick Up the Shovel», op. cit., p. I37. L'absence de retours techniques sur le matériel filmé explique en partie cette tendance, renforcée par le fait que les parents de John l'encourageent à tourner autant de plans qu'il le veut. Tout au long de sa carrière, John est davantage un opérateur qu'un monteur.

43 Nancie L. Gonzalez, "A Film Argument», op. cit., p. I8o. Dans un entretien en 200 avec Cynthia Close sur Studio One, la chaîne câblée de Cambridge, John affirme qu'il était dans le Sud-Ouest africain pendant dix-huit mois en 1952I953, revenant au Massachusetts pour quelque semaines pendant cette période («Between Two Worlds: John Marshall»).

44 Laurence proposera par la suite à des amis et collègues des séances de «visionnement stéréoscopique» dans son domicile à Cambridge (Ilisa Barbash, Where the Roads All End, op. cit., p. 83).

45 John Marshall, «Filming and Learning», op. cit., p. 137 . de 34 personnes comprend Charles O. Handley, un mammalogiste associé à la Smithsonian Institution, un botaniste du Jardin botanique national de Kirstenbosch (Afrique du Sud) et un linguiste de l'Université de Londres, ainsi que des preneurs de son et un photographe. Mais il n'y a toujours pas d'anthropologue. J. O. Brow, le directeur du Peabody, les rejoint rapidement pour un séjour de six semaines ${ }^{39}$.

Les Marshall reviennent au Massachusetts une année plus tard avec 8 o bobines de films (trois en noir et blanc, le reste en Kodachrome). L'équipement comprenait, outre une Bell et Howell et des petites caméras Kodak déjà utilisées lors des deux premières expéditions, une Bolex et une Kodak C2 (toutes deux avec des chargeurs de roo pieds) ${ }^{40}$. Les plans tournés lors de l'expédition de 1952-53 formeront le contenu de !Kung Bushman Hunting Equipment, The Hunters et Wildebeest (raccourci par la suite pour donner lieu à A Rite of Passage en I972) ${ }^{41}$. Mais tout cela n'interviendra que plus tard. Pendant plus d'une année sur le terrain, ils ne peuvent pas voir les rushes; et le laboratoire ne donnant aucune nouvelle, John a juste «tourné, tourné et encore tourné» ${ }^{42}$.

Pendant leur séjour de quatorze mois dans le Sud-Ouest africain, Lorna «quitte rarement la brousse»; elle consacre son temps à élargir et approfondir son étude des coutumes et des croyances des !Kung et à prendre des notes de terrain ethnographiques précises ${ }^{43}$. Elizabeth, qui a abandonné après une première année le Smith College, note ses impressions et ses expériences dans ses journaux, s’immergeant dans la vie sociale de leurs hôtes. Laurence supervise l'expédition et continue à prendre des photographies ${ }^{44}$. John, qui a appris à parler Tsumkwe, passe la plupart de son temps à chasser avec les !Kung et est passionné par le tournage. Des années plus tard, il décrira cette période «comme les meilleures années de [s]a vie, les plus heureuses, sans aucun doute. C'était une expérience extraordinaire pour un jeune homme de mon âge, dans un tel lieu avec un peuple comme les Tsumkwe, des gens tout à fait accueillants et bienveillants ${ }^{45}$.

Selon les souvenirs de John, il est évident que vivre avec les Ju/'hoansi constitue à tous les égards une «expérience extraordinaire» pour lui et sa famille; mais les journaux de Lorna témoignent de moments (compréhensibles) de dépression et de désillusion à Nyae Nyae. Par exemple, elle écrit: 
Elizabeth est vraiment déprimée. John se sent lamentable. [...] Ils ne sont pas heureux. La tension est trop forte. Aucun d'entre nous ne sommes formés à ce que nous faisons. Nous avons l'impression d'être inadaptés. ${ }^{46}$

Ils envisagent de mettre terme à leur voyage des mois plus tôt, sans le faire pour autant. Tous les membres de la famille Marshall éprouvent des difficultés physiques à Nyae Nyae: Laurence est mordu par un babouin et par la suite par un scorpion; Lorna a des problèmes intestinaux; Elizabeth se blesse le pied; John (qui est asthmatique) souffre de toux chronique.

Malgré ces désagréments, la famille persévère. Les journaux de Lorna rédigés pendant les années 1952-53 révèlent une habitude récurrente de débattre en famille de leurs buts et leurs méthodes. Par exemple, le 27 octobre 1952 :

Laurence et John sont en pleine discussion. [...] Le problème débattu porte sur les éléments dramatiques qui pourraient être développés à partir des matériaux tournés pour aboutir à un film comme ceux de Flaherty. Les Bochimans ne vivent pas théâtralement. Les dangers qu’ils endurent - la faim ou la soif - ne sont pas restituables plastiquement. [...] John a une très bonne compréhension des éléments dramatiques, mais aucun d'entre nous ne voit comment développer ces éléments. Ils ne sont pas visuels, ni adaptés au cinéma. Le réalisateur du film va devoir les mettre en forme. Est-ce possible sans jeu d'acteurs? ${ }^{47}$

John n'a pas encore vu Nanook of the North (1922), film classique que ses parents semblent connaître ${ }^{48}$. À propos d'un projet de film sur la cueillette des noix de mangetti, Lorna écrit:

Comment satisfaire le public en montrant [les Ju/'hoansi] qui arrivent sans encombre sur les lieux, cueillent les noix et reviennent en toute sécurité? ${ }^{49}$

En fin de compte, le film portera sur la chasse à la girafe et non sur la cueillette de noix pour répondre au désir des Marshall de reproduire la dramaturgie du cinéma de Flaherty - ce qui leur permet de mettre visuellement en scène des actions périlleuses qui pourront plaire au public sur le long terme. Lorna et Laurence sont "plongés dans un dilemme» par rapport aux circonstances de la mise à mort de la girafe; mais ils ont confiance dans le nombre de plans dramatiques accumulés par le jeune cinéaste qui peuvent donner lieu à un film répondant à leurs aspirations ${ }^{50}$.
46 Entrée du journal de Lorna Marshall datée du I8 octobre 1952, p. 273 (Peabody Museum 2003.36.I.4).

47 Id., p. 284.

48 John Marshall, «Filming and Learning», op. cit., p. 4 ०.

49 Entrée du journal de Lorna Marshall datée du 8 octobre I952, p. 285 (Peabody Museum 2003.36.I.4).

50 La chasse aux girafes était considérée comme le Jeu Royal. Chasser les girafes était interdit, bien que les lois en matière de chasse ne s'appliquent pas en général aux Bochimans. Comme la flèche a été tirée par les Bochimans depuis une jeep des Marshall, ils avaient peur d'avoir enfreint la loi. Laurence avait l'intention d'avouer aux administrateurs à Windhoek ce qui s'était passé et d'accepter les pénalités si nécessaire. Voir l'entrée du journal de Lorna Marshall datée du 8 septembre I952, pp. I80I8I (Peabody Museum, 2003.3.36.I.4). 
51 Lorna Marshall, citée par Ilisa Barbash, Where the Roads All End, op.cit., p. 72 .

52 John a par la suite décrit le montage comme un effort solitaire ( Filming and Learning», op. cit., p. 36); il faisait peutêtre référence au montage initial du film d'une durée de 45 minutes.

53 Gardner était le petit-fils de la collectionneuse d'art et de la philanthrope Isabella Stewart Gardner et le cousin du poète Robert Lowell.

54 Gardner avait réalisé Blunder Harbour (I95I) et Dances of the Kwakiuti (I95I), deux documentaires sur les Kwakiutl, et Mark Tobey (I952), un portrait du peintre homonyme.

55 Voir Scott MacDonald (American Ethnographic Film and Personal Documentary, op. cit., pp. 65-74) pour une discussion des relations entre Gardner et Marshall. La figure 7 (id., p. 67) présente une photographie de John Marshall à l'âge de 22 ans et de Robert Gardner à l'âge de 29 ans (portant des cravates), derrière une table de montage au Film Study Center du Peabody-Harvard.

56 Id., pp. 65-66. Le rôle de la "créativité» dans le cinéma ethnographique servira par la suite de ligne de partage permettant de distinguer les intentions et les pratiques des Marshall et de Gardner.
Cependant, les journaux de Lorna de cette période révèlent son angoisse (intermittente) de ne pas en faire assez:

Il serait formidable d'aboutir à un film documentaire de valeur au vu des efforts, des dépenses et du temps consentis, de l'absence de Nana la mère de Lorna] et des amis, du sacrifice de John et Eliz d'une année au collège, du délaissement de nos métiers et de nos prochaines étapes de vie. L'expédition est une expérience enrichissante mais, comme le disait Eliz l'autre soir, elle n'est dans l'intérêt direct d'aucun d'entre eux. ${ }^{51}$

Et en effet, pendant des années, le tournage de John à Nyae Nyae et les écrits d'Elizabeth sur ses expériences ne semblent guère s'inscrire «dans l'intérêt direct» de l'un comme de l'autre.

\section{Le montage de The Hunters}

Après leur retour en Nouvelle-Angleterre à la fin de l'été I953, John entreprend des études en anthropologie à Harvard et monte un studio de montage au troisième étage de la maison familiale à Cambridge ${ }^{52}$. Différents points de vue s'affrontent quant au degré d'implication et aux débuts de l'intervention de Robert Gardner sur le projet du montage de ce qui allait devenir un classique du cinéma ethnographique: The Hunters. Gardner appartient à une famille distinguée de Boston ${ }^{53}$. S’exprimant avec aisance, sûr de lui, habitué aux voyages, et de sept ans plus âgé que John Marshall, il avait en 1953 une licence de baccalauréat de Harvard et était un étudiant diplômé en anthropologie. Gardner a déjà produit, réalisé et monté trois films documentaires, dont deux sur des peuples autochtones (la tribu des Kwakiutl sur l'île de Vancouver) ${ }^{54}$. Il a fondé et dirigé une petite compagnie de production de films documentaires, Orbit Films. Laurence Marshall et Robert Gardner initient une correspondance en I953, après que J. O. Brew du Peabody Museum ait envoyé à Marshall une copie de la conférence prononcée par Gardner sur l'utilisation du film en anthropologie ${ }^{55}$. Marshall manifeste son intérêt; Gardner répond par une lettre de sept pages qui souligne les potentialités d'apprentissage expérimental par le biais du cinéma, relevant que «pour qu'un film réponde au mieux à cet effet d'apprentissage par l'‘expérience, il faut le laisser entre les mains des artistes créatifs ${ }^{56}$.

Au milieu des années I950, John et Laurence Marshall, Robert Gardner et J. O. Brew créent un Centre d'étude cinématographique [le Film Study Center] dans le sous-sol du Peabody Museum d'Harvard. 
Selon Laurence, l'«effort et le principe» du Centre est d'«utiliser la capacité [...] du cinéma à représenter au plus près une culture ${ }^{57}$. Selon John, le Centre a été créé «dans le but d'extraire les films potentiels inscrits dans les matériaux sur les Bochimans et d'investiguer la relation entre le film et les disciplines dédiées à l'étude du comportement humain ${ }^{58}$. Les principes directeurs du Centre ont rapidement fait figure de modèle pour les futures recherches en anthropologie visuelle:

La formulation d'une méthode est peut-être la tâche la plus importante du Centre. Les fondements de cette méthodologie sont les suivants:

I) Une enquête anthropologique approfondie doit précéder ou au moins accompagner le travail filmique.

2) L'action n'est pas mise en scène. Il n'y a pas de scénario écrit.

3) Lors du tournage de chaque séquence d'événements, l'action doit être restituée du début à la fin.

4) Le film d'origine conserve un statut de document [...], ainsi n'importe quel fragment de séquence peut être utilisé plusieurs fois. ${ }^{59}$

Ces règles méthodologiques rigoureuses, faisant appel à une observation impartiale, entrent en conflit avec le désir d'une dramaturgie à la Flaherty exprimé par la famille Marshall lors de leurs discussions à Nyae Nyae. Ces objectifs contradictoires peuvent expliquer en partie la première réaction de rejet de The Hunters par Laurence Marshall, qui ne tardera pas à promouvoir activement le film.

Dans un carnet d'expédition, Laurence consigne son «Plan pour le financement du Film Study Center». Il propose de couvrir les fonds de base pendant trois ans, pour un total annuel de i8 ooo dollars (comprenant le salaire d'un directeur, d'un assistant directeur et d'un technicien, ainsi que les dépenses pour la location de films, etc.). C’est lui qui conserverait le contrôle sur les matériaux filmiques originaux. Laurence mentionne aussi la nécessité de solliciter des lettres d’universités manifestant leur intérêt pour l'utilisation de tels matériaux filmiques et le soutien d'un distributeur reconnu pour prendre en charge les films. En échange d'espace, de bureaux et d'une secrétaire mis à disposition, le Peabody «bénéficiera d'un service de consultation de films, d'infrastructures de cinéma dans son bâtiment, de copies à Harvard de tous les films réalisés sans frais de location, et aussi du prestige induit et d'avantages indirects ${ }^{60}$.

Gardner se souvient en ces termes de sa collaboration avec John Marshall au Film Study Center:
57 Lorna Marshall, citée par Ilisa Barbash, Where the Roads All End, op.cit., p. I04.

58 John Marshall, cité par Ilisa Barbash, op.cit., p. I04.

59 Id., p. I05.

60 Entrée du journal de Laurence Marshall datée du ${ }^{\text {er }}$ septembre 1958 , p. 50 (Peabody Museum, 2003.36.I.I2). 
61 Robert Gardner, "Introduction », Making Dead Birds, Cambridge, Peabody Museum, 2007, pp. 6-7.

62 Id., p. 6. Le film ne contient qu'une ligne de générique: "Réalisé par John Marshall, en collaboration avec Robert Gardner». Dans les références filmiques qui suivent l'essai de John («Filming and Learning», op. cit., p. I32), les crédits sont les suivants: «Cinéaste: John Marshall. Collaborateur: Robert Gardner». Dans la filmographie établie par Sue Marshall Cabezas, John Marshall et Robert Gardner sont crédités comme monteurs. Le DVD (restauré and remastérisé à partir du film original en I6mm) actuellement distribué par DER présente le film comme réalisé par John Marshall.

63 Brian Winston affirme que le montage repose sur 250000 pieds de film "tournés sur une période de plusieurs années» (Claiming the Real: The Grierson Documentary and its Legitimations, Londres, BFI, I995, p. I72). Je considère plus réaliste l'estimation de Bishop qui affirme que les matériaux sources pour The Hunters consistent en 80 bobines assemblées en unités de rooo pieds (80 ooo pieds) tournées pendant la troisième expédition (1952-53) Voir John M. Bishop, «Hot Footage/Cold Storage», op.cit., p. 221. John note que quelques plans ont été remis en scène pour filmer des gros plans pendant l'expédition de 1955 («Filming and Learning», op. cit., p. 36).

64 Pour une opposition entre le début de The Hunters et les premiers plans d'autres films de Gardner ou encore de Jean Rouch, voir Karl G. Heider, «Gardner's First Shots: Vectored Landscapes», dans Ilisa Barbash et Lucien Taylor (éd.), The Cinema of Robert Gardner, Oxford, Berg, 2007, pp. 79-92.
Suivant la suggestion de Brew, on m’a demandé d'aider le fils de Marshall, John, qui était encore étudiant de premier cycle, à visionner les plans disponibles et à développer un film plus long que la version initiale de 45 minutes - et qui allait devenir The Hunters. Finalement, le film a atteint plus de 70 minutes; une fois terminé, le film a rapidement attiré l'attention d'un large public en tant que compte rendu non fictionnel (avoisinant la durée d'un long métrage) d'une société réduite, fragile et impressionnante de chasseurs-cueilleurs du désert du Kalahari dans le Sud-Ouest africain. ${ }^{61}$

En 2007, Gardner décrit Marshall comme «le jeune auteur principal et talentueux de The Hunters» 62 .

Les deux jeunes hommes s'efforcent sur une période de deux ans d'assembler une très grande quantité de plans non synchronisés en un film cohérent ${ }^{63}$. John a décrit son engouement pour la chasse lors de ses premiers voyages dans le Sud-Ouest africain; aussi n'est-il pas étonnant que ce jeune cinéaste exubérant veuille célébrer les chasseurs qu’il admirait tant et recourir à la dramaturgie de la chasse comme fil conducteur de ce documentaire en cours de réalisation.

\section{The Hunters}

Ce film de 72 minutes débute par un prologue de quatre minutes qui établit un sens de l'espace filmé. Le premier plan est centré sur la brousse, le vent agitant les frondaisons, suivi d'un plan d'oiseau sur un arbre, d'un vautour sur un baobab, celui d'un lézard se faufilant dans un trou, et enfin de deux antilopes partiellement masquées par la brousse. Ces cinq plans sont dépourvus de son. De la musique indigène débute quand deux hommes, à une certaine distance l'un de l'autre, surgissent et se dirigent vers la caméra. Les plans alternent entre la vie animale ou d'insectes (des papillons, une girafe, un vautour prenant la fuite, un trio de girafes, etc.) et les deux hommes. Après un moment, les deux hommes s'arrêtent, regardent un trou, puis reprennent leur marche. La séquence se termine sur le gros plan d'un homme !Kung, qui semble rechercher quelque chose ${ }^{64}$.

Le titre, The Hunters, apparaît, et avec celui-ci la séquence de prégénérique acquiert un sens nouveau: ces hommes avec des arcs traquent une proie; habitués à l'activité dynamique de ces lieux, ils se déplacent aisément au sein de formes de vie variées. Après cette ouverture artistique, le film emprunte des conventions ethnographiques classiques: en 
l'occurrence, une carte de la région, des images à fonction d'illustration (un groupe de !Kung qui traversent le paysage) et une voix over masculine. La voix est celle de John Marshall, qui commentera tous les films de la série !Kung, apportant un ton personnel. Il commence par des commentaires généraux:

Le nord du Kalahari est un pays dur, asséché. Dans cet âpre pays vit un peuple tranquille qui se désigne lui-même comme !Kung ou Ju/'hoan. $\mathrm{Ju} /$ 'hoan peut se traduire par «nous-mêmes».

La voix over expose le plus souvent sans détours la vie des Bochimans en général ou des actions plus spécifiques qui sont montrées. La première section du film décrit la pénurie d'eau, le terrain aride («un dur pays, en effet, où tous les arbres ont des épines»), le rôle crucial de la cueillette des femmes constituant «la plus grande part de la nourriture de ce peuple» et qui donnent leur temps sans compter; ensuite (après dix minutes), la chasse est introduite comme «le travail des hommes [...], leur passion et celle des garçons». Un ensemble de plans montre les garçons qui jouent, prétendant être des chasseurs, puis devenant chasseurs, acquérant «un sentiment de puissance en tant qu'hommes». La prise des garçons se limite à une mangouste, mais nous apprenons quaprès avoir tué un animal plus grand, un garçon sera scarifié, indiquant qu'il est devenu un homme prêt à être marié.

Après ces scènes donnant un aperçu de la centralité de la chasse dans la construction de l'identité masculine des !Kung, un moment particulier est isolé. «Un jour, au début de l'hiver, la viande venait à manquer depuis un mois», alors que la femme de $\neq$ Toma en avait besoin pour allaiter son nouveau-né. Cette nécessité pousse $¥$ Toma à chasser, ce qui deviendra le centre du film. Au vu du montage du film et des habitudes de la plupart des spectateurs, le film peut facilement être appréhendé comme l'enregistrement d'une seule chasse en continu, une lecture encouragée par la voix over. Mais si l'on regarde attentivement le film, cette interprétation ne tient pas, ce qui a poussé certaines personnes à critiquer les manipulations narratives de The Hunters dans sa construction synthétique d'une chasse à la girafe (à travers le recours à plusieurs girafes et chasses, à travers des plans tournés à différents moments). John a admis par la suite qu'il a «monté The Hunters en faisant progresser le récit vers l'avant» et en créant une narration linéaire; il avance même qu’il pensait que «les hommes traquaient [la girafe] avant tout pour [lui] et pour le film ${ }^{65}$.
65 John Marshall, «Filming and Learning», op.cit., p.36. Bien des années plus tard, dans A Kalahari Family (2002), ₹Toma soutient que la chasse avait été initiée par un besoin de viande, et non pour répondre au désir de John de tourner un film. 
The Hunters suit prétendument quatre chasseurs sur une période de treize jours, cinq jours étant consacrés à traquer et tuer une girafe, qu'ils repèrent à peu près au milieu du film. La chasse est ponctuée par une série de déceptions, qui vont d’une épine dans le pied à la découverte qu’un koudou qu'ils ont tué a été mangé par des chacals ou des hyènes; ils doivent se contenter de prises minimes, comme de petits oiseaux ou des porcs-épics. La traque, la blessure et la confrontation finale avec une splendide girafe constituent les moments les plus convaincants du film sur le plan visuel. Après des jours de traque, alors que les chasseurs ne parviennent pas à «constater de tendances» dans les déplacements de la girafe blessée, car son trajet «ne manifeste pas de signes clairs», ils découvrent la girafe affaiblie. Elle est «au bord de l'épuisement, et les hommes si proches d'elle». Le narrateur nous prévient: «Une longue lutte va à présent s'engager», précisant que «ses sabots peuvent découper un homme en deux». Le point culminant du film est imminent: «Elle rassemble ses forces pour tenir debout. Et ils commencent leur approche.» Une large part de l'assaut final de la girafe est soulignée par un silence révérencieux, tandis que nous voyons les hommes jeter leurs lances sur le fier animal depuis différents angles de prises de vues et échelles de plans. «Les hommes dépensent leur force sans compter, tandis qu'elle se tient immobile.» Finalement, «elle est plus qu'épuisée. Elle est déjà morte.»

Tout au long du film, le récit revêt par moments une qualité littéraire, presque verbeuse (ce qui n'est pas inhabituel dans les documentaires des années I930 et I940). Les répliques et les moments les plus poétiques interviennent lorsque les deux premiers chasseurs sont introduits:

$\neq$ Toma, le chef,

$\neq$ Toma, le valeureux et le valide,

C'est un homme aux paroles prolixes et à l'esprit vif,

Un homme qui a arpenté son environnement dans tous les sens.

Et un peu plus loin:

Kxao, le magnifique,

Kxao était un chasseur né,

Prenant grand plaisir à la traque.

Ses flèches étaient acérées et chaque partie façonnée selon sa propre fantaisie...

Nous apprenons aussi les qualités particulières de deux autres hommes: /Ui est un jeune homme simple et optimiste qui connaît tous 
des animaux et que les autres trouvent amusant; Ao// est franc, le meilleur artisan du groupe, qui peut entrer dans de longues et profondes transes et qui remplit la fonction d'homme médecine de tout son cœur. Ces descriptions s'apparentent à la présentation traditionnelle de personnages au début d'un roman ${ }^{66}$. Nous voyons parfois le visage des hommes en gros plans, mais le plus souvent ils sont filmés en plans larges ou moyens, cadrés dans leur entièreté, se déplaçant dans la brousse.

John a affirmé que la construction de son récit était influencée par l'œuvre des romanciers américains Herman Melville et William Faulkner ${ }^{67}$. Comme dans un roman, la narration omnisciente inclut des monologues intérieurs exprimant les pensées des chasseurs et même les sentiments de la girafe. À un moment, une surimpression, que l'on peut considérer comme l'équivalent visuel d'un «monologue intérieur», intervient; un scarabée (mentionné sur la bande son) se superpose au visage d'un chasseur éclairé par le feu ${ }^{68}$. De resplendissants plans longuement tenus sur le paysage au coucher du soleil, le feu découpant la silhouette des chasseurs, ajoutent une touche supplémentaire au sublime de la situation. Le récit souligne la relation intime entre les chasseurs et leur proie. La girafe n'est pas perçue comme un objet - le pronom «ça» n'est jamais utilisé pour la désigner - mais comme un être sensible: «Elle rejoint le troupeau, à la recherche de compagnie dans sa misère» et, par la suite, «Elle s'est déplacée avec une rare détermination d'esprit [...] petit à petit, à partir de ses traces, ils l'ont reconnue». Le plaisir apporté par la viande est contrebalancé par le sentiment que la mort de cette magnifique créature laissera «un vide dans le monde [...] une telle vie ne peut pas disparaître sans que l'on s'en aperçoive.»

Les chasseurs sont montrés en train de parler et de rire lorsqu'ils partagent une première fois la viande, suivant un modèle de distribution équitable décrit depuis fort longtemps. «Et ils commencèrent alors à manger, et ils mangèrent et ils mangèrent.» Un chasseur retourne chez lui avec sa part de butin; les autres restent sur place pour faire sécher les morceaux de viande. Les chasseurs voyagent deux jours avant de regagner leurs demeures. On ne laisse rien se perdre. L'après-midi, tout le monde cuisine et mange avec délectation, satisfait d'avoir de la viande pour neuf jours. La dernière séquence du film montre le groupe auprès du feu, avec $\neq$ Toma, «en bon parleur», qui narre la chasse et d'autres histoires dans un moment de bonheur partagé et de solidarité de groupe.
66 L'historien culturel William Irwin Thompson assimile les quatre chasseurs au Chef de la tribu, au Magnifique, au Shaman et au Clown; il considère ces quatre hommes comme des archétypes et le film comme «un modèle dans sa présentation d'une forme universelle de conflit» (At the Edge of History, New York, Harper and Row, I97ı, p. 75). Aux yeux de ceux qui tiennent à la spécificité culturelle, de telles descriptions amoindrissent la valeur du film; mais pour la plupart, l'universalité de The Hunters constitue une valeur cruciale.

67 John a décrit le caractère «verbeux du récit» comme «emprunté à Faulkner». 68 Marshall évitera ce type d’images «ostensiblement artistiques» dans ses films ultérieurs, alors que Gardner les privilégiera. 
69 Jean Rouch, "The Politics of Visual Anthropology», entretien avec Dan Georgacas, Udayan Cupta et Judy Janda, au Margaret Mead Film Festival, à New York, en I977; John P. Demos dans The Harvard Crimson, le 29 mars 1958 ; Eliot Weinberger, "The Camera People», dans Charles Warren (éd.), Beyond Document: Essays in Nonfiction Film, Hannover, Wesleyan University Press, I996, pp. I44-I46.

70 «Out of Words: A Conversation with Robert Gardner», dans Ilisa Barbash et Lucien Taylor (éd.), The Cinema of Robert Gardner, op. cit., p. IоI.
Des détails de la chasse et la reconnaissance du doute des hommes sont partagés; tous s'accordent pour dire que «la chasse est ce qui peut arriver de mieux à l'homme». The Hunters se termine sur la prédiction que cette chasse entrera dans la légende pour ses participants (et pour ceux qui auront vu le film). «Et les ancêtres se souvinrent, les jeunes hommes écoutèrent, et le récit de la chasse fut narré.»

Avec le temps, le récit de The Hunters a fait l'objet d'une attention particulière, tantôt positive, tantôt négative. Pour Jean Rouch, le principal praticien du cinéma ethnographique en France, «Le récit de The Hunters est vraiment merveilleux». D’autres se sont montrés sarcastiques: dans un compte rendu contemporain du film, John P. Demos écrit que «Marshall s'est prêté à quelque tirades incroyablement ridicules - peu importe qu'il fasse preuve d'humour ou de stupidité - récitées d'un ton obstinément monotone» (The Harvard Crimson, 29 mars 1958). Bien des années plus tard, Eliot Weinberger se gaussera du récit de Marshall et de son imitation du style de Hemingway ${ }^{69}$. De nombreux chercheurs en cinéma ont souligné les similitudes entre le récit de The Hunters et celui d'un film ultérieur de Robert Gardner, Dead Birds (1963), tourné parmi les tribus Dani de Nouvelle-Guinée, avançant parfois l'hypothèse que Gardner aurait exercé une forte influence sur la construction de The Hunters. Gardner rejette cette idée:

\begin{abstract}
J’ai commencé à développer ma propre «voix» [voicing] avec Dead Birds que j’ai réalisé immédiatement après The Hunters, film que j’ai aidé John Marshall à terminer. Il est l'auteur du commentaire et de la voix, comme vous le savez, et j’ai toujours pensé que cela faisait tout à fait sens dans la mesure où le récit repose sur son odyssée personnelle. Je trouvais qu'il apportait à la bande son un formidable apport personnel, malgré ce qu'il a bien pu dire récemment à ce sujet. ${ }^{70}$
\end{abstract}

\section{L'expédition de 1955 et Bitter Melons}

Avant de terminer The Hunters en I957, la famille Marshall retourne en I955 au Sud-Ouest africain pour un séjour de quatre mois et demi. Le Transvaal Museum de Pretoria se joint à la Smithsonian et au Peabody pour son financement, ce qui indique bien l'intérêt et le respect des institutions éducatives sud-africaines pour le projet des Marshall. Cette expédition - la dernière à inclure les quatre membres de la famille - comprend une équipe de dix-sept personnes, notamment des Sud-Africains blancs 
(un botaniste, un linguiste, un mécanicien) et une équipe d'«hommes de couleur et africains » (des interprètes et un cuisinier) ${ }^{71}$. Daniel Blitz, un ingénieur américain en électronique (de la Sanders Associate, à Nashua, New Hampshire), est engagé comme photographe. Ami de Laurence Marshall et protégé de Raytheon, Blitz est un «véritable génie de la high tech ${ }^{72}$. Malgré la dureté des conditions, le jeune ingénieur a développé des appareils sonores synchrones qui permettent d'approfondir les possibilités de documentation de la culture !Kung ${ }^{73}$.

Les premiers plans tournés (principalement sur trépied) recourant $\mathrm{au}$ «système de Danny» sont filmés dans les prairies sèches de /Ei hxa o dans le Kalahari Central (dans une région qui fait aujourd'hui partie du Botswana). Les Marshall y rencontrent un groupe de dix Khwe qui ont survécu en cueillant de la nourriture dans la brousse et en buvant de l'eau extraite de racines et de panses d'antilope ou du liquide de la pulpe de melons sauvages tsamma.

John et ses collaborateurs veulent «rendre hommage à la richesse de la musique, des traditions et des jeux musicaux développés au sein de cette économie marginale ${ }^{74}$. Oukwane, un musicien aveugle, figure dans le film; l'une de ses nombreuses chansons sur les melons, Bitter Melons ("probablement la composition préférée d'Oukwane»), donne son titre au film ${ }^{75}$. Un plan moyen sur Oukwane qui chante et joue d'un instrument rudimentaire à corde ouvre le film; des contre-champs sur les auditeurs assis et attentifs qui l'entourent marquent son importance au sein de ce groupe de dix personnes qui vivent ensemble. La voix over de John débute après trois minutes (le film dure 30 minutes) et revient régulièrement. Les chansons d'Oukwane décrivent la vie sociale du groupe (qui piège des animaux nocturnes) et des incidents singuliers le concernant (il se perd dans la brousse, et personne ne vient à son secours). Les compositions originales d'Oukwane et les chansons qu'il interprète ont une fonction d'avant- et arrière-plan sonore tout au long du film. Certains propos sont audibles (mais ne sont pas sous-titrés) parmi les sons d'oiseaux, de sabots d'animaux, etc. On entend et on voit des enfants qui interprètent des chansons traditionnelles imitant les cris d'animaux: la girafe, le koudou et la hyène.

Comme dans First Film et The Hunters, une voix over donne un aperçu de la vie de ces chasseurs-cueilleurs, de la façon dont ils subsistent dans ces conditions extrêmes, et des règles sociales qui gouvernent leur
71 Elizabeth Marshall Thomas, The Harmless People, New York, Vintage, I959; édition révisée, I989, p. 25 [Des gens sans méchanceté, Paris, Gallimard, I96I, trad. par Geneviève Hurel]. Elizabeth inclut sa famille à travers la désignation d'«Européens» lorsqu'elle mentionne les participants envoyés par des universités d'Union d'Afrique du Sud, d'Angleterre et des États-Unis. Elizabeth énumère quinze personnes, Ilisa Barbash dix-sept (Where the Roads All End, op.cit., p. 204). Les participants ne prennent pas forcément part à l'expédition dans son intégralité.

72 John Marshall, «Filming and Learning», op. cit., p. 138 .

73 John M. Bishop fournit une description technique détaillée du système extraordinairement inventif mis en place et utilisé par Blitz ( Hot Footage/Cold Storage», op.cit., p. 223). En I955, Laurence avait donnée à John une caméra Arriflex à trois objectifs avec une batterie et une capacité de roo pieds. John la décrira par la suite comme «la meilleure caméra qu'[il] a jamais utilisée» («Filming and Learning», op. cit., p. 40).

74 John Marshall, op. cit., p. 56. Le film, monté par Frank Galvin, avec une musique supervisée par l'ethnomusicologue Nicholas England, ne sera pas terminé avant I97I. England ne participe pas à l'expédition de I955, mais se joindra aux voyages en 1958, I959 et I96I, développant une réputation internationale en tant qu'expert en musique bochimane.

75 Le carton qui apparaît directement après le titre du film mentionne le musicien à travers la convention orthographique «Ukyone» et le peuple à travers celle de «/Gwi». Dans cet essai, je suis les conventions utilisées par John Marshall dans son essai «Filming and Learning» (op. cit.). 
76 Dans le générique de fin du film, Lorna Marshall est désignée comme «ethnographe», Frank Galvin comme «monteur», Nicholas England comme «ethnomusicologue» et «directeur musical», Daniel Blitz comme «ingénieur du son», «mixeur» et "assistant monteur», tandis que cinq «assistants à la production» sont énumérés. Les crédits se terminent ainsi: «tourné et dirigé par John Marshall, produit par le Centre pour l'Anthropologie Documentaire; tourné lors d'une expédition en I955 financée par le Peabody Museum de l'Université de Harvard et la Smithsonian Institution; copyright Laurence K. Marshall».

77 John Marshall, «Filming and Learning», op. cit., p. 57 .

78 Ibid. groupe $^{76}$. Nous apprenons que les Khwe ont appris à planter des melons grâce à leurs contacts avec les Bantous. Dans la dernière partie du film, un autre homme, !Gai, «le point de ralliement du petit groupe», part à la recherche de membres de sa famille après avoir repéré la fumée indiquant leur présence. Lorsque Gai revient, il conduit ses proches en file indienne, de la façon caractéristique des Bochimans, le groupe s’approchant du campement des Khwe (et de la caméra). Une atmosphère de convivialité et de joie réunit les hôtes et les invités. Les garçons miment des mouvements d'animaux, avant de se joindre aux hommes interprétant rythmiquement la «parade amoureuse de l'autruche». Lors d'une séquence dynamique, tournée en plan moyen avec une caméra fixe, on voit les danseurs se relayer, faisant tour à tour preuve de leur agilité et de leur grâce. Les femmes assises auprès d'eux frappent des mains, maintenant un rythme soutenu, accompagné par les mouvements de pieds des danseurs. L'un après l'autre, les danseurs lèvent la jambe au-dessus du dos de l'un des participants adultes, ce qui constitue un défi considérable pour les garçons du groupe. Cette séquence de danse, qui dure plus de quatre minutes, constitue le point culminant du film, témoignant de la centralité de la musique dans la vie de ces personnes. Après que les danseurs se soient reposés, la voix over reprend, expliquant que les visiteurs, Gai et les autres membres du groupe partent se joindre au peuple d'Okwa, car les melons tsamma ont été épuisés à /Ei hxa o. Le groupe se déplace à travers de hautes herbes agitées par le vent, sur fond de la musique d'Oukwane. Alors que les Bochimans disparaissent dans la brousse, on apprend qu'Oukwane et sa femme ont décidé de ne pas les accompagner, se considérant comme «trop vieux et épuisés». Ils resteront à /Ei hxa o.

Des années plus tard, John a dit qu'il avait tout d'abord pensé que Bitter Melons «apportait un éclairage plus réaliste sur le peuple Khwe que The Hunters ne le faisait à propos des Ju/'hoansi, en illustrant la musique d'Oukwane par des scènes qui montraient le sujet de ses chansons. Je n'ai appris qu'en 1972 à quel point je me trompais terriblement sur la réalité vécue par Oukwane» ${ }^{77}$. La réalité, c'est que peu de temps après le tournage, Oukwane est mort de soif; un autre membre du groupe est mort de faim; la maladie et le viol ont frappé les autres. John a fait preuve d'honnêteté en reconnaissant l'étendue de son erreur, «cherchant à trouver une fin émouvante» pour Bitter Melons au lieu de rendre compte de la gravité de la situation vécue par les Ju/'hoansi ${ }^{78}$. Lors de leur séjour auprès 
d'Oukwane et de son peuple en 1955, les Marshall ont donné au groupe et aux convives de l'eau provenant de leurs fûts; cet apport d'eau a permis au groupe Khwe de rester dans une région unique pendant le tournage et de danser sous le soleil. La résistance de ces Bochimans, aussi remarquable soit-elle, a ici atteint ses limites.

Lorsque Bitter Melons est diffusé au début des années i970, le public (bien que limité) apprécie la beauté du film, sa musique unique et l'admiration manifestée à l'égard d'un peuple éloigné et indépendant. Le film est commenté non seulement dans l'American Anthropologist (vol. 75, $\mathrm{n}^{\circ}$ 4, I972), mais aussi dans le New York Times (Io juin I972). Bitter Melons reçoit différents prix aux États-Unis et sur le plan international: au festival Flaherty, au CINE Golden Eagle, mais aussi au Festival des peuples de Florence, au Festival international du film d'Athènes, au Festival international du film de Salerne et au Philadelphia Festival of Short Films.

Suivant l'injonction de son père d'«écrire un livre», Elizabeth Marshall tient des journaux pendant son séjour au Sud-Ouest africain. Son livre The Harmless People (1959) rend compte de sa participation à trois expéditions familiales, entre I95I et 1955, pendant lesquelles ils rencontrent quatre groupes de Bochimans de langue différente; ils restent longuement auprès de deux d'entre eux. Le titre de l'ouvrage d'Elizabeth fait référence aux !Kung: «Les Bochimans Kung s'appellent eux-mêmes zhu twa si, le peuple inoffensif [the harmless people]» ${ }^{79}$. Écrit pour le grand public qui généralement ne connaît pas ces contrées retirées du monde ni leurs habitants, The Harmless People rend globalement compte de la vie et des coutumes des !Kung dans un style engageant. De nombreuses anecdotes personnelles, rapportées avec grâce par une jeune Américaine ouverte à de nouvelles expériences, sont entrelacées à des descriptions de coutumes culturelles. Elizabeth est déterminée à prendre des notes précises; à une occasion, lorsqu'«[elle] dût constater qu'[elle] avait une plume, mais pas de papier, il [lui] fallut noter [s]es observations sur $[\mathrm{s}]$ es bras et $[\mathrm{ses}]$ jambes ${ }^{80}$. Aucun des Bochimans rencontrés n'a vu de femme européenne avant Elizabeth et sa mère. Les liens de profonde amitié développés par les Marshall témoignent de la bonne volonté exprimée de part et d'autre.

Parmi les descriptions des activités de l'expédition, Elizabeth rapporte les conditions de tournage. De façon caractéristique, les !Kung sont filmés lors d'activités de routine, parfois à la demande des Marshall:
79 Elizabeth Marshall Thomas, The Harmless People, op.cit., p. 23 [Des gens sans méchanceté, op.cit.]. L'inoffensivité permet de renforcer les liens d'amitié. Elizabeth se souvient que lors de leur rencontre d'un groupe inconnu de !Kung, l'une des femmes «comprit que nous n'étions pas dangereux; elle vint s'asseoir auprès de moi» (Des gens sans méchanceté, op. cit., p.48).

80 Id., p. 93. 
81 Id., pp. 99-гоo.

82 Id., p. I05. Ces récits de «démonstrations» coïncident avec certains propos de Lorna dans First Film.

83 Id., p. Ioo. John a décrit ces redondances naturelles comme quelque chose de courant et de bénéfique pour les cinéastes documentaires: «Nous sommes tous redondants dans notre conversation et dans notre comportement. Les $\mathrm{Ju} /$ 'hoansi se répètent peut-être un peu davantage que la plupart d'entre nous» («Filming and Learning», op.cit., p.45). Presque cinquante ans plus tard, après avoir publié une série de livres centrés principalement sur le comportement animal, Elizabeth a sorti The Old Way: A Story of the First People (New York, Farrar Straus Giroux, 2006). Ce livre prend à nouveau en considération les Bochimans et leur culture, mais à travers une approche plus académique (dans The Old Way, Elizabeth décrit The Harmless People comme "un livre de voyage»). Elle ne mentionne pas comment le tournage a été pris en charge par les Marshall dans les années I950. Elizabeth soutient que les lecteurs de son livre et les !Kung s’inscrivent dans la même lignée humaine. Elle souligne que «l'expérience de ces lieux et de ce peuple a eu une influence profonde [sur elle]» (id., p.6). En I986 et I987, Elizabeth rend à nouveau visite aux personnes qu'elle avait rencontrées et les trouve tristement «très changées». La version révisée de The Harmless People (en I989) contient un épilogue de 40 pages; les deux derniers chapitres de The Old Ways ( $\mathrm{Re}$ turn» et «The Present») questionnent les conditions contemporaines auxquelles les !Kung sont confrontés en Namibie et décrivent les actions de sensibilisa-

Nous prîmes un film d’Ukwane tandis qu'il travaillait ses peaux. [...] nous demandâmes à Gai de confectionner une pointe de flèche [à partir de l'omoplate d'un chamois], afin de compléter notre film. [...] [Après une série de préparatifs], il nous appela. Nous pouvions commencer le film. ${ }^{81}$

\section{Elle donne aussi un autre exemple:}

Pour profiter de l'installation de notre appareil et de la pellicule qu'il contenait, nous demandâmes à Gai de nous montrer comment il tirait à l'arc; il consentit. ${ }^{82}$

Elizabeth, qui ne connaît ni le cinéma ethnographique ni l'anthropologie, résume en ces termes la situation fortuite qui les conduit à traiter les Bochimans en tant que sujets de la caméra:

Les Bushmen sont merveilleux quand on les photographie. Parfaitement naturels, ils ne regardent jamais la caméra et sont doués d’une patience infinie. Ils arrêtent leur travail, attendent, recommencent indéfiniment, et chaque fois ils donnent magnifiquement l'impression d'être aussi appliqués à leur besogne. ${ }^{83}$

Parallèlement à cette injonction à reproduire des gestes et comportements considérée par certains cinéastes ethnographiques comme contraire aux règles éthiques (constituant ainsi un tabou ethnographique qu'ignorait la sœur de John et que celui-ci respectera par la suite), Elizabeth mentionne une scène où des événements traditionnels ont été expressément modifiés pour le tournage. Elle s'en souvient en ces termes:

D'ordinaire, les danses ont lieu la nuit. Par égard pour nous et pour nous permettre de les filmer, ils dansèrent de jour, sur l'emplacement choisi par nous et d'où il était facile de les photographier. Nous les aidâmes au ramassage de bois; le feu est indispensable quelle que soit la chaleur du jour... ${ }^{84}$

Cependant, quand le danger se fait ressentir plus directement, il y a des limites aux contraintes imposées par le tournage auxquelles les !Kung ne dérogent pas. C’est ce qui se passe après que Kwi le Court ait arraché brusquement sa lance hors d'un gnou.

tion de John. Les chapitres quatre et cinq des mémoires d'Elizabeth, Dreaming of Lions (op.cit.), reviennent sur son expérience des expéditions au Kalahari.

84 Elizabeth Marshall Thomas, Des gens sans méchanceté, op.cit., p. I39. Les danses mentionnées sont présentes dans Bitter Melons. Finalement, les Marshall ont réalisé qu'ils pouvaient utiliser des phares de véhicules pour éclairer la scène du tournage de nuit (Ilisa Barbash, Where the Roads All End, op. cit., p. I28). 
John aurait voulu un plan de la scène et demanda à Kwi de répéter l'opération, mais celui-ci refusa. «Non, dit-il, cette fois, le gnou se méfierait». ${ }^{85}$

Les journaux d'expédition de John, écrits entre I95I et I955, témoignent de ses réflexions sur les tournages. Malgré les déclarations de John en I993, selon lesquelles je «ne pensai[s] justement pas. Je débarquais avec ma caméra, c'est tout», le cinéaste en herbe a pensé sérieusement et de façon critique à ce qu'il faisait, même s'il n'avait pas de formation ni de retours de la part de professionnels ${ }^{86}$. En I95I, John n'a que I8 ans quand il commence à prendre des notes cinématographiques; ses commentaires reflètent souvent l'incertitude et les fluctuations d'humeur d'un adolescent. Il réagit probablement à des rushes - en se prenant lui-même à parti - lorsqu'il écrit:

Un problème. Un vrai problème. Beaucoup trop de plans rapprochés.

Des plans rapprochés écœurants, déplacés, lamentables. Bon sang, uti-

lise un putain de trépied!

L'autoflagellation laisse place à l'hésitation lorsqu'il mentionne «une bobine sacrément bonne», ou qu'il décrit une «bobine (probablement) inutile» et «quelques plans réussis du Groupe IV». Dans une entreprise que l'on pourrait qualifier d'auto-éducation, John édicte une liste de 7I «Suggestions générales» (avec des schémas) ${ }^{87}$. Dans un journal postérieur, John pose des questions fondamentales portant sur la représentation visuelle et la définition du «réel»:

[Le film] a un potentiel extraordinaire par rapport aux autres formes d'art existantes pour dépeindre la réalité; et pourtant, il se limite toujours au statut de fac-similé de la réalité. Ses deux dimensions et l'étendue restreinte de l'objectif expliquent en partie ses limites. Des bribes et des fragments de la réalité - jamais des ensembles continus - qui sont parfaits dans les détails, mais l'impression et la sensation leur font toujours défaut. C'est ce qui rend si difficile cette fichue entreprise. C'est une chose que de tourner un film d'illustration - ce à quoi se réduit ce film, du moins jusqu'à présent. C'est tout autre chose que de réaliser un documentaire qui va au-delà de l'illustration, un film source, une image adéquate de la réalité. ${ }^{88}$

John se confronte à des problématiques qui hantent tout réalisateur de documentaires, mais aussi à des difficultés qui lui sont plus spécifiques:
85 Elizabeth Marshall Thomas, Des gens sans méchanceté, op. cit., p. $2 \mathbf{1} 2$.

86 Carolyn Anderson et Thomas W. Benson, "Put Down the Camera and Pick Up the Shovel», op. cit., p. I40.

87 Entrées du journal de John Marshall (Peabody Museum, 20o8.2I.I, John Marshall Journals, Peabody Museum of Archaeology and Ethnology, Harvard University, Folder I, n. p.; p. I; p. 9; p. I9; pp. 73-84).

88 Id., septembre 1953 (Folder 2, September 3, I953, n. p.). 


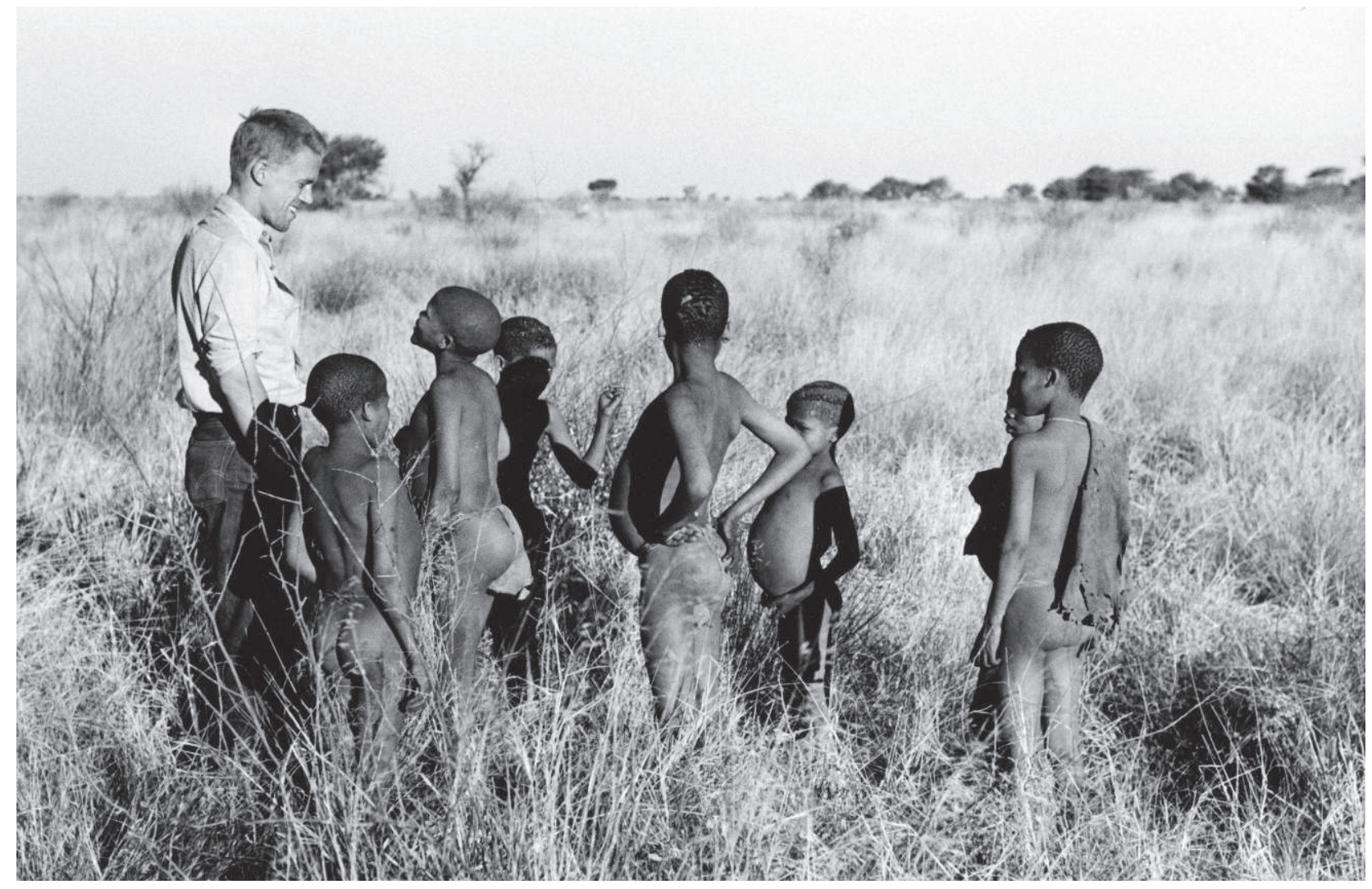


Illustrer une qualité abstraite, qui rend possible un mode de vie, c'est vraiment l'enfer. Des plans de regards - d'un mouvement rapide de la tête - d'un pas alerte - seraient utiles mais sont très difficiles à obtenir. Ces trépieds sont encombrants, mais tourner un plan sans trépied constitue une véritable prise de risque. La plupart de mes plans sont gâchés par des tremblements, et ma toux n'aide guère en la matière. ${ }^{89}$

Notant qu’il serait avisé de tourner des plans d'animaux, «le jeu occup[ant] un rôle crucial dans la vie des Bochimans», John se plaint de la situation:

Je résumerai tout cela à un seul terme: impossible. Ce n'est pas de l'art, c'est juste trop de boulot. Doux Jésus. La question la plus urgente, c'est que faire demain. [...] Le pire c'est que nous ne pouvons pas trop interférer dans leurs affaires. On doit se débrouiller avec les moyens du bord. ${ }^{90}$

Malgré le désarroi de John face à ces impossibilités, de nombreuses entrées de son journal en 1955 manifestent plus d'assurance quant aux plans tournés et à ceux dont il a besoin. Il incorpore un découpage de ce qui deviendra The Hunters (5I7 plans) et Bitter Melons ( 502 plans), un relevé d'identification des bandes magnétiques pour les sons à synchroniser, ainsi que différentes listes de plans qu’il voulait réaliser lors de certains jours de tournage. Comme en témoignent ses commentaires, John prend progressivement conscience que son tournage pourrait «faire l'affaire». À quel point il est prêt à admettre des imprévus semble une question ouverte pour lui. Le manifeste du Film Study Center - qui sera bientôt rédigé par John et différents collègues - recommande l'absence d'intervention; en tant que cinéaste ethnographique émergeant, John achoppe sur l'enjeu de la non-intervention.

De retour au Massachusetts en I955, les Marshall mettent en forme ce qu'ils ont appris sur les chasseurs-cueilleurs de différentes façons: Laurence et Lorna coécrivent un essai pour le South West Africa Annual; Elizabeth publie un article sur les Bochimans /Gikwe; Lorna fait paraître ses premiers articles dans le journal Africa; John termine une licence en anthropologie à Harvard, avec un mémoire de maîtrise intitulé «Ecology of the !Kung Bushmen of the Kalahari» ${ }^{91}$. Et surtout, les Marshall parviennent à présenter The Hunters en 1957.

The Hunters est «le premier film ethnographique nord-américain à connaître un succès mondial dans des festivals prestigieux» ${ }^{92}$. À
Ibid.

90 Id. (Folder 3, I955, n. p.).

91 Laura et Laurence Marshall, «!Kung Bushmen of South West Africa», South West Africa Annual, I956, pp. II-27; Elizabeth Marshall, «/Gikwe. Bushmen», Radcliffe Quarterly, novembre I956; Lorna Marshall, «The Kin Terminology System of the !Kung Bushmen », Africa, vol. 27, n ${ }^{\circ}$ I, I957, pp. I-25 et «N!ow», Africa, vol. 27, $\mathrm{n}^{\circ}$ 3, I957, pp. 232-240. Laurence, sans aucun membre de sa famille, a voyagé au Sud-Ouest africain en 1956 (deux photographes professionnels faisaient partie de l'équipe). En I958, John a publié «Man the Hunter, Part I», Natural History, ${ }^{\circ}{ }^{6} 7$, juin-juillet I958, pp. 29I-309, et «Man the Hunter, Part II», Natural History, $\mathrm{n}^{\circ}$ 68, août-septembre I958, pp. 376-395.

92 Jay Ruby, Picturing Culture: Explorations of Film \& Anthropology, Chicago, University of Chicago Press, 2000, p. II. Ruby décrit The Hunters comme l'équivalent filmique de ce que James Clifford avait appelé la «pastorale ethnographique» dans The Predicament of Culture: Twentieth Century Ethnography, Literature and Art, Cambridge, Harvard University Press, 2000. L'Exposition universelle de I958 à Bruxelles est l'un des lieux les plus renommés où The Hunters a été projeté. 
93 Robert Flaherty est décédé en I95I. En I955, sa veuve, Frances, a inauguré un séminaire consacré au cinéma non fictionnel en général, et à l'œuvre de Flaherty en particulier. Voir Patricia Zimmermann et Scott MacDonald, The Flaherty: Decades in Independent Cinema (Bloomington, Indiana University Press, 20I7, p.4I), pour un compte rendu approfondi et dynamique sur le plus ancien séminaire consacré au cinéma indépendant aux États-Unis. Jean Rouch a donné une conférence au séminaire en 1958 et a présenté trois films: Les fils de l'eau, Les Maîtres fous et Moi, un noir (Mick Eaton (éd.), Anthropology-Reality-Cinema: The Films of Jean Rouch, Londres, BFI, I979, p. II). Dans leur étude attentive de Flaherty, Zimmermann et MacDonald écrivent que le seul film de Rouch présenté en I958 était Les Maîtres fous (I955); en I959, Rouch était annoncé comme invité d'honneur mais il n’a pas assisté au séminaire, «sa femme présentant les films» (Patricia Zimmermann et Scott MacDonald, op. cit., pp. 43-44). Au début des années i960, les participants au séminaire considéraient que «les nouvelles façons de faire de l'ethnographie promues par John Marshall et Jean Rouch reposaient sur l'observation du participant» (id., p. 62). En I978, Jay Ruby a fait venir Rouch en tant que principal invité du séminaire (id., p. I03). The Hunters a aussi remporté le prix Blue Ribbon à l'American Film Festival et le Grand Prix du Festival de film de Florence.

94 Patricia Zimmermann et Scott MacDonald, The Flaherty: Decades in Independent Cinema, op. cit., pp. 42-43.

95 Id., pp. 46-50. l'été i956, Robert Gardner assiste au deuxième Flaherty Film Seminar, qui se tient à la ferme des Flaherty, à Dummerston, dans le Vermont; il y présente The Hunters et «montre aussi des rushes non montés » ${ }^{93}$. Très rapidement et aujourd'hui encore, The Hunters est comparé, de façon tantôt élogieuse tantôt critique, au film classique de Flaherty, Nanook of the North (I922), pour ses éléments mythiques et poétiques et pour sa mise en valeur d'une lutte pour la survie dans des conditions extrêmes. L'année suivante, The Hunters est de nouveau présenté dans ce contexte, comme ce sera le cas pour une troisième fois consécutive en I958. Cette année, John Marshall et Robert Gardner assistent au séminaire ${ }^{94}$. Tous deux prennent la parole au séminaire, à commencer par Robert Gardner qui sy exprime le plus longuement ${ }^{95}$. Gardner décrit le Film Study Center nouvellement créé et accueilli au Harvard Peabody Museum; il mentionne le projet de constituer vingt-cinq films à partir du «demi-million de pieds tournés» (lors des expéditions Marshall); il se demande «ce que le cinéma a à offrir à l'anthropologie... ou ce que l'anthropologie a à offrir au cinéma»; il admet qu’il a rédigé ses remarques sans consulter John Marshall et qu'il espère que John ne s'inscrira pas en faux contre celles-ci; il avance qu'«une science morale anthropologique ne pourrait se passer de films»; il se demande «à quel point en tant qu'anthropologues nous sommes libres d'utiliser notre imagination en assemblant des films»; et il insiste sur l'importance des connaissances techniques, académiques et psychologiques, parallèlement à la sensibilité, au discernement et à la sympathie. John s'exprime brièvement sur «ce qu'il est possible de faire avec le cinéma que l'on ne peut pas accomplir par l'écriture», soutenant que l'immédiateté du film participe à un important mode de compréhension anthropologique en établissant un contact direct avec le spectateur.

Les commentaires détaillés de Gardner peuvent laisser entendre qu'il est le principal responsable de l'équipe de tournage de The Hunters. Il est plus âgé que John et a davantage d'expérience en tant que cinéaste. Bien plus tard, John s'en souviendra en ces termes:

[Nous] avons reçu un prix. Ou plutôt ils ont donné un prix à Bob. Le film a été présenté dans le monde entier, mais je suis à présent d'accord avec mon père: c'est un film résolument artistique. C'est un peu 
le point de vue d'un gosse américain sur la chasse et la culture des cueilleurs-chasseurs. ${ }^{96}$

Le fait que Laurence est «gêné» par The Hunters et «pense que [John] aurait pu faire un plus grand effort du point de vue de la documentation» a sans aucun doute eu des effets sur l'aspirant cinéaste ${ }^{97}$. La réticence de Laurence paraît injustifiée, à l'égard de sa référence aux films de Flaherty comme modèle lors des discussions en famille. Le caractère contradictoire des réactions de Laurence s'intensifie encore lorsqu'il se rend à Los Angeles, après l'expédition de 1957-58. Une entrée dans le journal de Laurence indique qu'il a rencontré un membre de la $20^{\text {th }}$ Century Fox qui «a pensé que le scénario était excellent; il pensait le présenter au syndicat des producteurs ${ }^{98}$.

La distance affective de John envers The Hunters peut être en partie attribuée à la déception initiale de son père et à la réception négative du film de la part d'anthropologues et de chercheurs en cinéma - qui s'accentue avec le temps ${ }^{99}$. Lorsque John retourne en Afrique à l'occasion de l'expédition de $1957^{-5} 8$ (c'est-à-dire avant la première vague de réactions à The Hunters), il est persuadé que de nouvelles formes de cinéma sont nécessaires pour restituer de façon plus adéquate l'expérience vécue des Bochimans.

Lorna et Elizabeth Marshall n'ont pas pris part à l'expédition entreprise par Laurence et John de novembre 1957 à juin I958. D’après Lorna, «[]'enjeu de l'expédition de I957-58 porte sur le tournage de films par John Marshall et l'enregistrement de musique par Nicholas England» ${ }^{100}$. John se met aussitôt à filmer dès leur arrivée à Nyae Nyae. Laurence semble satisfait de la nouvelle approche de son fils filmant des événements de la vie quotidienne des Ju/'hoansi. Dans une lettre adressée

96 John Marshall, «Filming and Learning», op.cit., p. I40. Dans «An Argument about a Film» (in Jay Ruby (éd.), The Cinema of John Marshall, op.cit., pp. 179-193), Nancie L. Gonzalez conteste la critique de The Hunters par John Marshall comme un film «résolument artistique» et de peu de conséquence. Elle cite les journaux de Lorna Marshall et J. O. Brew pour remettre en cause l'affirmation de John selon laquelle «la chasse ne s'est pas déroulée comme elle est représentée dans le film». Gonzalez considère The Hunters comme «un chef-d'œuvre».

97 John Marshall, «Filming and Learning», op.cit., p. 39 .

98 Laurence ne précise pas qui sont ses contacts dans le studio de Hollywood, mais évalue la somme proposée - pour
The Hunters probablement (Peabody Museum, 2003.36.I.19, II septembre 1958, n.p.). Cette entrée surprenante dans le journal de Laurence constitue la seule trace que j’ai trouvée d'une sollicitation potentielle de fonds ou d'une distribution commerciale (plutôt qu'éducative) pour leurs films.

99 Pour une critique de The Hunters du point de vue d'un anthropologue reconnu, voir Karl G. Heider, Ethnographic Film (Austin, University of Texas Press, 1976, pp.3I-33); et pour celle d'un théoricien influent du cinéma, voir Bill Nichols, Ideology and the Image (op.cit., pp. 237-284). Les reproches portent sur le montage de différentes chasses, girafes et chasseurs en un récit unique et contestent l'idée que les Bochimans mouraient de faim et dépendaient essentiellement de la chasse pour leur survie. Par ailleurs, The Hunters ne manque pas de partisans: voir par exemple Peter Sutton Allen, "Ethnographic Cinema: Sources for Teaching Regional Courses», dans Jack R. Rollwagen (éd.), Anthropological Films and Videos in the I990s, Brockport NY, The Institute Press, 1993. L'anthropologue Peter S. Allen soutient que The Hunters «est le film définitif sur la chasse et la cueillette, et un véritable classique du genre ethnographique» (id., p. 403). L'édition DVD de The Hunters, qui reproduit un gros plan de $\neq$ Toma sur la couverture et qui est distribué par DER, comprend cet avertissement sur la quatrième de couverture: «[The Hunters] ne devrait pas être montré sans que l'on apporte une perspective plus contemporaine sur les conditions de vie des Ju/'hoansi actuellement».

100 Lorna Marshall, The !Kung of Nyae Nyae, op. cit., p. ro. 
101 Entrée des carnets de bord de Laurence Marshall, datée du 4 décembre i957, p. 22 (Peabody Museum, 2003.36.I.22).

102 Robert Gardner, «Anthropology and Film», Daedalus, n 86 , octobre 1957 , p. 350 .

103 Jay Ruby, Picturing Culture, op. cit., p.356. MacDonald commente en ces termes cette situation: "Gardner décrivait probablement son idée de mise en forme des matériaux !Kung en I957» (Scott MacDonald, op. cit., p. 356, note 8).

104 John Marshall, «Filming and Learning», op.cit., p. 7I.

105 Ibid. en décembre à l'administrateur d'Afrique du Sud, Claude McIntrye, Laurence écrit:

[John] travaille dur et bien à la tâche d'exprimer cette culture par le film, une tâche considérable, et on ne devrait pas lui demander de penser à quoi que ce soit d'autre. ${ }^{101}$

Robert Gardner s'est joint à l'expédition au début février I958. Avant de partir en Afrique, Gardner a publié un article dans la revue Daedalus, «Anthropologie et cinéma», où il semble se faire le porte-parole du Film Study Center qui vient d'ouvrir au Peabody Museum:

Il est probable que la série de films sur les Bochimans offrira une vue d'ensemble assez large sur la culture !Kung, bien que cela ne soit pas le principal objectif des membres du projet. Nous avons déterminé cinq aspects cruciaux de cette culture, avec le projet de consacrer à chacun de ces sujets un film d'une durée de 60 à roo minutes. Parallèlement à ces cinq films majeurs, nous avons l'intention de réaliser quinze ou vingt films plus courts et de moindre envergure. [...] Les cinq films principaux porteront sur les thèmes suivants: les Chasseurs, les Cueilleurs, les Joueurs, les Rythmes et les Saisons. [...] Les compétences particulières et les activités impliquées par la chasse, la cueillette et le jeu dans cette culture seront traitées exhaustivement dans les courts métrages, tandis que les longs métrages permettront de mettre en évidence leur importance et leur signification. [...] Depuis la création du Film Study Center, nous n'avons eu le temps que d'en produire un, The Hunters. ${ }^{102}$

Gardner ne mentionne pas le travail filmique de John Marshall, ni les projets en cours de la famille Marshall, ni même les Marshall comme «membres du projet». Comme Jay Ruby le fait remarquer, «Si vous n'aviez pas d'autres sources, l'article laissait entendre que c'est Robert Gardner lui-même qui a réalisé The Hunters» ${ }^{103}$.

John Marshall et Robert Gardner ont obtenu un fonds de la Section éducative de la Fondation nationale pour la science (FNS) pour réaliser des films enrichissant la documentation de Nyae Nyae. Selon John, «Bob voulait réaliser un film appelé The Gatherers» avec le fonds de la FNS; il a ainsi tourné en 1958 pendant l'expédition des Marshall de nombreux plans sur une vieille femme appelée /Gasa qui vit seule et est négligée ${ }^{104}$. Il a le projet de «retracer la vie typique d'une femme Ju/'hoan, repartant de sa jeunesse radieuse, poursuivant par sa maternité et s'achevant sur /Gasa dans la poussière » ${ }^{105}$. Dans une lettre adressée à Marshall en 1959, Gardner exprime ainsi ses intentions: 
Comme je te l'ai déjà dit, je m’intéresse aux Bochimans sur le déclin, à leur confrontation avec la mort, que j'interprète comme un signe de disparition et peut-être de renaissance. [...] Fasciné par le sujet, j’ai profité, de façon plutôt cynique, de la présence de notre chère Vieille Dame. Elle m’a donné accès, du moins de mon point de vue, à la paix et à la sérénité que ce peuple connaissait par le passé. The Gatherers commence véritablement lorsque j’ai pris place à ses côtés et que j’ai tenté en vain de voir son esprit à travers ma caméra. Le sujet (la Vieille Dame) que j’ai appris à aimer de plus en plus, est devenu la figure centrale d'un film qui dresse le portrait de la vie d'une femme !Kung, de cette femme, de tous les cueilleurs. ${ }^{106}$

John est peu favorable à ce projet pour plusieurs raisons. Premièrement, il «[est] opposé à l'idée de réaliser un nouveau film narratif comme The Hunters qui utilise différentes femmes dans une histoire à la fin convenue»; deuxièmement, il «ne [veut] tout simplement pas que des connaissances [à lui] soient faussement représentées » ${ }^{107}$. Le dévouement de Gardner envers «notre chère Vieille Dame» ne correspond pas au point de vue de Marshall. Il en résulte une opposition sur le plan de la représentation et un conflit quant aux droits d'auteur. Suivant l'opinion de Marshall, Gardner «voulait s'approprier le film. [...] [John rappelle par la suite que] nous sommes entrés en procès, et les juges ont finalement dit que le film appartenait à mon père, et non pas à Harvard...» ${ }^{108}$

Cinquante ans plus tard, en 2009, lorsque Gardner a 84 ans, le Bard College consacre une rétrospective à sa longue et admirable carrière de cinéaste. À cette occasion, Gardner assemble un film de compilation de 50 minutes qu'il intitule Nine Forsaken Fragments ${ }^{109}$. "The Old Lady (aka A Human Document)» (I958) constitue l'un de ces fragments. C'est le portrait d'une femme Ju/'hoan âgée, /Gasa, que Gardner a filmée lors de son voyage à Kalahari avec les Marshall; ce projet provoque un différend entre les deux cinéastes, Marshall pensant que Gardner déforme la vie !Kung en présentant/Gasa comme abandonnée.

«The Old Lady (aka A Human Document)» dure moins de quatre minutes. Ce fragment s'ouvre sur un plan d'ensemble de plusieurs huttes, et se poursuit à travers une série de très gros plans sur les différentes parties d'un corps âgé, émacié. Une main desséchée recherche apparemment quelque chose dans le sable. Finalement, le corps de la femme est montré dans son intégralité à travers plusieurs plans moyens. Le passage s'achève sur une figure desséchée rampant dans le sable jusqu’à
106 Robert Gardner, dans une lettre à John Marshall datée du 5 novembre I959, citée dans Robert Gardner, Making Dead Birds, Cambridge, Peabody $\mathrm{Mu}-$ seum, 2007, p.I4

107 John Marshall, «Filming and Learning», op.cit., p. 7I.

108 Id., p. I39.

109 Scott MacDonald, op.cit., pp. IoIıо6. Je ne sais pas si Gardner avait obtenu les droits pour ces séquences, vu que John se souvient d'un conflit juridique à ce sujet, le copyright revenant aux Marshall (John Marshall, «Filming and Learning», op. cit., p. 139). En 2009, Laurence, Lorna et John Marshall étaient tous trois décédés. DER prépare une version DVD des fragments filmés de Gardner, qui pourraient atteindre le nombre de treize (e-mail à l'auteure de Frank Aveni, directeur Design et Media au DER, le 28 juin 20I8). 
110 Robert Gardner, «Kalahari Journal», dans Charles Warren (éd.), Just Representations/Robert Gardner, Cambridge, Mass., Peabody Museum/Studio7Arts, 20I0, p. I7. une hutte. La bande son est composée de sons d'insectes et de gémissements intermittents. Vers la fin du fragment, on entend brièvement une voix, mais personne n'apparaît. C'est peut-être la femme qui se parle à elle-même. Bien que des casseroles vides et des ustensiles ménagers signalent que le lieu est habité, «la vieille dame» (jamais désignée comme /Gasa) est représentée comme complètement isolée (ce qui constitue un contraste saisissant par rapport aux films de Marshall qui montrent toujours les Ju/hoansi en situation de relations sociales). Le portrait sans fard de ce que Gardner considérait comme «une confrontation avec la mort» est obsédant dans son intimité sensuelle. Le second titre, «A Human Document» [Un document humain], nous encourage à interpréter ce fragment comme un commentaire sur l'universalité de la vieillesse et de la mort.

Une année après la rétrospective de Bard et quatre ans avant son décès, Gardner publie Just Representations (2010). Le livre inclut une section, «Kalahari Journal», qui revient sur ses expériences avec les Marshall au Sud-Ouest africain. Les commentaires de Gardner sont cinglants:

L'aîné Marshall est un homme d'une telle impétuosité et d'un tel dédain envers ce qui ne correspond pas à ses propres convictions que la situation en vint rapidement à se détériorer, ne pouvant être en partie rétablie quaprès bien des dommages et des dépenses. Le jeune Marshall est si admiratif de son père qu'il n'est pas capable d'exercer librement son jugement, même lorsque sa pensée le conduit en ce sens. J’ai été stupéfait par cette débauche de biens et d'énergie dépensés sans objectif défini ou but en vue. Le bon sens est ici subordonné au caprice et au hasard. Nous avons avec nous une trousse de secours complète mais personne ne sait l'utiliser correctement. Nous disposons de cinq véhicules sophistiqués dans lesquels nous nous précipitons, mais personne ne les conduit de façon adéquate. Tout est entrepris sur la base de l'essai hasardeux et de l'erreur, et malheureusement l'échec semble inévitable au vu de la confusion qui règne quant aux prémisses et aux intentions... ${ }^{110}$

Il n'est pas possible de déterminer à quel point l'absence de Lorna, à l'esprit attentionné et bienveillant, a affecté en mal cette expédition (c'est elle qui avait aussi en charge les soins médicaux lors des autres expéditions). Laurence Marshall est connu pour son obstination, mais les journaux qu'il a tenus lors de ses expéditions, et qui sont actuellement conservés au Peabody Museum, témoignent d'un sens de l'orga- 
nisation beaucoup plus poussé que ne le laisse entendre Gardner. Les «carnets de bord» de Marshall sont remplis de décomptes quotidiens, de notes de dépenses, d'informations sur la planification du voyage (listes d'ustensiles, distances entre les haltes prévues et kilométrages, cartes dessinées à la main, etc.) et de coordonnées de différents associés, laboratoires de développement et compagnies de voyage ${ }^{111}$. Dans son étude attentive des expéditions, Ilisa Barbash note à propos des premiers voyages: «Le meneur des expéditions Laurence Marshall compensait son manque d'expérience par un sens aigu de l'organisation » ${ }^{112}$. L'expédition de $1957-58$ intégrait deux mécaniciens ${ }^{113}$. Cela ne fait aucun doute que John Marshall admirait son père. Dans l'entrée de son journal datée du 27 juin 1952, Lorna cite son fils encore adolescent: «John assure que Laurence est le plus grand homme qu'il a jamais connu et qu'il ne connầtra jamais» ${ }^{114}$.

\section{L'expulsion de John Marshall hors du Sud-Ouest africain}

En 1958, les autorités gouvernementales retrouvent John Marshall à Nyae Nyae et l'informent que son visa n'est plus valide. L'administration coloniale du Sud-Ouest africain l'expulse «pour soutien aux Ju/'hoansi lors de plusieurs incidents aux frontières», selon certains témoignages ${ }^{115}$. Des années plus tard, John écrit:

J'ai appris la raison officielle de mon expulsion par un fonctionnaire qui a émis mon permis pour me rendre dans le Bushmanland [en I978]. J'étais censé avoir fait un enfant à une femme Ju/'hoan. Ce mensonge m’a sidéré. Bien entendu, j’avais flirté avec des jeunes filles à Nyae Nyae dans les années 1950, mais la plupart des Ju/'hoansi que ma famille connaissait étaient extrêmement stricts à propos de la vie procréative de leurs filles. Les Ju/'hoansi ont été accusés de débauche. On m’a accusé d'avoir abandonné mon enfant. ${ }^{116}$

Que John ait conçu un enfant avec une femme Ju/'hoan alors que les relations sexuelles entre Blancs et Noirs étaient illégales sous le régime de l'apartheid au Sud-Ouest africain constitue peut-être un mensonge sidérant; mais d'après le témoignage de son ancienne femme, «les fiançailles de John à une jeune fille Ju/'hoan ont été célébrées (en tant que chasseur méritant, il a dû être très demandé) ${ }^{117}$. Dans The Old Way, publié en 2006 (juste après le décès de Lorna et John), Elizabeth Marshall Thomas écrit:
111 Voir Ilisa Barbash, Where the Roads All End, op.cit., p. 43, pour la reproduction d'une page du journal de Laurence qu'il a intitulée «South African Expenditures », $\mathrm{I}^{\mathrm{er}}$ juillet 1957-2I mars 1958 . Les montants sont indiqués en dollars US; la liste est d'une telle précision qu'elle inclut un «rabais» de \$ 187.II. Dans les carnets et les journaux d'expédition de Laurence, des notes approfondies font preuve d'une planification attentive, de la quantité d'essence nécessaire à chaque véhicule aux salaires payés aux membres de l'expédition, en passant par la nourriture achetée, le nombre de bobines envoyées pour tirage ou aux copies de textes envoyés par télégramme (Peabody Museum, 2003.36.I).

112 Ilisa Barbash, Where the Roads All End,op.cit., p. 4 o.

113 Id., Appendix A, p. 205.

114 Entrée du journal de Lorna Marshall datée du 27 juin 1952, p. 40 (Peabody Museum, 2003.36.4).

115 Voir Marshall Cabezas, "Photographic Essay of the Early Expeditions (195I-I958) to Study the Ju/'hoansi of Nyae Nyae», dans Jay Ruby (éd.), The Cinema of John Marshall, op. cit., p. I69. 116 John Marshall, «Filming and Learning», op.cit., p. 74 .

117 Nancie L. Gonzalez, «A Film Argument», op.cit., p. I89. Nancie Gonzalez et John Marshall ont été mariés de I97I à 1973. 
118 Elizabeth Marshall Thomas, Dreaming of Lions, op.cit., p. 286. John s'est marié à quatre reprises aux ÉtatsUnis. Au moment de son décès en 2005, il était marié à Alexandra (Lexi) Eliot Marshall.

119 John M. Bishop («Hot Footage/ Cold Storage», op.cit., p. 2I4) évalue le métrage à 350000 pieds (I65 heures). D’autres témoignages rapportent des chiffres bien supérieurs.

120 En i96i, Elizabeth a voyagé dans le nord-est de l'Ouganda, où elle a vécu auprès de la peuplade Dodoth. Elle est accompagnée par Timothy Asch, dont les photographies illustreront son ouvrage, Warrior Herdsmen (op.cit.). Asch a réalisé le film Dodoth Morning (1963) à partir de plans tournés lors de cette expédition. Elizabeth publiera par la suite douze livres de fiction et non fictionnels, centrés principalement sur le comportement animal.

121 Entrée du journal de Laurence Marshall, p.50 (Peabody Museum, 2003.36.I.3).

122 Ibid.
Lorsque John avait la vingtaine, il est tombé amoureux et il s'est marié à une femme Ju/'hoan. Bien qu'ils aient tous deux contractés d'autres mariages par la suite, ils ont maintenu des liens d'amitié toute leur vie; et s'ils n'ont pas eu d'enfants ensemble, leur relation a définitivement intégré John dans leur tissu social, celui-ci devant répondre à des obligations auxquelles il a volontiers consenti. ${ }^{118}$

Quelle qu'en soit la raison, John ne mentionne pas de cérémonie de fiançailles ou de mariage avec une femme Ju/'hoan, lorsqu'il s'exprime «officiellement» sur son expulsion du Sud-Ouest africain. Mais de la même façon, en tant que jeune homme et tout au long de sa vie, John a été «définitivement intégré dans le tissu social» des Ju/'hoansi.

Au moment de son départ du Sud-Ouest africain en 1958, des centaines de milliers de mètres de films I $6 \mathrm{~mm}$ couleur avaient été tournés à Nyae Nyae, la plupart par John lui-même ${ }^{119}$. La tâche immense d'assembler ce métrage en des films compréhensibles attend le jeune cinéaste. En 1959, Elizabeth (à présent mariée à Steve Thomas) a publié son livre The Harmless People et se consacre à d'autres projets ${ }^{120}$. Laurence et Lorna retournent au Sud-Ouest africain pour une expédition de recherche en 1959 pendant deux mois et à nouveau pour une autre expédition en I96I sur trois mois. Les Marshall ont apporté avec eux des copies de The Hunters. Les tergiversations antérieures de Laurence à propos du film se sont estompées. Dans une lettre à un administrateur de Windhoedk, Laurence écrit:

Nous avons hésité à vous envoyer ce film auparavant, mais comme il a remporté de nombreux prix mondialement et qu'il est bien connu aux États-Unis, nous nous sommes dits que ce serait une erreur que de le soustraire plus longuement au public du Sud-Ouest africain. [...] nous n’aurions évidemment pas d'objection à le louer à des sociétés ou des personnes intéressées. ${ }^{121}$

Les Marshall ont aussi envoyé une copie de The Hunters à Claude McIntyre, le préposé aux Affaires Bochimanes, «comme marque de notre reconnaissance pour les services rendus à diverses occasions, depuis que nous avons commencé notre travail sur les Bochimans en $1950{ }^{122}$. On ne peut que spéculer sur la façon dont ces copies de The Hunters ont été utilisées, si elles ne l'ont jamais été.

L'ethnomusicologue Nicholas England a accompagné les Marshall pendant les expéditions de 1959 et de 196r, enregistrant de la musique !Kung. Deborah Marshall, une artiste, qui était mariée à John à cette 
période, s'est jointe à l'expédition de 1959 pour dessiner «des paysages, des personnes et des biens culturels» ${ }^{123}$. Tout au long des années i960, les aînés Marshall vivent entre la Nouvelle Angleterre et Nyae Nyae, leur dernier voyage en Afrique intervenant à la fin des années I960, Laurence ayant 80 ans et Lorna 70 ans ${ }^{124}$. En 1976 , les années d'observation attentive de Lorna et d'amitié partagée avec les !Kung portent leurs fruits avec la publication de !Kung of Nyae Nyae, un ouvrage d'ethnographie tout à fait remarquable écrit par une autodidacte ${ }^{125}$.

\section{Les «films-séquences »}

Dans l'essai de Gardner publié dans Daedalus en I957, celui-ci mentionne le projet de produire quinze ou vingt courts métrages sur les !Kung. Gardner n'utilise pas le terme de «films-événements» [«event-films»] ou de «films-séquences» [«sequence-films»], mais il affirme que ces futurs films seront «strictement conçus». Il est probable que lors de la préparation de leur demande de soutien à la FNS, John ait fait part de ses changements d'orientation dans ses objectifs filmiques. Des années plus tard, John décrira ainsi sa logique:

J'ai fait l'observation commune que la plupart d'entre nous organisons notre vie sociale - ou laissons ainsi disposer de notre vie - en événements. Que nous soyons participants ou observateurs, nous avons en commun une idée générale de quand un événement s’arrête et un autre commence. [...] Les événements correspondent à des séquences dans un film, et ce concept est utile pour envisager la réalisation filmique. En réinventant le langage des angles et de la distance de prise de vues, je m’appuyais sur le fait que les activités dans la plupart des événements sont organisées par les participants comme de petits drames qui sont circonscrits dans l'espace et le temps. J'ai toujours essayé de filmer comme le membre d'un groupe plutôt que de tourner de l'extérieur comme un observateur. ${ }^{126}$

Quelle que soit la pertinence des souvenirs de l'expédition de 1958 par Gardner, John est intensément impliqué en I957-58 dans le tournage de séquences qui seront assemblées en dix-sept films distincts: $A$ Group of Women, A Joking Relationship, An Argument about a Marriage, A

123 Ilisa Barbash, Where the Roads All End, op. cit., pp. I4I-I42.
124 Elizabeth Marshall Thomas, Dreaming of Lions, op. cit., p. 286. En plus de leur résidence principale à Cam- bridge, les Marshall ont également des maisons à Peterborough (New Hampshire) et dans l'île de Nantucket, au Massachusetts. Laurence a acheté une ferme de moutons dans le Sud-Ouest en 1958.

125 Lorna Marshall, !Kung of Nyae Nyae, Cambridge, Harvard University Press, I976. Voir en particulier la liste I («Places and Periods of Work with !Kung in the Nyae Nyae Area», p. Io) et la liste 2 («Bushman Groups Visited outside the Nyae Nyae Region», p. II). Lorna obtient un baccalauréat en littérature anglaise de l’Université de Californie (Berkeley) en I92I et un Master en littérature du Radcliffe College en I928; elle commence un doctorat. Depuis le début des années I950, Lorna lit avec assiduité divers ouvrages relatifs à l'anthropologie et des sujets proches, assiste à des cours en anthropologie à Harvard après son retour d'expéditions, et s'est adressée à de nombreux anthropologues, y compris son amie Margaret Mead, pour solliciter des conseils.

126 John Marshall, «Filming and Learning», op.cit., pp.40-4I, p.42. Lors de sa première expédition, dans l'entrée de son journal du 9 juillet i95ı, Lorna énumère onze «séquences» (par exemple Boire, Remplir des coquilles d'œufs d'autruche, Chasser, Cuisiner) qui semblent constituer le sujet de films, puisque les séquences sont mentionnées après et avant des informations sur les objectifs utilisés ou le stock de pellicule (Peabody Museum, 2003.36.r.2). La famille Marshall tient fréquemment des «conseils» (pour reprendre les termes de Lorna) afin de discuter de leurs buts et objectifs; il en résulta très probablement un vocabulaire commun. Aussi le concept de John de «film-séquence» remonte-t-il probablement à i95 I. 
127 Ces courts métrages ont été réalisés entre 196r et I974 à partir de plans tournés en 1957-58. Des séquences tournées par John en 1957-58 (et auparavant) sont aussi incluses dans des films plus tardifs et dans le documentaire de la $\mathrm{Na}$ tional Geographic Society, Bushmen of the Kalahari (I974).

128 Asch a établi un index partiel par sujet des 300 heures de plans tournés dans les années i950, annotant la plupart des bobines de l'Expédition IV (I955) et VI (I957-58) avec des descriptions plan par plan et des «détails sur le moment, le lieu, les acteurs et le type de plans» (John M. Bishop, «Hot Footage/Cold Storage», op.cit., p. 224). Le terme d'«acteurs» semble ici particulièrement peu heureux.
Curing Ceremony, N/um Tchai: The Ceremonial Curing Dance of the !Kung Bushmen, Lion Game, The (N!owa T'ama) Melon Tossing Game, Debe's Tantrum, !Kung Bushmen Hunting Equipment, Playing with Scorpions, A Rite of Passage, The Wasp Nest, Men Bathing, Baobab Play, Children Throw Toy Assegais, The Meat Fight et Bushmen Tug of War ${ }^{127}$. John est crédité pour la photographie et la réalisation de chacun de ces films; Laurence Marshall, John Marshall et DER sont désignés comme producteurs; John et/ou Frank Galvin ont monté la plupart de ces films. Ceux-ci durent entre quatre et 37 minutes; la plupart sont en couleur; et ils se concentrent soit sur une activité unique, soit sur une série d'événements qui se déroulent progressivement. Ces courts films-événements représentent une rupture significative dans l'approche et le style de Marshall. En un sens, il invente le cinéma direct de son côté: il ne se concentre pas sur le tournage de plans agencés en un récit thématique au moment du montage, mais sur des événements en cours, tels qu’ils se développent, pour révéler le drame intrinsèque de la vie quotidienne. Marshall et sa caméra s'approchent au plus près de ces événements, de sorte à introduire un éventuel spectateur dans l'action en cours, pour mieux comprendre et même faire l'expérience des interactions sociales des participants.

En i959, Robert Gardner et J. O. Brew demandent à Margaret Mead si elle connaît une personne susceptible d'assister John sur le montage des séquences des Bochimans, afin de répondre aux exigences de la bourse de la FNS alloué à ce projet de film. Mead recommande Timothy Asch qui a été son assistant à l'Université de Columbia, après avoir récemment terminé sa licence de baccalauréat et commencé des études de second cycle dans la région de Boston/Cambridge ${ }^{128}$. Selon Asch,

[...] ils recherchaient un monteur, tout particulièrement quelqu'un qui ne partageait par leurs intentions ou opinions, pour aider à monter leurs films. [...] Après avoir pris en considération les 500000 pieds de tournage de John sur les Bochimans, j'ai découvert ces brèves séquences d'interaction sociale qui étaient tournées dans le plus grand détail, car le père de John disait que si vous tourniez, il fallait le faire en détail. Aucun d'entre nous n'avait suffisamment de moyens financiers pour tourner autant de séquences. [...] Dans dix de ces brèves séquences, j’ai découvert un matériel remarquable pour l'enseignement. [...] Donc nous consacrions toute notre énergie à monter ces brefs films. Gardner pensait que nous étions fous. Joe Brew [...] croyait que nous avions perdu la raison. Gardner et Brew étaient inquiets car ils devaient répondre aux exigences de 
la FNS. Mais Brew nous a soutenu car j’ai plaidé avec conviction en faveur de la qualité éducative de ces films. ${ }^{129}$

Tim Asch a le même âge que John - 27 ans. Asch apporte au projet son regard averti (il a étudié la photographie avec Ansel Adams, Minor White et Edward Weston), une sensibilité autocritique (qui contraste avec les personnalités enflammées de Marshall et de Gardner) et un dévouement inconditionnel pour l'enseignement (il fondera et dirigera par la suite le Centre d'anthropologie visuelle à l'Université de Caroline du Sud). Asch a activement contribué au développement de la méthode de John qui consiste à suivre les événements sur un mode successif et ensuite à monter ces séquences selon un schéma chronologique linéaire ${ }^{130}$. Selon Jay Ruby, Asch a aidé à monter la plupart des courts métrages constitués à partir des plans tournés en $1957-58^{131}$.

À la fin des années 1950, les caméras ont considérablement évolué. La caméra Arriflex à batterie que John utilise comporte une visée reflex, ce qui lui permet de cadrer et faire le point à travers l'objectif, ayant la possibilité de se déplacer avec la caméra et de refaire le point dans ses mouvements. Des lentilles focales plus longues permettent de maintenir nets les sujets lorsqu'ils se déplacent. Le filmage s'apparente à un mode de rencontre plus intime grâce à la maniabilité de la caméra en mouvement. Pour John, «un lien moral entre lui et ses sujets éclipsaient les contraintes du tournage ${ }^{132}$. John devient non seulement un cinéaste de plus en plus compétent, il met également un point d'honneur à filmer de façon adéquate la complexité de la vie des Ju/'hoansi de leur point de vue.

A Rite of Passage est le premier film où John «a réellement commencé à déplacer [sa] caméra au sein des événements et à suivre de près une histoire vécue [...]» ${ }^{133}$. Ce film de I4 minutes revient sur le thème de la chasse, établissant un lien entre la structure narrative de The Hunters et le concept développé par John Marshall de «film-action» à partir de la perspective d'un participant-observateur. A Rite of Passage recourt encore à la pratique du commentaire en voix over dans son ouverture, mais en éliminant le «langage verbeux» dont John regrette la présence dans The Hunters. Le film progresse en suivant une logique narrative, mais (à la différence de The Hunters) la logique émerge des événements que John a filmés comme une série d'actions successives : la chasse et la mise à mort d'un animal imposant, un gnou, par un garçon de I3 ans nommé /Ti!Kay (aidé par son père et le pisteur expérimenté Crooked /Qui);
129 Timothy Asch, à partir d'entretiens avec Jay Ruby, cité dans Jay Ruby, Picturing Culture, op. cit., p. II7.

130 Scott MacDonald (American Ethnographic Film and Personal Documentary, op. cit.) cite «A Proposal for Making Ethnographic Film», le premier article écrit par Timothy Asch (en septembre i964) après le début de ses études dans le programme $\mathrm{PhD}$ en Anthropologie à Harvard: "La proposition suivante est un prolongement de mon travail avec John Marshall sur le projet de films autour des Bochimans au Peabody Museum et de mes études actuelles en anthropologie; le terme ‘film-séquence`, tel que je l'utilise ici, a été initié par John Marshall» (id., pp. II6-II7).

131 Jay Ruby, Picturing Culture, op.cit., p. II7 et p. 285 , note 6. Cependant, A Rite of Passage (I972) est le seul film sur lequel Asch est crédité comme co-monteur (aux côtés de Frank Galvin et Joyce Chopra) dans la filmographie comprise dans The Cinema of John Marshall (op. cit.). Asch est désigné dans les crédits de nombreux films-séquences comme «assistant à la production".

132 John Bishop, «Life by Myth: The Development of Ethnographic Filming in the Work of John Marshall», dans Rolf Husmann (éd.), Origins of Visual Anthropology: Putting the Past Together, Göttingen, Institut fur den Wissenschaftlichen Film-Knowledge and Media, 200I, pp. I-2. Voir Fadwa El Guindi, Visual Anthropology: Essential Method and Theory, Walnut Creek, CA, AlataMira Press, 2004, pp. 97-98.

133 John Marshall, «Filming and Learning», op. cit., p. 40. 
la violence de la première mise à mort de /Ti!Kay; et la cérémonie «de passage» lors de laquelle le jeune homme est scarifié et reconnu comme chasseur. Cette cérémonie signifie son accession à une maturité sociale et au statut concomitant de gendre acceptable. Kan//a, le père de /Ti!Kay, incise l'avant-bras, le bras, la poitrine, le dos et le visage du garçon; l'enfant demeure stoïque. La voix over explique la signification de chaque incision et suggère leur raison d'être:

Lorsqu'un homme est paresseusement assis chez lui, il pensera soudainement: «Pourquoi suis-je assis ici? Pourquoi est-ce que je ne participe pas au Grand Jeu de la chasse?»

Le cadrage de Marshall diffère de la perspective distante qui caractérise la plupart du temps The Hunters, puisque la caméra (ou l'objectif) se rapproche souvent de l'action (tout particulièrement lors de la cérémonie de la scarification) et le rythme du montage est plus rapide.

A Group of Women (I96I) et A Joking Relationship (I962) sont les deux premiers films montés à partir des séquences tournées en $1957^{-5} 8$ qui «prennent leur temps et suivent la forme induite par leur contenu». Ces deux films s'écartent du schéma convenu du commentaire en voix over en empruntant les potentialités émotionnelles de la narration visuelle et, ce qui est tout aussi important, en sous-titrant le propos des participants. Filmés parfois avec une étonnante proximité, ces films révèlent des moments de forte intimité. A Group of Women ne dure que six minutes. Le film propose un bref aperçu de la vie quotidienne d'un groupe de femmes !Kung étendues sous un baobab, bavardant, allaitant, partageant leur intimité avant de s'endormir. L'une des femmes se plaint du fait que les hommes veulent aller cueillir des baies qui sont «trop loin». Elle ne veut pas s'y rendre. On lui recommande: «Eh bien, refuse d'y aller!» À un moment donné, leur relation de complicité est interrompue par l'irruption d'une femme - qui est filmée de dessous et à distance, ce qui implique que John filme par terre parmi le groupe de femmes. Elle

134 La plupart des films dans la série !Kung qui utilisent des sous-titres sont précédés d'une mention qui précise que le son n'est pas synchrone mais «a été enregistré au moment du tournage et reconstruit pendant le montage. Les traductions sont réalisées à la fois à partir des enregistrements et de notes ». les traite de «créatures paresseuses» et demande qu'on l'aide à aller chercher de l'eau, mais on ignore ses propos et par conséquent elle quitte le groupe. La réticence du bébé de Koa à prendre le sein devient un sujet de conversation, qui va de pair avec la concentration de la caméra en très gros plans sur les seins de Koa (et les mouches qui ne semblent pas la déranger). Le son n'est pas synchrone, mais les propos échangés soulignent l'enjouement et la sérénité des images ${ }^{134}$. Leur aisance par rapport à la 
présence de John dans une situation de complicité féminine montre qu'il est accepté par les femmes !Kung, de la même façon que ce film sensible manifeste son respect envers elles.

A Joking Relationship est un film plus long (13 minutes) et plus complexe émotionnellement, car il décrit la relation de séduction entre une fille (N!ai) et un homme plus âgé (son grand-oncle, T!ikay) [à seulement I3 ans, Nlai est déjà la femme de /Gunda, mais elle a refusé de consommer son mariage; nous ne pouvons connaître ces faits qu'à partir de données extérieures au film]. Dans le film, l’homme appelle la fille «ma petite tsima», ce qui semble être un terme affectueux; et par la suite, il dit: «Nous sommes parents et ne devrions pas nous battre», indiquant ainsi par le dialogue leur relation de famille. Les gestes taquins sont souvent sensuels et le dialogue souvent provocateur: l'homme dit à la fille que «son mari désespéré va abandonner sa femme paresseuse», à quoi la jeune fille répond: «je ne suis pas une femme». L'ambiguïté de leur relation crée une tension qui est palpable.

Scott MacDonald décrit avec perspicacité les nuances de ce film:

Marshall parvient à capturer à la fois l'affection manifeste d'un oncle pour sa nièce, une situation qui est rarement montrée au cinéma, et la dimension sexuelle sous-jacente de cette relation et peut-être de toute relation entre un homme mûr et un jeune membre de sa famille. Ici, cette attirance sexuelle, qui semble réciproque, est tout du long évidente, même si les deux parties redirigent cette envie irrépressible qui pourrait poser problème dans la petite communauté dans laquelle ils vivent en une badinerie d'humeur joviale et en un échange physique non sexuel (mais sensuel). ${ }^{135}$

N!ai, la «fille insouciante» filmée dans First Film, réapparaît dans A Joking Relationship comme une présence fascinante à l'écran. Elle semble à l'aise avec les badineries grivoises qu'elle échange avec son grand-oncle, tandis qu'ils se débattent à l'ombre d'un baobab. La caméra tenue à la main est si proche, que l'on ne peut souvent pas identifier qui est filmé. Parfois, /Ti!kay est l'agresseur physique, lorsqu’ils luttent pour un bâton; d'autres fois, N!ai saute sur son dos en s'exclamant: «Si je ne te maîtrise pas au sol, tu te retourneras et me flanqueras une fessée». Il l'appelle serpent, insecte, et prétend qu'il va «écraser ce petit insecte». Cette menace simulée de violence va jusqu’à inclure une dimension sexuelle, lorsqu'il lui dit qu'il va lui «mordre un téton et le manger», tandis que
135 Scott MacDonald, American Ethnographic Film and Personal Documentary, op.cit., p.3r. MacDonald cite les commentaires de N!ai dans un entretien non publié où elle précise que cet incident filmé est devenu problématique pour elle (id., p. 352, note 22). 
136 Id., p. 32.

137 Dans un essai qui revient sur l'utilisation des films-séquences de Marshall dans le cadre de cours d'introduction à l'anthropologie sociale, Timothy et Patsy Asch suggèrent l'utilité de A Joking Relationship pour aider «les étudiants à comprendre la signification des liens de parenté dans l'organisation de l'univers social !Kung» et pour les encourager «à examiner comment ces liens déterminent dans leur propre société la définition d'un comportement approprié». Les Asch proposent des conseils pédagogiques par rapport à onze films-séquences sur les !Kung (et N!ai) dans «Images that Represent Ideas: The Use of !Kung Films to Teach Anthropology", dans Megan Biesele, Robert Gorden et Richard Lee (éd.), The Past and Future of !Kung Ethnography, op. cit., pp.327-351:341-342. 138 MacDougall, «Subtitling Ethnographic Films», dans Lucien Castaing-Taylor (éd.), Transcultural Cinema, Princeton, Princeton University Press, I998, p. I65.

139 Jean Rouch, «La caméra et les hommes», dans Claudine de France (éd.), Pour une anthropologie visuelle, Paris/ La Haye/New York, Mouton/EHESS, I978, p. 66. Jean Rouch fait référence à un «film très simple», The Pond, comme à un «modèle du genre». Il a peut-être vu une version antérieure de Men Bathing, présentée sous un autre titre.

140 Ibid. Au vu des inconvénients induits par le commentaire et le soustitrage, Rouch renvoie à une version de son film Un lion nommé l'Américain qui fait l'économie de ceux-ci (id., p. 66). Rouch recommande d'accompagner chaque film ethnographique d'une brève brochure (ou manuel d'explication). l'on voit à l'écran la poitrine de N!ai, qui n'est pas encore pleinement développée. Au milieu du film, ils prennent conscience que leur interaction intense est filmée. Le grand-oncle interpelle N!ai, qui est montée à un arbre: «Ne vois-tu pas qu'il attend que tu redescendes? Il veut te filmer quand je te fais culbuter.» N!ai demeure imperturbable et change de sujet: «Il veut me filmer lorsque je cueille des aliments». Plus tard, lorsque N!ai ajuste sa chemise, /Ti/kai épingle le sujet du tabou: «Ça va, rhabille-toi ou tu provoqueras ma perte!» Il continue à la taquiner, l'enjoignant à interpréter la danse de l'antilope pour lui (ce qu’elle avait commencé à faire dans l'arbre). Le film se termine sur le comportement apparemment responsable de N!ai: elle réajuste son collier de perles et part, laissant/Tikai! assis seul.

MacDonald reconnaît que l'«aisance» de Nlai pendant le tournage est toute relative, lorsqu'il écrit:

Les gros plans de Marshall sur les visages de N!ai et /Ti!kay restituent le plus souvent non seulement leur bonne humeur mais aussi un embarras subtil, probablement la reconnaissance implicite que l'attraction de l'homme et de la fille est observée; par ailleurs, la fascination de Marshall envers ce que /Tilkay semble considérer comme un nonévénement l’amuse visiblement. ${ }^{136}$

Ce «non-événement» constitue, parmi tous les films de Marshall, l'une des séquences les plus fascinantes sur le comportement interpersonnel ${ }^{137}$.

Le recours au sous-titrage dans A Group of Women et A Joking Relationship constitue une étape importante dans l'évolution de Marshall vers un tournage plus authentique. Le cinéaste ethnographique David MacDougall considère l'introduction de sous-titres dans les filmsséquences de Marshall comme une innovation significative:

Les sous-titres ont propulsé le cinéma ethnographique dans une nouvelle phase. Le public n'écoute plus des informations portant sur des personnes, mais commence à les regarder et à les écouter plus directement. ${ }^{138}$

Pour Jean Rouch, «Le titrage et le sous-titrage [...] apparaissent donc comme les moyens les plus efficaces pour échapper au piège du commentaire» ${ }^{139}$. Rouch affirme que Marshall est le premier à recourir à ce procédé. Le cinéaste ethnographique français note les difficultés du procédé:

[...] en dehors de la mutilation de l'image, l'obstacle le plus difficile est celui du temps de lecture: [...] le sous-titre ne peut être qu'un condensé de ce qui est dit. ${ }^{140}$ 
Malgré ces difficultés, les sous-titres permettent de rapprocher le spectateur des expériences vécues par les sujets filmés ${ }^{141}$. Les filmsséquences des Marshall sur les !Kung anticipent une revendication qui se généralisera dans les sciences sociales quelques décennies plus tard: que la recherche réponde aux voix (littéralement et métaphoriquement) des sujets étudiés.

\section{Des films denses}

Lorsqu'il discute ses films-séquences, John utilise souvent le terme «dense» [thick] pour décrire des films dans lesquels «le ratio du contenu par rapport à la durée filmique» est élevé ${ }^{142}$. Il donne comme exemple The Meat Fight (1974) pour illustrer à quel point «un contenu important peut émerger d'un événement mineur ${ }^{143}$. Tourné en couleur à $/ \mathrm{O}$ ! pendant la saison des pluies de 1958 , ce film de I4 minutes se concentre sur les conflits qui se nouent autour du partage de la viande d'une antilope tuée par la flèche empoisonnée qu’un garçon (N!amshi) a tirée. C’est sa première prise conséquente, qui est donc d'une importance cruciale pour lui. À cause de pluies abondantes, N!amshi perd la trace de l'animal. Khan//a, un homme d'un autre groupe, prétend que l'animal a été foudroyé, une affirmation qui exaspère la famille de N!amshi. Les deux groupes sont sur le point de se battre; un homme sage d'un troisième groupe, ₹Toma, intervient. À l'opposé du partage harmonieux de la viande au sein du groupe filmé dans The Hunters, les contentieux qui portent parfois sur la distribution de la viande sont au centre de The Meat Fight. La violence est heureusement évitée quand «un homme d'une intégrité irréprochable» [₹Toma] supervise le partage ${ }^{144}$.

En montant les plans qui aboutiront à The Meat Fight, John se confronte au problème sempiternel de maintenir la «densité» d'un événement filmé, tout en le présentant de façon compréhensible à un public non autochtone. Dans The Meat Fight, une nouvelle solution remplace les interventions antérieures de la narration en voix over et/ou le soustitrage du discours des participants. Cette nouvelle technique repose sur l'explication de la situation par la voix over de John (dans ce cas, un conflit entre groupes portant sur la distribution de la viande) sur fond d'images gelées (des photogrammes fixes) qui identifient les individus impliqués, avant que la séquence d'action live ne commence. Les informations apportées par le résumé introductif permettent au spectateur de
141 Peter Loizos revient sur le rôle de Asch dans les films-séquences de John Marshall; il écrit qu'Asch «a une influence sur la décision d'introduire des sous-titres dans certains filmsséquences de Marshall sur les !Kung, qui ont suscité l'enthousiasme général lors de leur présentation à UCLA en I968.» (P. Loizos, Innovation in Ethnographic Film: From Innocence to Self-Consciousness, 1955-1985, Chicago, University of Chicago Press, I993, p. 23).

142 John Marshall, «Filming and Learning», op. cit., p. 46.

143 Ibid.

144 Id., p. I47. 
comprendre la situation générale, pour ensuite se concentrer sur les matériaux filmés qui suivent perçus sur le plan de l'expérience - à un degré d’intensité qui n’aurait pas été possible autrement.

The Wasp Nest (1972) recourt aussi à cette stratégie qui consiste à donner des informations à travers un résumé introductif, suivi d'images gelées qui identifient les sept participants et leurs relations, la plus grande partie du film étant constituée de plans d'action live dans lesquels les événements préalablement décrits se déroulent à travers un «temps présent» cinématographique. L'événement central de ce film de 13 minutes est simple mais essentiel: des femmes cueillent de la nourriture qui vient de la brousse, laquelle constitue le moyen de subsistance de base du peuple de Nyae Nyae. Chercher de la nourriture constitue un travail sérieux, mais ce n'est pas une affaire morose. Les deux adolescents du groupe se battent; un enfant mange des baies oley pendant la cueillette; les femmes frappent des mains et chantent. Des gros plans de visages, de mains, de plantes immergent le spectateur dans la scène. N!ai découvre un nid de guêpes; avec son amie elle l'attrape; N!ai le fait brûler. Lorsque sa mère lui demande de ramener le jeune Debe particulièrement agité à la maison, N!ai, si souvent serviable, refuse et rejoint son amie, rappelant ainsi les complications de la vie de famille.

Certains membres de la famille sont présents dans Debe's Tantrum (I972), où le personnage obstiné et conflictuel est le petit Debe. Ce film s'ouvre sur un schéma généalogique de la famille, une anomalie parmi ces films, même si la plupart d'entre eux explorent des relations de famille. La voix du narrateur apparaît et disparaît dans ce charmant film de neuf minutes, expliquant que Dilai, la mère de Debe, âgé de 5 ans, entend participer à la cueillette, sans s'encombrer des « 40 livres d'un enfant agité». Dilai demande à la demi-sœur de Debe, Nlai, de ramener l'enfant à la maison. Le petit garçon pique une crise. Pendant ce temps, son père se tient «à l'écart de ces affrontements». U! rit de la situation difficile de sa sœur, tandis que Dilai se débat, «portant sur son dos son enfant triomphant». Ce simple événement, qui n’a probablement pas duré plus longtemps que le temps de la séquence, révèle une caractéristique culturelle importante: les parents !Kung punissent rarement leurs enfants.

Cinq courts métrages à partir de plans tournés en I957-58 montrent des garçons !Kung qui jouent: Playing with Scorpions (1972), Lion Game (1970), Children Throw Toy Assegais (1974), Bushmen Tug of War (1974) et 
Baobab Play (1974). Playing with Scorpions commence avec la voix over de John décrivant les comportements des !Kung face au danger; les quatre autres films sont dépourvus de voix over. Nous entendons les garçons parler et crier, mais il n'y a pas de sous-titres. L'attention est centrée sur les actions des garçons, leur énergie et leur imagination. Qu'il s'agisse de jouer avec un scorpion, de prétendre être un lion, tout à la fois agresseur et proie, de jeter des lances contre un arbre, de se disputer au sujet de la longueur d'un tuyau de caoutchouc, ou de jeter des bouts de bois depuis une branche dans un baobab, les actions des garçons sont tout à la fois enjouées et agressives. Chaque film célèbre la nature insouciante de l'enfance masculine chez les !Kung. Au sein de cet ensemble, Baobab Tree paraît le plus remarquable. Il est filmé à partir de deux points de vue distincts: dans l'arbre, avec les garçons les plus âgés (parfois magnifiquement filmés comme des silhouettes) qui grimpent sur les branches solides du baobab, et depuis le sol, où les garçons plus jeunes se rassemblent pour bombarder ceux qui grimpent à l'arbre. Le point de vue de la caméra varie: elle cadre tantôt en haut, tantôt en bas. Le résultat de ce montage alterné produit une séquence de combat ludique qui est cinématographiquement captivante.

Le thème de l'amitié masculine et du jeu s'applique aux adultes dans Men Bathing (1973), se déroulant de façon surprenante dans des poches d'eau ouvertes qui ressemblent à de petits lacs. Dans le prologue, des hommes !Kung sont filmés arrivant à une poche d'eau. Ces hommes apparaissent en images gelées tandis que la voix over de John les identifie et explique leurs relations mutuelles. Trois hommes forment une unité, tandis que deux autres hommes s'en séparent. Le film revient à des plans mobiles lorsque les hommes entrent dans l'eau. Des plans de Ti!Kay lavant ses vêtements (reçus dans la ferme blanche de laquelle il a aidé les femmes à s'enfuir) sont intercalés avec le bain et le batifolage des autres hommes. La beauté de la journée et la joie des hommes sont visibles à travers le miroitement de la lumière sur l'eau et les gros plans sur l'eau éclaboussée par les corps forts et foncés des hommes qui se baignent et qui se nettoient mutuellement le dos. Les paroles des hommes ne sont pas sous-titrées, mais on les voit qui rient (le résumé du début promettait des blagues salaces). Le film se termine sereinement, avec un plan longuement tenu sur le dos des hommes, à présent silencieux, faisant face à l'eau. Le récit de John reprend: «Quand ils quittèrent l'eau pour 
145 Id., p. 59. Il a aussi reconnu qu'une «erreur d'importance [dans les documents sur Nyae Nyae] est le manque d'effort sérieux pour montrer les conséquences de la peur de l'eau». Dans des films ultérieurs, de telles préoccupations deviendront centrales.

146 Scott MacDonald, American Ethnographic Film and Personal Documentary, op. cit., p. 39 .

147 A quel point le contexte culturel doit être inclus dans ce (ou tout) film ethnographique est une question qui demeure toujours problématique. Dans une critique de The Curing Ceremony, Nancie L. Gonzalez suggère qu'«il aurait été utile qu'un commentaire nous explique qu'une naissance sans complications dans la brousse est plutôt inhabituelle» («Curing Ceremony by John Marshall», American Anthropologist, vol.77, $\mathrm{n}^{\circ}$ I, mars I975, p. I75). Fadwa El Guindi questionne la «notion même de filmséquence» lorsqu'elle écrit: «Le genre qui se concentre sur une activité courante ou une conversation est-il adéquat lorsque de tels moments s'inscrivent dans les actions plus larges de la vie des Ju/'hoansi?» (F. El Guindi, Visual Anthropology: Essential Method and Theory, op.cit., p. 99), De nombreux filmsséquences!Kung sont accompagnés de manuels introductifs (produits par DER) à destination de l'enseignement. se sécher au soleil, ils se sont répartis dans l'espace suivant la nature de leurs relations.» John se souviendra par la suite de sa participation à de tels moments de joie masculine:

Nous aimions tout simplement nous baigner et jouer dans l'eau douce de N!ama après une saison de fortes pluies. ${ }^{145}$

MacDonald décrit Men Bathing comme «le film le plus serein de Marshall et l'un des plus beaux - un dernier vestige, peut-être, de l'innocence sur le point de disparaître du cinéaste» ${ }^{146}$. On retrouve l'esprit de sérénité caractéristique de Men Bathing dans A Group of Women. Ces deux films témoignent d'une admiration pour la dimension physique du peuple !Kung et leur absence de gêne par rapport à leur corps. Les femmes sont le plus souvent seins nus, le bas du corps revêtu d'un tablier en cuir à l'avant et à l'arrière. Men Bathing est le seul film de la série !Kung à montrer des hommes totalement nus, lavant plutôt que portant leurs pagnes.

Dans cette série, trois films-séquences témoignent du rôle central du rituel et plus particulièrement de la transe dans la vie !Kung. A Curing Ceremony (1969), le plus court de ces trois films, d'une durée de huit minutes, est un compte rendu en noir et blanc de la lutte pour la vie d'une jeune femme enceinte de huit mois de son premier enfant. La voix over de John informe le spectateur que Sha//ge est tombée malade et a donc besoin de l'assistance d'un guérisseur. Elle est couchée sous un arbre, entourée par des femmes parentes et des amies. Deux guérisseurs surveillent la femme, procédant à des rituels destinés à écarter la menace de cette fin de grossesse anormale. L'un des guérisseurs est le demi-frère de la femme; l'autre est Ti!kay. Les hommes crient et chantent; Tilkay entre en transe dans le but d'extirper la maladie de la femme enceinte. Des gros plans sur le visage douloureux de la femme et sur le visage du guérisseur en proie à la transe sont entrecoupés, créant une ambiance d'urgence. Le film s'interrompt abruptement par un long plan sur l'arbre, un enfant sain et le groupe en cercle dans l'expectative, tandis que le narrateur rapporte:

Ils ont attendu tout l'après-midi. Ce n'est qu'en début de soirée que l'enfant est mort-né après un court et douloureux labeur. Sha//ge a survécu. ${ }^{147}$

Aussi filmé en noir et blanc, N/um Tchai: The Ceremonial Dance of the !Kung Bushmen (1969) s'ouvre sur une voix over qui explique le rôle de 
n/um tchai dans la guérison et la prévention des sortilèges (tchai signifie se rassembler pour danser et chanter; $n / u m$ se traduit par la médecine ou le pouvoir surnaturel). On voit la silhouette d'hommes qui dansent tandis que le narrateur précise que les hommes ont dansé toute la nuit jusqu'au matin. Des images d'une beauté saisissante créent une ambiance d'intemporalité et soulignent la dignité de ce peuple. Le film revient ensuite à la danse qui durera du coucher au lever du soleil. Lorsque le rituel de la danse devient plus rapide et que les chants s'amplifient, la caméra se rapproche et le rythme du montage s'accélère, la danse atteignant son moment d'intensité le plus élevé lorsque le soleil se lève (John participe parfois à ces danses, en plus de les filmer) ${ }^{148}$. Les femmes s'assoient en groupe, entonnent des chansons contrapuntiques sans paroles et frappent des mains suivant différents rythmes; de temps en temps, l'une d'entre elles danse. Les hommes chantent et soulignent des pieds des rythmes compliqués. Plusieurs hommes entrent dans différents états de transe, certains atteignant la phase la plus profonde, appelée par les !Kung «demi-mort». Ceux qui perdent connaissance sont soutenus par d'autres hommes.

John reconnaît qu'un film comme N/um Tchai «exige une longue explication à propos de la relation entre la guérison et le monde surnaturel pour que le public puisse comprendre une cérémonie de cure» ${ }^{149}$. Dans ce but, Lorna Marshall et Megan Biesele ont édité un manuel d’introduction à N/um Tchai qui inclut la voix over, une liste des plans, des commentaires et des propos des guérisseurs qui décrivent leurs expériences de transe. De plus, les principaux principes de la religion !Kung sont rappelés ${ }^{150}$.

N!owa T'ama/The Melon Tossing Game (I970) est le troisième filmséquence qui présente une situation de transe. Dans ce film en couleur exceptionnel, on voit des femmes de trois différents groupes !Kung qui s'adonnent au jeu du melon à !O. La danse débute d’abord avec des femmes qui chantent et frappent des mains. Chaque femme se précipite au centre du demi-cercle qui a été formé, danse plusieurs pas, puis jette le melon à la prochaine femme qui se trouve dans le groupe. La caméra suit l'action depuis l'intérieur du cercle, le rythme du montage s'accélérant lorsque la danse devient chaotique, des hommes venant rompre ce schéma harmonieux. /Gunda, le mari de N!ai, danse avec une exubérance toute particulière. L'une des femmes les plus âgées, N/aoka, se
148 Voir l'entrée du journal de Lorna Marshall datée du 2i juin i953, p. 456 (Peabody Museum, 2003.36.r.4). Dans un entretien avec Jean Rouch (conduit aussi avec John W. Adams) au premier Margaret Mead Ethnographic Film Festival, John rapporte son expérience singulière de la «transe» («John [sic] Rouch Talks about His Films to John Marshall and John Adams», American Anthropologist, no 80, 1978, pp. 1005-1022). Voir les descriptions des danses de transe par Elizabeth et ses premières réactions à cellesci dans The Old Way, op. cit., pp. 267-273. Pour des photographies de transe et de rituels, voir Lorna Marshall, The !Kung of Nyae Nyae, op.cit., pp. I3I-I39; cet ouvrage comprend une analyse détaillée de la transe dans la vie !Kung.

149 John Marshall, cité par Timothy Asch, dans Jay Ruby (éd.), Picturing Culture, op. cit., p. 8.

150 Lorna Marshall et Megan Biesele, N/um Tchai: A Study Guide, Watertown, Mass., DER, I974. 
151 John Marshall, «Filming and Learning», op. cit., p. 45.

152 Id., p. 32.

153 Keyan G. Tomaselli et Arnold Shepperson, "Course File for « Documentary Film, Visual Anthropology, and Visual Sociology »", Journal of Film and Video, vol. 49, $\mathrm{n}^{\circ} 4$, hiver i997, pp. 54-55.

154 Ibid. déplace de façon sexuellement provocatrice; N!ai répond en narguant N/aoka et en lui jetant du sable au visage. Ce qui a débuté comme un jeu structuré se termine de manière déstructurée à travers une tension interpersonnelle.

\section{La précision dans le tournage}

Décrivant sa théorie du tournage de films-séquences, John affirme ses convictions:

Pour moi en tant qu'opérateur, le critère le plus important était la précision. Je voulais que l'on voie et entende les personnes dans mes films avec un minimum de distorsion. Dans les films-séquences terminés de 1957-58, les Ju/'hoansi sont montrés plus ou moins tels qu'ils sont. Ils parlent entre eux et interagissent sans être mis en scène et sans qu’on leur dicte leurs propos. ${ }^{151}$

Cette attitude représente un tournant crucial dans la pensée de John sur la précision, la distorsion et l'authenticité. Il se rappelle qu'«[e]n i955, [il] ôtai[t] encore les boîtes de conserve des plans pour que les Ju/'hoansi à Nyae Nyae aient l'air plus réels » ${ }^{152}$. À partir de I957, le sens du «réel» de John a changé. Même s'il n’a pas manipulé le cadre des films tournés en I957-58, les paramètres qu'il a choisi d’inclure dans ses films-séquences (à une exception près) continuent à dépeindre les Bochimans comme essentiellement isolés. Keyan G. Tomaselli et Arnold Shepperson, après avoir examiné les rushes et les chutes des films de Marshall aux Human Studies Film Archives à la Smithsonian Institution, décrivent les films achevés de Marshall comme comprenant des «absences structurées» ${ }^{153}$. Ces deux chercheurs de l'Université de Natal (Union d'Afrique du Sud) soutiennent que Marshall «a exclu des plans [qu'il avait tournés] des liens sociaux des!Kung avec des groupes noirs avoisinants, des migrations territoriales de familles!Kung, de leur engagement par des Héréros, d'exemples de relations avec l'équipe de tournage, et d'illustrations de différents modes d'acculturation» pour suivre la pensée anthropologique dominante des années i950, «qui envisageait les !Kung comme les derniers chasseurs-cueilleurs isolés et purs...» 154

An Argument about a Marriage (1969) constitue une exception importante à cette «absence structurée» d'interaction interculturelle: la situation à partir de laquelle émerge un conflit entre deux groupes de $\mathrm{Ju} /$ 'hoansi repose sur le travail forcé de Bochimans assujettis par des fer- 
miers Boers dans des fermes blanches. La reconnaissance explicite que les Marshall ont joué le rôle d’intermédiaire entre la police locale et les $\mathrm{Ju} /$ 'hoansi est tout aussi exceptionnelle. Le film s'ouvre sur des plans du retour joyeux des Bochimans dans les camions des Marshall. Les Bochimans portent des habits occidentaux, un signe sans équivoque de leur appartenance (temporaire) à un autre monde, auxquels ils sont heureux d'avoir échappé. Le récit qui ouvre le film dure sept minutes et rapporte les péripéties qui ont conduit à la libération des Ju/'hoansi des fermes suite à l'intervention des Marshall auprès des autorités du Sud-Ouest africain, à la demande du groupe indigène. Cependant, deux semaines après leur retour, des tensions émergent autour du statut de l'une des femmes, Baou. Bien que déjà mariée, elle a donné naissance à /Qui/ pendant leurs années de captivité; en conséquence, des hommes de deux groupes différents la revendiquent comme femme. Les beaux-pères se disputent farouchement car tous deux risquent de perdre les services d'un beau-fils. Des images gelées introduisent les principaux protagonistes du conflit.

Suivent des plans d'irruption d'émotions, certains échanges verbaux étant sous-titrés, mais pas tous, car les dialogues tendent à se superposer parmi les groupes en conflit. À un moment donné, quelqu’un qui renvoie au moment de la libération, dit: «C’était grâce aux Marshall», pour se faire interrompre par le père de Baou, Ti!kay, qui s'exclame: «Au diable les Marshall!» Le ton monte et les gens s’invectivent. La caméra en mouvement, filmant souvent en très gros plan, cherche à suivre ces disputes interminables, passant d'un interlocuteur à l'autre, restituant un sentiment de discorde, à la limite du chaos. N!ai exprime son dédain envers cette dispute, lui opposant les contingences de la vie quotidienne auxquelles il faut répondre: «Je ne cautionne pas ces personnes jalouses et pitoyables. J'en ai assez. Allons plutôt ramasser du bois pour le foyer.» $\neq$ Toma, la voix de la raison comme toujours, tempère ce tumulte, en disant: «Quand nous nous comportons dignement, ces situations n’arrivent pas». Sa déclaration résonne comme une prophétie sur plus d'un point, car la jalousie et les conflits manifestés dans An Argument about a Marriage iront en s'intensifiant dans les années à venir, lorsque les Ju/'hoansi seront déplacés. Le film se termine sur une image gelée de $\neq$ Toma; la voix over de John réapparaît, affirmant tristement que «l’inimitié perdurera». 
155 Peter Loizos, Innovation in Ethnographic Film, op. cit., pp. 20-2I.

156 David MacDougall, «Beyond Observational Cinema», dans Paul Hockings (éd.), Principles of Visual Anthropology, Berlin/New York, Mouton de Gruyter, i975, p. iा6.

157 Voir Scott MacDonald, American Ethnographic Film and Personal Documentary, op.cit.

158 John Marshall, «Filming and Learning», op. cit., p. I42. John pensait que «les réseaux télévisés à Chypre fabriquaient de toutes pièces une guerre».
Dans son étude sur le cinéma ethnographique de 1955 à 1985 , l'anthropologue Peter Loizos juge les films-séquences de Marshall en ces termes:

[...] à cette époque, ce matériau filmé était inégalé dans la restitution intime et vive de la vie de ces chasseurs-cueilleurs, y compris de leurs conflits, et de l'intensité dramatique des rituels destinés à la guérison. La capacité de Marshall et ses collaborateurs à donner vie et authenticité à ses sujets, qui étaient aussi ses amis ou des gens qu'il connaissait très bien, en tant qu'individus singuliers, en chair et en os, ne connaissait pas d'équivalent; ses films ont été encensés par des chercheurs sudafricains très critiques envers la plupart des films représentant la vie des Africains noirs. ${ }^{155}$

L'intimité, la vivacité et l'authenticité des films-séquences de Marshall sur les !Kung ont exercé une fascination sur bon nombre de personnes au sein de la communauté de l'anthropologie et au-delà. Ces films «sont essentiellement de l'ordre de la révélation et non de l'illustration, car ils explorent l'expérience dans sa substance plutôt que la théorie» ${ }^{156}$. Comme le soutient MacDonald, la qualité expérimentale des films-séquences de Marshall les relie aux buts et aux procédés du cinéma à la première personne ${ }^{157}$.

\section{Le cinéma-vérité et le cinéma direct dans les années 1960 aux États-Unis}

Après son expulsion du Sud-Ouest africain en 1958, John retourne en Nouvelle-Angleterre et commence des études supérieures en anthropologie à Yale. Par le biais de son ami Dean Brelis, un correspondant au journal télévisé de la NBC-TV, John est engagé pour filmer des informations à Chypre en I964 et en Grèce l'année suivante pour la compagnie de télévision américaine. Malgré une bonne paie, John n’est pas satisfait de ce travail pour les nouvelles télévisées ${ }^{158}$.

Au début des années i960, un nouveau style de documentaire, labellisé cinéma-vérité ou cinéma direct, s’impose mondialement. Les cinéastes Richard Leacock et D. A. Pennebaker sont à l'avant-garde du mouvement du cinéma-vérité aux États-Unis, suite à leur collaboration avec le producteur innovant Robert Drew sur le documentaire révolutionnaire Primary (1960), et sur d'autres documentaires qui ont rapidement suivi. Utilisant des caméras légères, tenues à la main, avec de la pellicule à développement rapide, un équipement sonore synchrone portable et des micros directionnels, les Drew Associates produisent une 
série de documentaires convaincants sur de nombreux aspects de la vie américaine contemporaine qui sont diffusés sur la télévision nationale au début des années 1960 ${ }^{159}$. Leacock et Pennebaker quittent les Drew Associates après quelques années pour établir eux-mêmes un partenariat, de courte durée; à partir de 1963, ces deux cinéastes talentueux produisent leurs films indépendamment. Des années plus tard, John se souviendra:

J'ai travaillé pour Ricky et Penny. J'étais à la Fac et j’avais pris l'habitude de me rendre à New York deux jours par semaine, mais j’ai fini par écrire des demandes de financement pour eux en vue d'un film sur le vieillissement. [...] Je n’ai pas pu mettre la main à la pâte [...] car ils n'avaient pas de travail à me proposer. ${ }^{160}$

On ne peut pas s'empêcher de se demander quelle direction la carrière de John aurait pris si Leacock et Pennebaker avaient proposé un projet filmique l'incluant en i962.

Mais un autre homme, qui deviendra une figure importante du cinéma direct, allait proposer du travail à John. À l'improviste, Frederick Wiseman appelle John et lui demande s'il serait intéressé à tourner un documentaire avec lui sur une prison du Massachusetts ${ }^{161}$. Marshall accepte. Les deux hommes ne s'étaient jamais rencontrés, mais Shirley Clarke (la réalisatrice de The Cool World, 1963, produit par Wiseman) est une amie de Leacock et Pennebaker. Utilisant les caméras I6mm Auricon et Éclair de John et la pellicule qu’il a achetée, Marshall et Wiseman commencent à filmer au Massachusetts Correctional InstitutionBridgewater en avril ı966. Excepté quelques jours où Timothy Asch filme avec une seconde caméra (pendant les répétitions et le spectacle de «Titicut Follies» dans l'institution carcérale), Marshall tourne seul tous les plans; Wiseman prend le son (une première pour lui) avec le Nagra I de John pendant les vingt-huit jours de tournage ${ }^{162}$.

159 Leacock et Pennebaker ont tenu la caméra pour de multiples productions de Drew: On the Pole (1960), Yanki No! (1960), On the Road to Button Bay (1962), Football [Mooney vs. Fowle] (196r), Jane (1962), The Chair (1962), et Crisis: Behind a Presidential Commitment (1962). Voir Stephen Mamber, Cinéma Vérité in America: Studies in Uncontrolled Documentary,
Cambridge, MIT Press, I974, pour une première évaluation de cet important mouvement documentaire. Bien qu'il y ait des différences entre le cinéma-vérité et le cinéma direct, je suivrai dans cet essai la position de John Marshall qui utilise ces termes de façon interchangeable.

160 John Marshall, dans Carolyn Anderson et Thomas W. Benson, «Put Down the Camera and Pick Up the Shovel», op.cit., p. I42. En i96o ou I96ı, Marshall rencontre Jean Rouch qui est à New York pour discuter avec Drew, Leacock, Pennebaker et Mitch Bogdanovich de la création du système portable sonore synchrone Aurican/Nagra. Voir Brenda Baugh, «An Interview: John Marshall on Jean Rouch», avril 2004, DER. Rouch et Marshall deviennent des amis proches et par la suite des collaborateurs. En I977, Rouch est à la caméra et Marshall au son pour un Ciné-portrait documentaire de 35 minutes sur Margaret Mead, tourné à New York pendant le festival du film qui se tient en hommage à Mead. Le duo collabore aussi sur un autre portrait filmique, Capt'ain Mori (I980, 40 minutes), sur un capitaine de marine marchande qui a inauguré la première ligne commerciale entre le Japon et l’Afrique du Sud. Rouch et Marshall étaient au Japon pour assister au festival consacré aux films de Marshall sur les Bochimans.

161 Carolyn Anderson et Thomas W. Benson, «Put Down the Camera and Pick Up the Shovel», op. cit., p. I43; voir pp. I43-I54 pour les commentaires de Marshall sur le projet de Titicut Follies. Marshall a 33 ans au printemps I966, et Wiseman 36 ans.

162 David Eames, journaliste, voisin et ami de Wiseman à Cambridge, les assiste sur le tournage en rechargeant les magasins de film, en tenant un registre et en fournissant une camionnette pour les déplacements. Il a été nommé président du Bridgewater Film Corporation. Voir Carolyn Anderson et Thomas W. Benson, Documentary Dilemmas: Frederick Wiseman's Titicut Follies, Carbondale, IL. Southern Illinois University Press, I999, pour un compte rendu détaillé de ce film. 
163 Le film résultant a pu être décrit comme "ethnographique». Dans son blog du I2 février 20I4 (http://Psycho CulturalCinema.com/Category/Anthro pology/), Robert Lemelson considère Titicut Follies comme l'un des «vingt films ethnographiques et documentaires que les anthropologues psychologiques devraient enseigner» (Lemelson inclut également A Kalahari Family de Marshall).

164 John Marshall, dans Carolyn Anderson et Thomas W. Benson, «Put Down the Camera and Pick Up the Shovel», op. cit., pp. I45-I46.

165 Après une série de jugements, un compromis a été trouvé par la Cour suprême judiciaire du Massachusetts, Titicut Follies ne pouvant être montré qu'à un public spécialisé. Cette décision judiciaire a été appliquée jusqu’en I99I. Voir Thomas W. Benson et Carolyn Anderson, «The Freeing of Titicut Follies», Reality Fictions: The Films of Frederick Wiseman [deuxième édition], Carbondale/ Edwardsville, Southern Illinois University Press, 2002, pp. XXII-XXXVI.
À certains égards, l'environnement à MCI-Bridgewater, une prison de haute sécurité pour les criminels aliénés, est aussi étranger que le Kalahari pour John ${ }^{163}$. Même si Marshall et Wiseman filment quelques entretiens (des scènes qui ne sont pas forcément destinées à la version finalisée du film), leur démarche procède généralement du style observationnel du cinéma direct:

[...] il s'agissait en fait de réaliser un film à partir d'événements existants, de choses qui se passent, et non pas de tenter de les expliquer. ${ }^{164}$

Marshall envisage le tournage avec son enthousiasme caractéristique. Des plans montrant l'isolement cellulaire, des gardes qui rient d'un prisonnier, des plaintes envers le traitement subi, un prisonnier bredouillant dans la cour, des soins médicaux inadaptés, etc., s'accumulent, créant une image puissante d'un désespoir sans issue et d'une négligence institutionnalisée. Le reste du film est composé d'une série de séquences discrètes, toute reliées au même lieu, l'univers épouvantable d'une prison arriérée. Il y a trois exceptions au schéma général qui consiste à suivre une action ou un événement dans sa durée: tout d'abord, les scènes du spectacle de théâtre de la prison, les «Titicut Follies», auquel participent à la fois les détenus et le personnel, qui interviennent à trois reprises : à l'ouverture, au milieu et à la fin du film. À deux moments dans le film, des scènes sont alternées, un procédé de montage construisant des comparaisons/oppositions que Wiseman évitera par la suite comme trop évident. Au début du film, une fouille au corps de prisonniers est juxtaposée à un entretien d'entrée d'un pédophile par un psychiatre; plus loin dans le film, des plans d'un homme qui est nourri de force sont montés en alternance avec le même homme apprêté pour ses funérailles.

La question de l'accord des personnes filmées et celle du contrôle des images, forcément complexes dans le cinéma documentaire, deviennent particulièrement problématiques dans le cas de Titicut Follies. L'État du Massachusetts a déposé une injonction juridique contre le film et une plainte contre Wiseman, avec pour motif l'atteinte à la vie privée (des détenus) et une rupture de contrat (oral) ${ }^{165}$. Wiseman a invoqué le fait que le public a le droit de savoir ce qui se passe dans une institution publique, qu'aucune procédure de consentement n’a été violée, et qu'aucun accord oral de droits n’a été passé avec l'État. Marshall n’a pas témoigné lors de ces procès, mais il a décrit par la suite ce tournage à Bridgewater comme 
constituant un contact personnel et émotionnel avec les personnes filmées et non comme une activité «dirigée» par Wiseman. Marshall caractérise son approche comme étant toujours attentive aux désirs des sujets filmés; mais il précise aussi qu'une fois qu’il a commencé à tourner, il faut «une main placée devant l'objectif de la caméra» pour l'arrêter ${ }^{166}$.

Marshall participe aux premières phases du montage, mais finalement Wiseman lui dit:

Nous n'avons plus besoin de toi derrière la table de montage. Je veux faire ce film, et à ma façon. ${ }^{167}$

La tension entre les deux jeunes cinéastes monte d'un cran lorsqu'en septembre 1967, immédiatement après l'annonce de l'injonction contre Titicut Follies, John et sa femme Heather démissionnent de leur fonction d'agents de la Bridgewater Film Corporation (BFC), sur le conseil de l'avocat de la famille Marshall. Wiseman, qui est avocat, a fondé la BFC, mais sans en être membre; la BFC, avec les investisseurs, détient les droits du film.

Dans leurs témoignages, Eames et Wiseman présentaient ces démissions comme une formalité judiciaire sans véritables conséquences et ne manifestaient aucune rancune. En privé [selon Marshall], Wiseman était furieux. ${ }^{168}$

Dans la plupart des productions de cinéma direct, le réalisateur est aussi l'opérateur. Cette tradition évite la «mise en scène», dans le sens théâtral d'une action dirigée, qui est remplacée par la sélection de moments filmés et enregistrés de l'action telle qu'elle se déroule. Avec les années, de nombreux critiques et membres du public ont présumé à tort que Fred Wiseman tournait tous les documentaires qu'il a produit. Au séminaire Flaherty de 1967 , Wiseman présente la nouvelle version de Titicut Follies et répond aux questions. L'un des participants au séminaire remarque: «J'ai l’impression que Titicut Follies a été tourné par un opérateur formé en recherches anthropologiques», enchaînant aussitôt avec cette question: «Si John Marshall a tourné le film, quelle est votre part de réalisation; pourquoi est-ce votre film?» Wiseman répond: «J'ai sélectionné ce qui a été tourné, j’ai réalisé le son et j’ai monté le film.» ${ }^{169}$ Pendant des années, les copies de Titicut Follies présentaient le film comme «coréalisé» par John Marshall, tout en créditant Marshall pour la photographie. La mention de coréalisation a été supprimée du générique des copies distribuées par la compagnie de Wiseman, Zipporah
166 Carolyn Anderson et Thomas W. Benson, Documentary Dilemmas, op. cit., p. 22.

167 Selon les souvenirs de Marshall, dans Carolyn Anderson et Thomas W. Benson, «Put Down the Camera and Pick Up the Shovel», op. cit., p. I49.

168 Carolyn Anderson et Thomas W. Benson, Documentary Dilemmas, op.cit., p. 62.

169 Cité par Patricia Zimmermann et Scott MacDonald, The Flaherty: Decades in Independent Cinema, op.cit., p.76. Voir Thomas W. Benson et Carolyn Anderson, Reality Fictions: The Films of Frederick Wiseman, op. cit., pp. 307-309 pour des remarques sur les collaborations avec Wiseman à partir d'entretiens conduits avec les quatre opérateurs talentueux qui ont travaillé pour lui (outre Marshall, Richard Leiterman [sur High School (I968)], William Brayne [dix films dans les années i960-70] et John Davey [tous ses films depuis I978]). Leiterman et Brayne (tous deux décédés) étaient canadiens; Davey est anglais, ce qui a pu encourager l'opérateur à appréhender la culture américaine (et parfois française) comme quelque peu étrangère de lui. 
170 Concernant le générique et le processus créatif, MacDonald écrit: «J'ai entendu dire que Ricky Leacock pensait que c'était vraiment le film de Marshall» (Scott MacDonald, American Ethnographic Film and Personal Documentary, op.cit., p. 354, note 48 ). Titicut Follies a lancé la carrière de Wiseman en tant que documentariste réputé. Au printemps 20ı8, à l'âge de 88 ans, Wiseman monte son $4 \mathrm{I}^{\mathrm{e}}$ film documentaire.

171 En i968, les tensions entre les citoyens et les forces de police prennent de l'ampleur, avec des émeutes dans toutes les villes d'Amérique suite à l'assassinat de Martin Luther King, Jr. en avril et de Robert Kennedy en juin. En août, en marge de la Convention nationale du Parti démocratique à Chicago, des milliers de militants anti-guerre affrontent la police dans ce qui a été décrit par la suite comme «une émeute policière». En novembre i968, le républicain Richard M. Nixon, qui s'est présenté à travers la campagne de «la loi et l'ordre public», est élu président américain.

172 Marshall est assisté par les opérateurs Randy Franken et J. D. Smith; Franken, Chat Gunter et Chris Tilliam prennent le son.

173 Ces films n'ont pas été présentés au public ordinaire de Pittsburgh «avant bien des années». Voir les commentaires de Marshall sur les plans qu'il a tournés d'une personne «qui transformait l'actualité». John Marshall, «Filming and Learning», op.cit., p. I54.
Films. Le générique a été ainsi modifié: «Réalisateur et producteur: Frederick Wiseman; Photographie: John Marshall» ${ }^{170}$.

\section{La série policière de Pittsburgh}

Ne pouvant retourner dans le Sud-Ouest africain à la fin des années ig6o, John entreprend un projet qui le conduit dans un environnement américain rarement montré: le travail de la police urbaine. Sur une période de neuf mois en I968-69, John poursuit son exploration des potentialités du film-séquence en suivant le travail de routine quotidien des policiers du Poste 9 à Pittsburgh (Pennsylvanie) ${ }^{171}$. Le projet est soutenu par le Centre Lemberg pour l'Étude de la violence à Brandeis University et est initié grâce au Dr. John Speigel, une relation de travail de John à Brandeis. Tournant dans des situations de haute intensité émotionnelle et de danger potentiel, John s'immerge physiquement dans les activités de la police. Le métrage tourné - souvent en longs plans ininterrompus, avec du son synchrone - est saisissant dans sa forme brute ${ }^{172}$. Marshall et ses collègues montent ce matériel en vingt films, assemblés entre 1970 et $1973^{173}$. Plus de la moitié des films, qui souvent durent moins de dix minutes, se concentrent sur un seul événement/séquence: Vagrant Woman (197I), After the Game (1973), \$40 Misunderstanding (1973), The Informant (1973), Manifold Controversy (1973), \$2I or 2I Days (1973), Two Brothers (1973), Wrong Kid (1973), Youth and the Man of Property (1973), Henry Is Drunk (1973) et Appitsch and the Drunk (1973). Certains films mettent en jeu des séquences multiples, soit pour donner un aperçu d'ensemble (Inside/Outside Station 9, 1970, 90I/904, 1972), soit pour suivre un récit comme fil rouge (Investigation of a Hit and Run, I972, et You Wasn't Loitering, I973), soit pour se concentrer sur des situations identiques (Three Domestics, I971, et Nothing But My Pride, I973). Une troisième approche consiste à documenter l'usage de ces films-séquences (ou des références à ceux-ci) à l'école ou lors de débats (A Legal Discussion of a Hit and Run, 1973, T-Group, 1973, et The $4^{\text {th }}$, $5^{\text {th }}$, and Exclusionary Rule, 1973). Dans ce cas, des extraits de films-séquences sur le travail de la police sont montés parallèlement à des discussions; parfois, les remarques d'un participant sont utilisées en voix over, tandis que la bande image montre un heurt avec la police. Ce projet répond à un but pédagogique et non à des aspirations artistiques, car l'ambition de Marshall est de mettre ses films au service de la police, des formateurs de la jus- 
tice pénale et des membres de la communauté préoccupés par les abus de la police.

Le film le plus long de la série et le premier à bénéficier d'une diffusion; Inside/Outside Station 9 (1970) a remporté un prix au Festival dei Popoli à Florence, confirmant la réputation internationale de Marshall comme acteur de premier ordre du cinéma-vérité ${ }^{174}$. Le film s'ouvre sur des policiers qui frappent à la porte d'un appartement. Nous sommes aussitôt plongés dans un espace domestique et un conflit interne: une femme furieuse prétend qu'elle a prêté 40 \$ à son petit ami qui ne veut pas les lui rendre. Des sous-titres tentent de restituer le dialogue, le plus souvent sans succès car les paroles se superposent, mais l'ambiance est inoubliable. Le travail d'opérateur de Marshall met ici en jeu une qualité qu'il a décrite ainsi :

Je ne sais pas ce qui s'est passé, mais j’ai été très vite absorbé par la situation. Je tombe sur un conflit interne dans un appartement et je commence à filmer, tandis que le conflit se poursuit et que les événements se déroulent. J'ai un don pour ça. ${ }^{175}$

La femme qui s'est adressée à la police, devenue violente, doit être maîtrisée par les policiers qui la conduisent ensuite au poste, afin de la verbaliser pour ébriété et perturbation de l'ordre. Le policier blanc, qui conduit, sadresse avec sympathie à la femme noire, lui dit que son inculpation ne sera pas retenue et lui donne un conseil: sa première erreur, c'est «d'avoir ce petit ami blanc». Cette séquence impressionnante est aussi montée dans 4o\$ Misunderstanding, tout comme la séquence suivante (la police arrêtant un adolescent) qui est présente dans Wrong Kid. Le film se poursuit en suivant les policiers pendant leurs rondes, qui le plus souvent ont affaire à des conflits personnels entre personnes (impliquant parfois la police dans les combats) et à des infractions mineures comme le vagabondage. Ces séquences sont montées en alternance avec des candidats aux forces de police qui expliquent leurs raisons - la sécurité du travail, la diversité des tâches, l'aventure - d'intégrer leurs rangs. Les officiers de police (à une exception près), les magistrats, les détectives et les demandeurs d'emploi sont tous des hommes blancs; la plupart des personnes que la police arrête sont noirs. Des hommes endimanchés discutent de la meilleure façon de renforcer les lois contre le vagabondage de sorte à ce que ces cas «ne finissent pas entre les mains de l'ACLU» (l'Union américaine pour les libertés civiles). Des tensions raciales constituent
174 La filmographie incluse dans The Cinema of John Marshall (op.cit.) note une durée de 90 minutes, mais la version distribuée par DER ne dure que $78 \mathrm{mi}-$ nutes. Le troisième documentaire de cinéma direct de Wiseman, Law and Order (1969), est aussi un film consacré à la police. Tourné à Kansas City (Missouri), Law and Order partage beaucoup de traits communs avec Inside/Outside Station 9, y compris un remarquable travail d'opérateur (par William Brayne).

175 Carolyn Anderson et Thomas W. Benson, «Put Down the Camera and Pick Up the Shovel», op. cit., p. I50. Lorsqu'on lui a demandé si la qualité qu'il décrivait n'était pas l'invisibilité mais «une façon de se présenter comme quelqu'un de fiable», John répliqua: «Ça doit être quelque chose de cet ordre» (id., p. I5I). 
la toile de fond d'une longue séquence fascinante (également utilisée de façon autonome sous le titre The Informant): un jeune Noir est interrogé sur sa participation à des pillages durant des «troubles civiques» et sur son éventuelle volonté de devenir indicateur de police. La caméra cadre le plus souvent son visage, tandis que trois policiers haut placés jouent tour à tour le «bon flic», dans le but d'instaurer une relation de confiance. Les tensions raciales sont explicitement exposées dans la séquence suivante, à travers le langage raciste et la fureur d'une femme blanche qui a fait venir la police chez elle. Elle et son amie « ont peur de ces gens de couleur».

Dans Vagrant Woman, un court film de huit minutes, les policiers sont en discussion avec une femme blanche distinguée et bien habillée qui a dormi dans sa voiture, ce qui est illégal, l'informe-t-on. Elle est accusée d'avoir brandi un pistolet (ce qu'elle nie; les policiers ne trouvent pas d'arme). Lorsque les policiers fouillent sa voiture, elle demande: «N'êtes-vous pas supposés avoir un mandat de perquisition?» Sa question est ignorée. Lorsqu'on lui demande d'expliquer les circonstances qui l'ont conduites à dormir dans son véhicule, elle révèle qu'elle a quitté son mari à cause de son infidélité et qu'elle a été mise à la porte de son propre domicile. Ici comme toujours, les policiers promulguent leurs conseils: retourner auprès de son mari (peu importe les circonstances) et vendre sa voiture. Elle n'est pas disposée à se plier à l'une ou l'autre de ces injonctions («C'est une question de principe»). Elle accepte leur proposition de dormir à l’Armée du salut, mais s'adresse en ces termes à l'agent de l’Armée du salut qu'on lui présente: «Ne me touchez pas!»

After the Game, un film-séquence de neuf minutes, suit les policiers qui, répondant à une nouvelle plainte, se rendent dans une maison où un groupe de jeunes hommes blancs jouent aux cartes. Ils affirment qu'ils ne font rien d'illégal, mais ils sont visiblement sous l'emprise de l'alcool, alors qu'un seul participant du groupe satisfait à l'âge légal de consommation, 2I ans. Les policiers trouvent trace de drogue et emmènent le groupe au poste de police. Un extrait de ce film est repris (comme d'autres tirés de différents films-séquences) dans The $4^{\text {th }}$, $5^{\text {th }}$ and Exclusionary Rule, un film en deux parties qui s'ouvre sur cet avertissement: «Les affaires policières montrées dans ce film ont été sélectionnées au vu des questions constitutionnelles qu'elles soulèvent et ne sont pas nécessairement caractéristiques du travail de la police». Un capitaine de police, 
un représentant de la télévision publique de Boston, un lieutenant de la force de police de Cambridge, un étudiant en droit, un avocat de la défense et un organisateur communautaire participent à un débat modéré par James Vorenberg, un professeur de la Faculté de droit de Harvard (trois des participants au débat sont africain-américains: une femme de WGBH-TV, un étudiant en droit et un organisateur communautaire; ils mentionnent souvent la couleur de peau comme un facteur important dans les décisions prises par la police). Les participants interrogent les techniques de la police exposées dans After the Game: au moment de leur intervention, les policiers n'avaient pas de mandat de perquisition et il n'y avait pas d'altercation; leurs actions violent ainsi le $4^{\text {e Amendement }}$ (contre la violation de propriété). Dans le débat, l'intrusion de la caméra ou de l'équipe de tournage n'est pas mentionnée. Marshall en conclut-il que, comme il n'y avait pas d'objection au tournage, les jeunes hommes effrayés l'acceptaient tacitement?

En discutant les films Hit and Run et The Informant, les participants au débat interrogent les techniques montrées, suggérant qu'elles entrent en violation du $5^{\mathrm{e}}$ Amendement (contre l'auto-incrimination) dans l'empressement des policiers à obtenir des aveux. Les suspects n'ont pas bénéficié de conseil juridique, ce qui amène l'un des participants à déclarer: «La dispense du droit d'un prévenu à un avocat ne constitue jamais un acte intelligent». La question primordiale de savoir «Qui garde les gardiens?» amène à s'interroger sur la Règle d'exclusion des preuves (concernant le comportement policier). The $4^{\text {th }}, 5^{\text {th }}$, and Exclusionary Rule montre clairement que Marshall a l'intention de réaliser des films utiles pour les différentes parties prenantes.

En réalisant cette série sur la police, John Marshall poursuit et élargit une pratique initiée par Robert Flaherty: vivre avec les personnes filmées, apprendre à les connaître en tant qu'individus et comprendre leur mode de vie ${ }^{176}$. Les liens personnels de John avec un petit groupe de Bochimans ont permis d'approfondir ses observations dans les films !Kung; de la même façon, ses liens étroits avec les six hommes au centre des films sur la police ont permis d'apporter une nouvelle dimension à cette série de films. Des années plus tard, John en parlera en ces termes:

Lorsque j’ai tourné de nombreux films sur les policiers à Pittsburgh, nous vivions dans le poste de police. Nous devions apprendre à connaître
176 Paul Henley, The Adventures of the Real: Jean Rouch and the Craft of Ethnographic Cinema, Chicago, University of Chicago Press, 2009, p. 253. Rouch a aussi été influencé par le mode de relation que Flaherty a développé avec les personnes filmées. Ces mêmes qualités sont revendiquées dans la méthode de l'«observation participante» qui s'est imposée dans l'anthropologie culturelle dans les années i950. Il y a beaucoup de points communs entre la notion de «séquence» chez Marshall et la revendication par Karl G. Heider de filmer les «actions dans leur intégralité». Voir Karl G. Heider, Ethnographic Film, Austin, University of Texas Press, I976, pp. 82-86. 
177 Carolyn Anderson et Thomas W. Benson, «Put Down the Camera and Pick Up the Shovel», op. cit., p. I50. À l'opposé, John pensait que «nous n'avions appris à connaître personne, en somme, dans [Titicut Follies]». Je ne cautionne pas cette opinion pour ma part.

178 John Marshall, «Filming and Learning», op. cit., pp. 73-74.

179 John Marshall et Emilie de Brigard, "Idea and Event in Urban Film», dans Paul Hockings (éd.), Principles of Visual Anthropology, op. cit., p. I34. ces types... Un petit groupe, deux voitures, six types. [...] Ce qui importe, ce sont les gens; ils définissent la structure et la continuité du film. Apprendre à les connaître constitue le propos du film. [...] Certains d'entre nous ont fini par vraiment s'apprécier. ${ }^{177}$

Les premiers membres du public étaient les officiers de police qui ont été filmés. John s'en souvient:

J'ai moi-même utilisé les séquences comme des études de cas lors de discussions avec les policiers dans les locaux du Poste 9. Certains d'entre nous se réunissaient avec quelques six-packs de bière après le changement d'équipe à minuit. Les échanges [sur la façon dont les policiers devaient traiter les conflits domestiques] étaient vifs. [...] Les policiers du Poste 9 se départageaient en trois écoles de pensée: s’impliquer et essayer de venir en aide à la famille; arrêter l'homme, ou toutes les personnes impliquées; ne rien faire et éventuellement contacter le Service social. [...] Les policiers étaient conscients de la réalité - un rouquin avait déclaré: «Je vois au-delà du blouson en cuir»- et tous avaient trouvé bénéfique de confronter leurs points de vue et laisser libre cours à leurs sentiments. ${ }^{178}$

Dans un essai co-écrit, publié peu après la réalisation de la série de films sur la police, Marshall et Emilie de Brigard décrivent les buts et les procédures des films-séquences dans des termes qui les relient à la recherche en sciences sociales:

Le film peut observer de près des événements discrets, en prenant le temps nécessaire à leur développement. Il en résulte une séquence qui se caractérise par son absence de cadre conceptuel et contextuel, à l'opposé de ce qui est recherché dans les autres formes de cinéma. La plupart des cinéastes ne sont pas prêts à considérer une séquence comme un film, et ils ont probablement raison. Mais une séquence est vérifiable si elle est réalisée convenablement, et un rapport approfondi valide peut être corroboré par une preuve indépendante [je souligne]. ${ }^{179}$

La réticence à considérer une séquence comme un film s'appliquerait sans doute aux films de la série sur la police qui ne durent que trois ou quatre minutes. Néanmoins, Marshall a donné un titre à chacune de ces brèves séquences; DER les distribue comme des films autonomes; et elles ont trouvé leur public, d'abord constitué des policiers lors de sessions de formation, et plus largement par la suite. Ces publics ne considèrent peut-être pas ces séquences comme des «films», mais ils les trouvent utiles. Des facultés de droits aux classes d'enseignement secondaire, des 
étudiants ont débattu des problématiques suscitées par la vision de ces séquences ${ }^{180}$. Ces films ont été présentés lors de colloques de cinéma comme des exemples remarquables de «cinéma observationnel», un terme qui relie les buts et les procédures du cinéma documentaire et ethnographique ${ }^{181}$. Les films sur la police de Marshall ont aussi été reçus par les chercheurs et étudiants en comportement interpersonnel et familial. E. Richard Sorenson considère «les films de John Marshall sur les forces de l'ordre» comme des «enregistrements phénoménologiques [qui] restituent la subtilité et les complexités de l'interaction sociale» ${ }^{182}$. Les cinéastes et les étudiants en cinéma sont attirés par la densité émotionnelle et la complexité des situations révélées en quelques minutes de film documentaire. Comme Marshall et De Brigard l'expriment brièvement: «Les idées précèdent les événements, et perdurent après ceux-ci » ${ }^{183}$.

Souvent, dans des contextes académiques mais pas seulement, une série de films sur la police sont programmés ensemble. Peter Ian Crawford recommande cette approche:

La contextualisation de films d'expériences ne peut être établie que s’ils sont mis en relation avec d'autres films qui en fait forment une série. C’est le cas avec les soi-disant films-séquences entrepris par Marshall auprès des Ju/wasi du Kalahari aussi bien quauprès de la police de Pittsburgh. ${ }^{184}$

L'anthropologue Paul Hockings envisage les années I967-I974 comme «une période centrale [...] durant laquelle la plupart des fondements de l'anthropologie visuelle ont été établis » ${ }^{185}$. Hockings commente les résultats remarquables accomplis durant ces années, relevant le fait que «Timothy Asch et John Marshall étaient engagés dans leur projet expérimental de réaliser de courts 〈films-séquences〉 utilitaires et centrés sur un thème, en présentant trois cultures différentes à travers ce nouveau format: les Yanomami, les !Kung/San, et les forces de police de Pittsburgh ${ }^{186}$. Pendant cette période, John participe au premier congrès du film ethnographique à UCLA (l'Université de Californie à Los Angeles) en I968 et prend part à de nombreuses autres conférences et séminaires où ses films sont présentés et les enjeux relatifs à l'anthropologie visuelle débattus. La réputation de Marshall en tant que cinéaste ethnographique est telle qu'en I975, Margaret Mead peut écrire au sujet des «films de Marshall sur les Bochimans»: «Ces rares efforts passionnés et incroyables sont tout ce que nous pouvons présenter après presque un siècle de disponibilité des outils
180 Marshall et De Brigard reviennent sur l'utilisation pédagogique d'Investigation of a Hit-and-Run (id., pp. I42I43). Le film se concentre sur l'interrogatoire d'une adolescente enceinte qui a pris la fuite suite à l'accident d'un enfant de 3 ans par la voiture que conduisait son petit ami.

181 After the Game est présenté au Séminaire Flaherty en 2000 qui a pour thème «Essays, Experiments and Excavations» (Patricia Zimmermann et Scott MacDonald, The Flaherty: Decades in Independent Cinema, op.cit., p. 220). Le terme de «cinéma observationnel» a d'abord été théorisé par Colin Young. Voir son essai «Observational Cinema», avec un commentaire de Gerald Temaner, dans Paul Hockings (éd.), Principles of Visual Anthropology, op. cit., pp. 65-8o. Young donne comme exemple privilégié les séquences de la danse de l'autruche dans Bitter Melons.

182 E. Richard Sorenson, «Visual Records, Human Knowledge, and the Future», dans Paul Hockings (éd.), Principles of Visual Anthropology, op.cit., pp. 463-464.

183 John Marshall et Emilie de Brigard, «Idea and Event in Urban Film», op.cit., p. I43.

184 Peter Ian Crawford, «Film as Discourse: The Invention of Anthropological Realities», dans Peter Ian Crawford et David Turton (éd.), Film as Ethnography, Manchester, Manchester University Press, i992, p. 77.

185 Paul Hockings, «Preface to the third edition", Principles of Visual Anthropology, New York, Mouton De Gruyter, 2003, p. VIII.

186 Ibid. 
187 Margaret Mead, «Visual Anthropology in a Discipline of Words», dans Paul Hockings (éd.), Principles of Visual Anthropology, première édition, op.cit., p. 4 .

188 Emilie de Brigard, «The History of Ethnographic Film», dans Paul Hockings (éd.), Principles of Visual Anthropology, op.cit., p. 34 .

189 Marshall se souvient que les bailleurs de fonds s'impatientaient face à ses films-séquences sur la vie quotidienne des Ju/'hoansi, car ils ne parvenaient pas à «attirer un large public à la différence de films comme The Hunters». (John Marshall, «Filming and Learning», op.cit., p. 7I).

190 Timothy Asch, «The Ethics of Ethnographic Film-making», dans Peter Ian Crawford et David Turton (éd.), Film as Ethnography, op.cit., p. 203. L'article de Asch propose des conseils pratiques et avisés qui demeurent pertinents.

191 Le nom de l'organisation a été modifié comme suit en I97ı: Documentary Educational Ressources. Lutilisation du terme «ressources» au lieu de celui de «recherche» désigne un tournant important dans son identité et ses buts. DER distribue à présent tous les films produits par les Marshall et les films qui portent sur eux, y compris deux films que John a réalisé en Nouvelle-Angleterre dans les années I970: Vermont Kids (I975), un regard fascinant sur des enfants qui jouent (qui sera plus tard découpé en quatre films-séquences), et If It Fits (I978), qui documente les activités (y compris une élection municipale) dans la ville industrielle sur le déclin de Haverhill, Mass. DER distribue aussi les films de (et sur) Timothy Asch, Robert Gardner et Jean Rouch, parmi bien d'autres.

filmiques» ${ }^{187}$. Pour Emilie de Brigard, «[1]es documents de John Marshall sur les Bochimans constituent à ce jour l'entreprise d'ethnographie visuelle la plus spectaculaire et la plus influente jamais réalisée» ${ }^{188}$.

Rendre accessible à un public potentiel les films indépendants (tout particulièrement les courts métrages), quelle que soit leur réputation, constitue un problème insoluble; les difficultés de diffusion pour les cinéastes ethnographiques (en particulier ceux qui réalisent des «filmsséquences») ont longtemps été exacerbées ${ }^{189}$. Et ce, jusqu’à ce que John Marshall et Timothy Asch trouvent une solution en i968: avec l'aide de Frank Galvin, Laurence et Laura Marshall, et Marilyn Wood, ils fondent Documentary Educational Research (DER), une organisation à but non lucratif qui vise à supporter financièrement, à produire et à distribuer des films ethnographiques et documentaires. DER produit aussi des manuels d'étude, allant à l'encontre des règles prévalant dans la diffusion de livres et de films, car, en général, «les distributeurs de livres ne diffusent pas des films, et les diffuseurs de films ne distribuent pas des livres» ${ }^{190}$. Pendant de nombreuses années, John a été le directeur de DER, qui a coproduit de nombreux films ethnographiques majeurs. Le catalogue impressionnant de films internationaux distribués par la compagnie a largement contribué à l'accessibilité des productions ethnographiques ${ }^{191}$.

À l'automne 1972, ne pouvant toujours pas se rendre dans ce qui s'appelle alors la Namibie, John voyage au Botswana ${ }^{192}$. Son voyage est financé par la National Geographic Society, dans le but de produire un documentaire sur l'histoire des Ju/'hoansi et les relations de John avec ceux-ci. ₹Toma, !Nai, /Qui et plusieurs autres !Kung de Nyae Nyae ont franchi la frontière pour voir leur ami américain. Le contact des !Kung avec le monde extérieur s'est considérablement accru depuis l'expulsion de John en 1958. L'année suivante, une route pour Tsumkwe est ouverte. Nyae Nyae n'est plus une région isolée. En i96o, un poste gouvernemental est créé pour protéger les !Kung contre l'exploitation, pour leur apprendre l'Afrikaans, et pour les assister dans leur transition vers un monde plus globalisé ${ }^{193}$.

192 En i968, le Sud-Ouest africain est devenu la Namibie suite à la décision de l’Assemblée générale des Nations Unies de changer son nom.
193 Lorna Marshall, The !Kung of Nyae Nyae, op. cit., pp. 6o-6I, note 8o. 
Le retour de John en Afrique en 1972, sa rencontre chaleureuse avec ses amis Ju/'hoansi et Khwe, ainsi que les changements drastiques qui sont intervenus dans leurs vies après vingt ans d'absence, sont au centre d'un documentaire télévisuel de 50 minutes. Réalisé et filmé par Robert M. Young, écrit par Bud Wiser et produit par David Wolper Productions et la National Geographic Society, Bushmen of the Kalahari retrace les années de relation de John avec les Bochimans, des plans extraits de The Hunters et de Bitter Melons étant juxtaposés avec la vie des Ju/'hoansi au début des années i970. Diffusé à un large public américain sur CBS le i7 mai i974 comme le premier épisode de la National Geographic, le documentaire est commenté par l'acteur américain Leslie Nielson (avec des commentaires additionnels de John) ${ }^{194}$.

À la même période, Lorna Marshall fait également retour sur le passé tout en regardant vers le futur. Dans son ouvrage d'ethnographie longuement attendu et fort apprécié, publié en 1976, Lorna affirme clairement: «Ce livre porte sur les!Kung avant que des changements profonds ne soient intervenus pour eux» ${ }^{195}$. Plus loin dans son livre, elle exprime ses sentiments sur la transition difficile à laquelle les !Kung font face:

Je souhaite personnellement que les !Kung restent tels qu'ils étaient, isolés, autonomes, indépendants et dignes; mais c'est un vœu pieux. Notre société moderne ne permet pas aux peuples de demeurer isolés. De plus, de nombreux !Kung désirent le changement; ils veulent bénéficier de terres et de bétail comme les Bantous. ${ }^{196}$

\section{Le retour de John Marshall à Nyae Nyae}

En I978, John s'est dit: «Si je veux revoir mes amis Ju/'hoansi, c'est maintenant ou jamais» ${ }^{197}$. Il part pour l'Afrique du Sud, sans visa d'entrée pour le Sud-Ouest africain. Des contacts haut placés l'ont aidé, un ami de la famille Marshall organisant une rencontre entre John et M. T. Steyn, l'administrateur général anti-apartheid du Sud-Ouest africain. Steyn est sensible à l'histoire du père de John, aux études de la famille sur les $\mathrm{Ju} /$ 'hoansi et aux documents filmiques de John; le cinéaste reçoit un permis pour visiter le pays des Bochimans ${ }^{198}$. À présent âgé de 46 ans et devenu un cinéaste expérimenté, John retourne à Nyae Nyae en changeant d'attitude par rapport au tournage; il est déterminé à réaliser des films qui se confrontent aux bouleversements en cours dans la vie des Ju/'hoansi. À ce défi répond N!ai, the Story of a !Kung Woman
194 Voir Scott MacDonald, American Ethnographic Film and Personal Documentary, op. cit., p. 353, note 4I. Certaines filmographies créditent Marshall comme coréalisateur.

195 Lorna Marshall, The !Kung of Nyae Nyae, op. cit., p. 15. Le travail ethnographique de Lorna repose sur des observations et des entretiens conduits de I95I à 1955 .

196 Id., p. 6I, note 8o. Pendant la visite de John en I972, les !Kung ont fait part de leur vœu d'avoir du bétail.

197 John Marshall, «Filming and Learning», op. cit., p. 74 .

198 Ibid. Voir Elizabeth Marshall Thomas, The Old Way: A Story of the First People, op. cit., p. 288 quant à la «légende [qui] a accompagné le retour [de John]». 
199 N!ai a remporté le Grand Prix du Cinéma du Réel (Paris); un Blue Ribbon, à l'American Film Festival; un CINE Golden Eagle Award; une médaille d'or pour le meilleur documentaire télévisuel à l'International Film and Television Festival, New York; le grand prix à l'International News Coverage Festival (Luchon, France); et une distinction de la part du Royal Anthropological Institute (Londres).

200 L'expression fréquemment utilisée de «mouche sur le mur» renvoie au cinéma direct ou à une approche du filmage strictement observationnelle. Henri Breitrose a proposé l'expression opposée «cheveu dans la soupe» pour décrire l'implication explicite du cinéaste. Voir Henri Breitrose, «The Structures and Functions of Documentary Film», CILECT Review, vol. 2, nº I, I986, p. 47.

201 Le succès planétaire de The Gods Must Be Crazy et de sa suite en I989, The Gods Must Be Crazy II, a perpétué ce que John décrit comme une «mort par le mythe» pour les !Kung, qui ne pouvaient plus vivre de la chasse et de la cueillette en 1978 .
(1980). Nombreux sont ceux qui le considèrent comme son meilleur film ${ }^{199}$. L'approche de Marshall a évolué de la position d’une «mouche sur le mur» [«fly-on-the-wall»] à celle d'un «cheveu dans la soupe» [«fly-in-the-soup»] ${ }^{200}$. Les limitations anhistoriques du cinéma direct ont amené John à se tourner vers une autre forme de filmage pour construire un récit se déroulant sur des décennies et combinant des éléments biographiques, historiques et autobiographiques. En 1978, N!ai avait la trentaine, toujours attrayante mais pour reprendre la chanson qu'elle chante, «la mort [la] fait danser en haillons». Les Marshall ont commencé par filmer N!ai alors qu'elle était une fille de 8 ans toujours audacieuse; elle réapparaît dans un ensemble d'autres films de Marshall, qui articulent un récit historique de sa vie en tant que membre de la société !Kung et plus particulièrement fille/femme !Kung, et ce que cela implique et a impliqué. N!ai et John alternent en tant que narrateurs, à travers un récit à la fois personnel et culturel, tandis que N!ai se souvient de sa vie et ce faisant relate l'histoire déchirante de son peuple sur trois décennies. Les plans tournés par Marshall dans les années 1950 (certains facilement reconnaissables, d'autres inédits) présentent N!ai et sa famille comme des cueilleurs-chasseurs isolés, pleins de ressources et généralement heureux. Les plans des années i950 contrastent violemment avec les images d'observation qui détaillent la vie désespérée de !Kung dans une réserve de Tsumkwe à la fin des années I970, ponctuée de querelles à propos de la nourriture et des biens, d'examens médicaux pour contrer la propagation de la tuberculose, de tentatives de conversion au christianisme et de recrutement militaire par l'armée d'Afrique du Sud.

Construit autour de N!ai qui s'adresse directement à la caméra, ce film anticipe un tournant réflexif majeur dans le cinéma documentaire et ethnographique, N!ai attestant la présence de la caméra de John et reconnaissant les conséquences négatives du tournage sur sa vie. L'argent qu'elle a gagné en apparaissant dans ces films a suscité la jalousie parmi les autres Ju/hoansi. N!ai a un rôle secondaire (en tant que la femme !Kung du protagoniste Xi, joué par N!xau) dans The Gods Must Be Crazy (1980), une comédie réalisée par le cinéaste sud-africain blanc Jamie Uys ${ }^{201}$. Marshall a filmé Uys dirigeant le tournage (en 1978) de la fin de The Gods Must Be Crazy (montrant des plans répétés à quatre reprises) et a incorporé ces scènes à son documentaire N!ai. L'artifice 


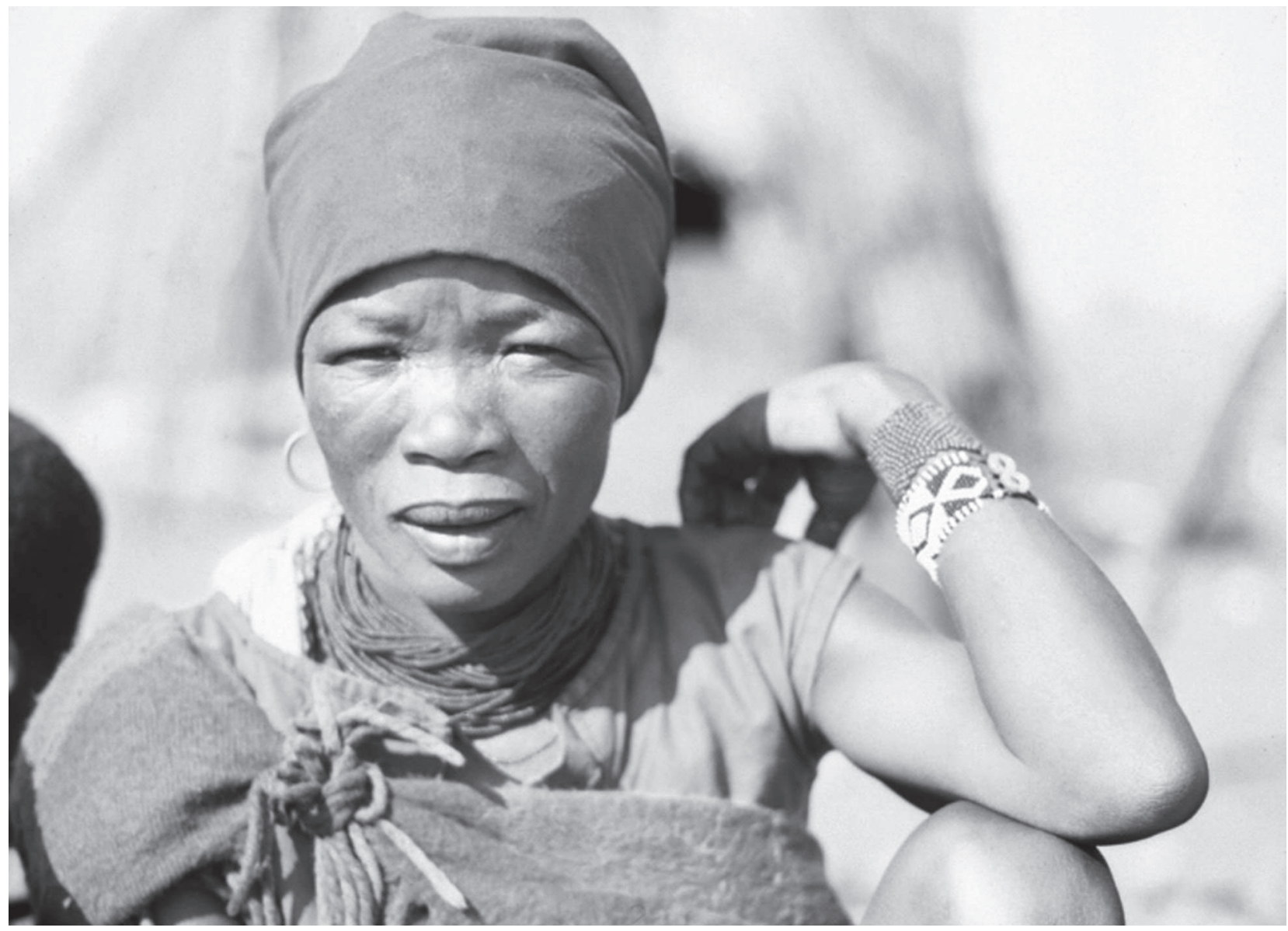


202 En 2009, DER a opéré un nouveau transfert du film original, a nettoyé et corrigé le contraste et la couleur des images, et a proposé un nouveau soustitrage. Le DVD distribué par DER comprend une comparaison en split-screen des images originales avec celles restaurées en 2009. Karl G. Heider décrit $N$ !ai comme un exemple éloquent de «la sexualité et du changement» (K. G. Heider, Seeing Anthropology: Cultural Anthropology Through Film, $2^{\mathrm{e}}$ édition, Boston, Allyn and Bacon, 200I, pp. 310-3I4).

203 Elizabeth Marshall Thomas, The Old Way: A Story of the First People, op.cit., p. 288. John a soutenu cette entreprise avec ses propres économies, un fonds de départ de ses parents et une contribution de sa sœur; avec le temps, l'Union a bénéficié de fonds d'œuvres de charité internationales (id., p. 289). Laurence Marshall est mort en I980 à l'âge de 9i ans. Les bénéfices de la vente de la ferme de moutons acquise par Laurence à la fin des années I950 au Sud-Ouest africain ont été reversés à la Fondation pour le développement. du film d'Uys qui représente les Bochimans comme vivant encore librement en tant que chasseurs-cueilleurs en i978 est en flagrante opposition avec la démarche de Marshall dans N!ai, qui se confronte au désespoir actuel des Ju/'hoansi. «Ne regarde pas mon visage» (injonction répétée) sont les derniers mots prononcés par N!ai. Son injonction met fin au film; le cinéaste ethnographique et son public sont amenés à prendre en considération les effets du tournage sur les autochtones. Ce film de 59 minutes a été diffusé dans le cadre de l'émission Odyssey sur la télévision publique américaine. Cette diffusion télévisuelle (ainsi que la diffusion antérieure de Bushmen of the Kalahari) a restitué l'histoire de N!ai et le travail de Marshall avec les !Kung dans un contexte populaire, le film étant par ailleurs largement utilisé dans les milieux académiques ${ }^{202}$.

\section{Un plaidoyer dans la Namibie des années 1980}

Durant les années i980, John passe la plupart de son temps dans ce qui s'appelle aujourd'hui la Namibie. Il intensifie ses activités de sensibilisation à travers une série de nouvelles initiatives. Avec un groupe d'hommes Ju/wa, il a formé l'Union des paysans Ju/wa, «dans le but de venir en assistance à tous ceux qui désiraient garder de petits troupeaux de bétail [...] et cultiver des jardins [...] en réclamant le droit à posséder leurs propres terres et à se nourrir eux-mêmes et leurs familles » ${ }^{203}$. Il a aussi cofondé la Fondation pour le développement de Nyae Nyae en Namibie (NNDFN) avec l'anthropologue spécialiste du développement et cinéaste Claire Ritchie. Ils ont produit ensemble des courts métrages montrés à la presse, à des organismes de financement et à des groupes dont les opinions peuvent avoir une influence politique et aider les Ju/'hoansi à établir des fermes et développer les ressources en eau. La carrière cinématographique de John a été subsumée par sa résolution à aider les Ju/'hoansi dans leur adaptation difficile à un mode de vie agricole. Marshall est parvenu avec succès à impliquer en 1989 les autorités locales et les coopératives de propriétaires fonciers dans la Constitution namibienne. L'engagement de John dans l'organisation communautaire pour le compte des!Kung se poursuit jusque dans les années I990. To Hold Our Ground: A Field Report (I99I), diffusé sur la télévision namibienne pendant un débat sur la politique des terres communales, est caractéristique d'un ensemble de documentaires vidéo 
dont le discours est fermement articulé que Marshall a produits durant cette période ${ }^{204}$.

$\mathrm{Au}$ vu de son engagement sincère et indéniable envers les Ju/'hoansi, Marshall a été relativement épargné par les critiques portées à l'encontre de nombreux cinéastes du Premier Monde dont la représentation de l'«Autre» a été remise en cause, tandis qu'une mise en crise de la représentation gagnait la pratique de l'anthropologie sauvage dans les années 1980-1990. Cependant, John a pu faire l'objet d'accusations occasionnelles pour cause d'exploitation des Ju/hoansi ${ }^{205}$. Des critiques plus fréquentes dénoncent les expéditions de la famille Marshall au début des années 1950 et I960 comme créant une situation artificielle qui permet aux groupes de Ju/'hoansi de vivre «comme dans l'ancien temps» ou décrivent le contact avec les Marshall comme un facteur de destruction des «anciennes coutumes». Robert Gardner exprime ces deux opinions (contradictoires) dans son «Journal Kalahari»:

La vie traditionnelle des Bochimans touche clairement à sa fin. Certains sauront mieux prendre la mesure des changements que d'autres. De mon point de vue, la seule raison qui permet d'expliquer la persistance de quelques !Kung tient à ce que que certains d'entre eux n'ont jamais été en contact avec les Marshall. Quant aux autres, ils ont la possibilité de toucher une paie en jouant les Bochimans quand les Marshall sont dans le coin. ${ }^{206}$

Cette remise en cause de l'authenticité du projet de Marshall s'exprime radicalement à travers le reproche selon lequel les !Kung de Nyae Nyae, «[tels qu']on a fini par les percevoir, ne sont [...] rien d'autre qu'une construction élaborée par la famille Marshall» ${ }^{207}$. Sur un plan pratique (et éthique), ces accusations de destruction sont souvent articulées au fait que les pistes frayées par les camions des expéditions Marshall ont créé des routes ouvrant la région de Nyae Nyae au contrôle du gouvernement du Sud-Ouest africain (puis de la Namibie) ${ }^{208}$. La plupart de ces critiques sont intrinsèquement attachées à l'activité de l'anthropologie visuelle. Leur degré de généralité ne signifie pas pour autant qu’il faut rejeter ces critiques, mais qu’elles doivent être considérées dans la

204 Marshall a produit à cette époque différents films qui portent sur l'effondrement de l'économie de la chasse et de la cueillette et sur la dépossession des terres !Kung: Pull Ourselves Up or Die Out (1985), The !Kung San: Traditional Life (1987) et The !Kung Resettlement (I988). Pour une analyse de ces films, voir Scott MacDonald, American Ethnographic Film and Personal Documentary, op.cit., pp. 49-53.

205 Voir les commentaires de John Marshall à ce sujet dans Carolyn Anderson et Thomas W. Benson, «Put Down the Camera and Pick Up the Shovel», op. cit., p. 166.

206 Robert Gardner, «Kalahary Journal», op. cit., p. $2 \mathrm{I}$.

207 J.D. Lewis-Williams, «Foreward», dans Lorna J. Marshall, Nyae Nyae !Kung Beliefs and Rites, Cambridge, Mass., Peabody Museum/Harvard University Press, 1999, p. x. LewisWilliams ne défend pas ce point de vue lui-même. Il mentionne cette opinion dans sa discussion des critiques exercées par d'autres à l'encontre de l'authenticité du projet Marshall.

208 Voir E. M. Thomas, The Old Way, op. cit., pp. 277-278 qui rapporte qu'un homme, après une projection de A Kalahari Family au Margaret Mead Ethnographic Film Festival, a demandé à John s'«il ne sentait pas coupable d'avoir ouvert une brèche à l'intérieur du Kalahari, introduisant le monde occidental au sein de la société des Bochimans et entraînant un processus inéluctable de changement». Elizabeth se leva d'un bond pour défendre son frère. Mais dans The Old Way, elle admet que sa famille a été "partiellement responsable de ces changements, et pas seulement à cause des pistes des camions». John exprime des sentiments analogues dans ses commentaires dans A Kalahari Family. 
209 Scott MacDonald suggère que l'utilisation du singulier dans le titre de A Kalahari Family peut impliquer «une famille étendue qui inclut de nombreux !Kung ainsi que les parents [de John] et sa sœur» (American Ethnographic Film and Personal Documentary, op. cit., p. 55).

210 John et Lorna Marshall sont les producteurs exécutifs; la série est financée par la Corporation for Public Broadcasting, la Rock Foundation, la Rockefeller Foundation, le National Endowment for the Humanities, et Tim Disney.

211 Baskin est une actrice et lectrice professionnelle qui travaille dans la région de Boston. Son récit a été écrit par l'équipe de production avec l'aide du conseiller scientifique Robert Gordon. Pour des détails sur la production, voir www.der.org/kalfam/series-credits.

212 Des extraits de The Hunters, First Film, N/um Tchai, Baobab Play, A Curing Ceremony, A Rite of Passage, An Argument about a Marriage, A Joking Relationship apparaissent, parmi d'autres plans non retenus dans les films montés, tel qu'un moment attendrissant de !U avec son enfant nouveau-né (qui s'appellera!Ungka Norna en hommage à Lorna) et une scène de N!ai terrifiée lors de son mariage, de même que le tournage déjà mentionné de la rencontre des Ju/'hoansi avec les ouvriers noirs des mines. perspective plus large des buts et des accomplissements du projet de Marshall. La prise en compte et les réponses de John Marshall à ces critiques sont intégrées dans A Kalahari Family.

\section{A Kalahari Family}

Le dernier tournage de John en Namibie et son quinzième voyage à Nyae Nyae coïncident avec le nouveau millénaire. Ce tournage en Namibie sera intégré à l'opus magnum de John: A Kalahari Family (2002) ${ }^{209}$. Cette série de six heures, découpée en cinq parties, résume et conclut la documentation des Ju/'hoansi par la famille Marshall sur cinq décennies (1950-2000) ${ }^{210}$. Les cinq parties comportent des plans tournés par Marshall dans les années I950; mais le premier épisode, «A Far Country», se concentre sur la première décennie d'engagement de la famille Marshall auprès des Ju/'hoansi (même si l'épisode s'ouvre sur le présent ethnographique à travers un mémorial érigé sous le baobab familier en honneur du mentor et homonyme de John, ¥Toma). Sept narrateurs racontent l'histoire de la famille Kalahari: John et cinq Ju/'hoansi ( $\neq$ Toma, sa femme!U, leur fils Tsamko, la nièce de $¥$ Toma, N!ai et son mari /Gunda), dont les propos sont traduits en anglais et récités par des acteurs sud-africains. En recourant aux Ju/'hoansi en tant que narrateurs et pas seulement en tant que personnes interviewées, et en rapportant leur histoire orale, le film poursuit et développe la pratique qui consiste à donner une voix et par conséquent à octroyer une agentivité aux locuteurs indigènes, inaugurée par Marshall dans N!ai, the Story of a !Kung Woman. Le septième narrateur, Rena Baskin, fournit des renseignements sur les souvenirs rapportés, présente des informations historiques et d'autres explications à travers une voix over intermittente ${ }^{211}$. Des extraits de films de Marshall tournés dans les années 1950 (et magnifiquement restaurés) sont recontextualisés en étant intercalés à des entretiens et des commentaires de Ju/'hoansi et incorporés à un récit qui relate les contacts des Bochimans avec le monde extérieur au fil des siècles ${ }^{212}$. Un sentiment de révisionnisme émane à l'occasion du tournage dans les années 1950 d'une rencontre d'un groupe de Ju/'hoansi avec des indigènes noirs et de taille plus grande revenant du travail dans les mines; cette séquence nous rappelle que les aspects interculturels de la vie des !Kung, bien que filmés par Marshall, ne sont pas présents dans ses films réalisés au début des années 1970. 


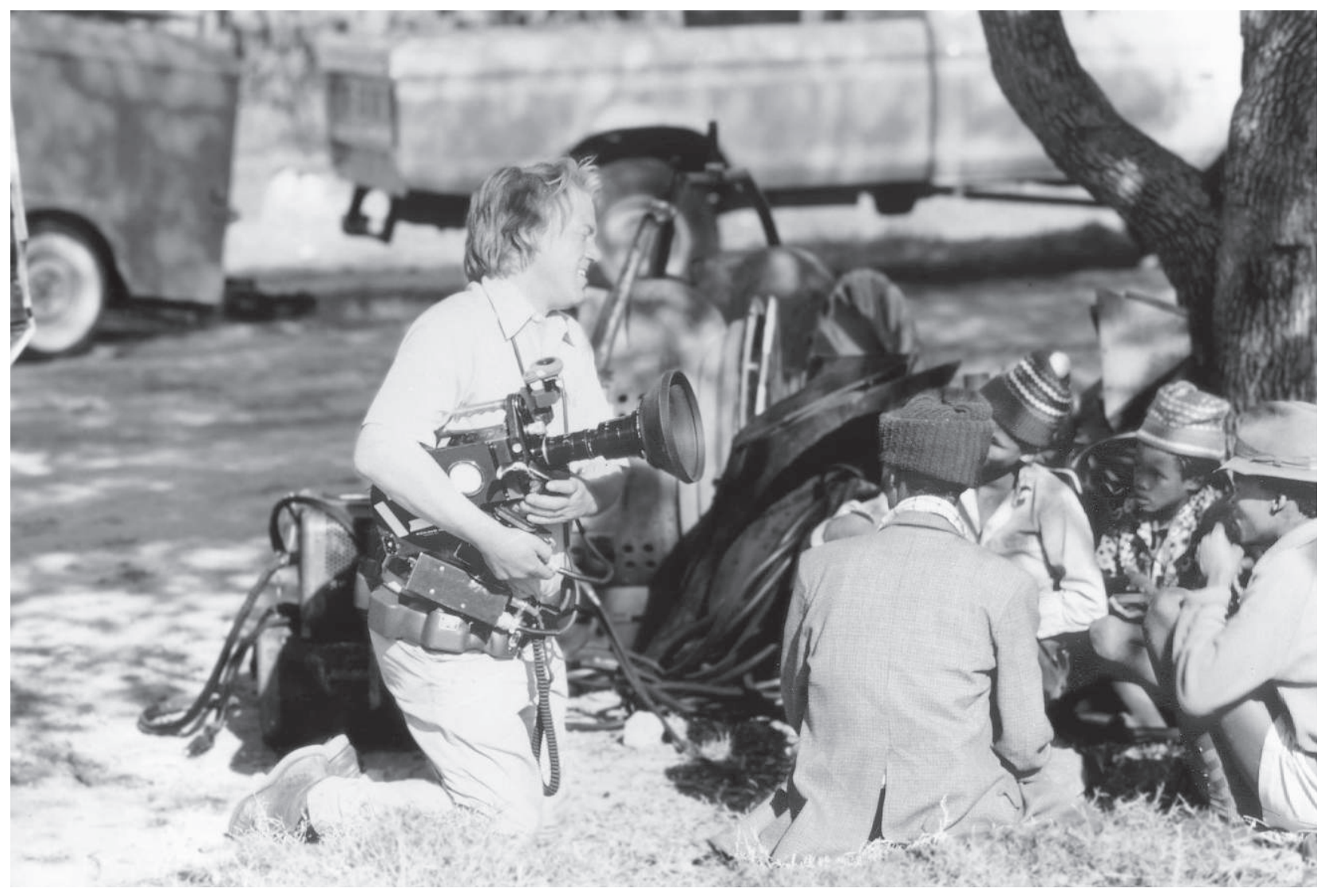


213 Le récit de John est écrit par celui-ci. Les propos des Ju/'hoansi sont extraits d'entretiens conduits dès les années i950; plus de vingt entretiens ont été enregistrés avec les principaux acteurs Ju/hoansi entre 1978 et 2000 (www. der.org/kalfam/series-credits).

214 Laurence Marshall et Anneliese Scherz ont pris les photographies utilisées dans cet épisode, ainsi que celles figurant dans la deuxième partie, prises également par Claude McIntyre (id.).

215 Ilisa Barbash, Where the Roads All End, op.cit., p. I85. Les photographies apportent aussi des informations biographiques sur les Marshall, en particulier Laurence. Voir Barbash pour des informations et des exemples du travail de photographes professionnels engagés par les Marshall sur leurs différentes expéditions.

216 Ross McElwee et Mark Erder ont aussi tourné des plans pour N!ai.
Les contacts noués entre la famille Marshall et les Ju/'hoansi sont évoqués oralement par les narrateurs Ju/'hoansi et John ${ }^{213}$. Lorna fait une apparition (filmée en i992). Elle commente le projet de la famille et fait part de ses impressions en lisant ses carnets d'expédition, ce qui constitue encore une autre façon de rapporter le public aux années 1950. Les relations entre la famille Marshall et les Ju/hoansi sont aussi visualisées pour la première fois, dans la série de documentaires sur les !Kung, à travers l'utilisation de photographies en noir et blanc ${ }^{214}$. Comme le note Ilisa Barbash, «l'association aux plans de récits intimes, parfois amusants, extraits d'entretiens, confère aux photographies le statut de preuves de la rencontre des Marshall et des Ju/'hoansi, témoignant de ce qui se passait en dehors du cadre photographique mais aussi à l'intérieur de celui-ci» ${ }^{215}$.

Le documentaire de 90 minutes "A Far Country» se termine sur des extraits de Men Bathing, probablement le plus beau film de John. Ces images resplendissantes sont rendues poignantes par la voix over de John. Il note qu'il faisait partie du groupe d'hommes qui se baignaient dans le point d'eau, et que ces plans ont été tournés lors de la dernière matinée passée parmi ses amis avant son expulsion en 1958 . «En y repensant», il est frappé «par la naïveté qu’il partage avec eux à l'égard de leur futur». Seulement une année après l'expulsion de John, les hommes filmés en train de se baigner avec un réel abandon ont été déplacés avec leurs familles dans une colonie de Tsumkwe. À la fin des années i950, les Marshall n’avaient «aucune idée de la rapidité et de la détermination avec laquelle la plupart de ces personnes renonceront à une vie de chasseurscueilleurs». On perçoit nettement une impression d'innocence perdue.

Les quatre épisodes suivants - «End of the Road», «Real Water», «Standing Tall» et «Death by Myth»- déroulent chronologiquement ce récit affligeant. La deuxième partie, «End of the Road», se concentre sur la fin des années I970, en repartant du retour longtemps attendu de John à Nyae Nyae en 1978 . Sa rencontre chaleureuse avec $\neq$ Toma témoigne de la proximité de leurs liens (et de la maîtrise du langage Ju/ hoan par John). De nombreux thèmes inscrits dans N!ai sont reconduits, à côté de plans tournés à la fin des années I970 qui illustrent les conditions de vie misérables des Ju/'hoansi demeurant à Tsumkwe ${ }^{216}$. En réponse au caractère idyllique des plans tournés en I950, John reconnaît que durant cette période «la vie était difficile pour les !Kung affa- 
més, mais ils se comportaient comme si ce n'était pas le cas». À la fin des années I970, les conditions et les attitudes ont drastiquement changé; les gens sont découragés, "pris au piège dans une logique d'aumône et un système d'emplois précaires».

₹Toma, filmé par John (assis par terre, proche de son père adoptif), fait remarquer en riant: "Ton père et moi sommes des chefs qui ne travaillent pas vraiment». Parallèlement à des photographies en noir et blanc, ₹Toma raconte son histoire et celle de sa famille à la fin des années I950, lorsqu'ils ont travaillé pour l'administrateur du gouvernement Claude McIntyre: un puits a été creusé; d'autres personnes se sont jointes à eux; ils ont créé des jardins et élevé des chèvres. Mais dix ans après le départ de McIntyre, les conditions de vie des Ju/'hoansi se sont considérablement détériorées; ils incarnent désormais la misère qui règne à Tsumkwe. John reconnaît que «les expéditions de sa famille ont joué un rôle dans l'occupation sud-africaine de Nyae Nyae», notamment par le biais des routes qu'ils ont créées dans ce territoire auparavant inexploré. John et sa collègue Claire Ritchie ont développé une Fondation pour le développement et encouragent les Ju/'hoansi à utiliser les routes pour quitter Tsumkwe, le quartier délabré de la réserve de Nya Nyae, et revenir à /Gautscha. L'épisode se clôt sur une note d'optimisme quand - avec surprise et plaisir - John découvre que $\neq$ Toma et sa famille ont quitté Tsumkwe du jour au lendemain pour revenir à leur cher/Gautscha. À présent accompagné de leurs animaux, le groupe tentera de développer un nouveau mode de vie communautaire.

La troisième partie, «Real Water», déplace le récit dans les années I980 pour évaluer les défis qui attendent les Ju/'hoansi à /Gautscha. Au milieu du film, l'un des narrateurs Ju/'hoansi déclare: «L'eau c'est la vie». «Real Water» se concentre sur ce fait crucial. Dans l'une des rares utilisations de plans des années 1950 dans cet épisode, des garçons Ju/'hoansi sont montrés en train d'extraire de l'eau de racines. Mais le bétail ne peut pas survivre avec l'eau extraite des racines. Soutenu par des fonds de charité étrangers pour trouver de l'eau, le forage commence. Toutes les personnes impliquées sont euphoriques lorsque l'eau salvatrice jaillit du trou de forage.

Les fonds de soutien internationaux aux Ju/'hoansi et la curiosité qu'ils éveillent se manifestent jusque dans l'intervention d'une équipe de télévision japonaise. Dans un entretien pour le Japon, John (qui est 
217 En dehors de cette équipe japonaise, d'autres opérateurs et opératrices ont filmé les activités de John durant les années I980 et par la suite. John a engagé des équipes pour tourner des événements qui se sont produits à Nyae Nyae, auxquels ils ont parfois pris part, de sorte à ce que la documentation visuelle ne cesse pas; treize personnes (en plus de Marshall) sont créditées à la caméra dans cette série (www.der.org/ $\mathrm{kalfam} /$ series-credits). présenté à l'écran comme un anthropologue) s'insurge contre «un gouvernement qui veut ramener [les Ju/'hoansi] à un pittoresque âge de pierre ${ }^{217}$. Le gouvernement tend à présenter les Ju/'hoansi comme une attraction touristique, de la même façon qu'il se pose en défenseur des lions et des éléphants. Les paysans Ju/'hoansi ne sont pas autorisés à tuer les lions qui attaquent leur bétail (bien que rapporter des trophées de chasse soit autorisé dans le pays). Les éléphants, totalement absents de Nyae Nyae dans les années 1950, marchent le long des routes; on en a décompté plus de 400 en i988. Non seulement ces énormes animaux assèchent les points d'eau, mais ils détruisent les trous de forages et les autres structures.

Réalisant qu'ils ont besoin de «nouvelles lois pour une nouvelle époque», les Ju/'hoansi ont formé une Coopérative de fermiers. Le fils de ¥Toma, Tsamko, suit les pas de son père en tant que dirigeant sage et efficace. On voit John prendre des notes, tandis que les hommes Ju/'hoansi, réunis sous l'éternel baobab, débattent de leurs stratégies. L'épisode se conclut sur un ton d'espoir et de solidarité; le narrateur Ju/'hoan prédit qu'uni sous la bannière de la Coopérative, «son peuple grandira comme un arbre solide».

La quatrième partie, «Standing Tall», se tourne vers le futur, suivant une stratégie énoncée par un Ju/hhoan qui affirme que «nous devons regarder les Blancs droit dans les yeux», et vers le passé, dans une séquence touchante lorsque Long Visage (John) montre des plans tournés en 1950 à Nyae Nyae à un groupe fasciné de Ju/'hoansi qui se pressent autour d'un petit écran de télévision. Les gens sont ravis de se reconnaître, eux ainsi que des proches aujourd'hui décédés. La valeur de ces «films de famille», en tant qu'incarnation de leurs «anciennes coutumes», est inestimable pour les Ju/'hoansi.

Les préoccupations à propos de l'accès à l'eau et des droits fonciers se poursuivent, encore problématisées par la compétition avec le peuple Héréro pour les maigres ressources à disposition. En I987, John et Claire Ritchie ont remis la direction de la Fondation pour le développement de Nyae Nyae à Megan Biesele, une anthropologue spécialisée dans l'autodétermination économique. Biesele a immédiatement été confrontée à des problèmes de financement. L'aide internationale apportée à la Namibie n'est presque jamais arrivée jusqu'aux paysans Ju/'hoansi, tels que /Kxao et/Qui. 
Lors d'un rassemblement pré-électoral (soutenu par la DTA/l'Alliance démocratique de la Turnhalle), un conflit éclate entre les partisans du peuple Héréro (qui financent la DTA) et John (qui, avec de nombreux Ju/'hoansi, soutient le SWAPO/l'Organisation du peuple du Sud-Ouest africain). John est attaqué pour usurpation et utilisation de la fortune de son père en n'apportant de soutien qu'«à quelques individus choisis, y compris lui-même». Lorsqu'on lui demande ce qu'il fait ici, il répond en colère: «Pour creuser 27 trous de forage. C'est un problème? Qu'est-ce que je fais ici? J'aide les gens à conserver leur terre!» ${ }^{218}$ L'épisode se termine sur la célébration des partisans du SWAPO et sur le départ de John. Dévisageant la caméra, l'un des Ju/'hoansi dit: «Merci, Long Visage. Nous te remercions tous.» Nous voyons les familles rassemblées; les enfants apprennent traditionnellement à jouer à l'arc; et un homme danse avec joie, reliant les coutumes ancestrales aux espoirs futurs.

La cinquième partie, «Death by Myth», clôt la série. À nouveau, John est de retour à Nyae Nyae. Nous sommes en 1992. John explique à ses amis qu'il a plaidé en leur faveur dans les milieux les plus haut placés, écrivant au président de la Namibie (avant de le rencontrer), Samuel Njoma, et témoignant lors d'une audience au sujet des droits territoriaux communautaires. Un jugement a été prononcé en faveur de la Coopérative Ju/'hoansi, stipulant que les Héréros doivent quitter les lieux. Dans son récit, John affirme que «tout va dans le bon sens», après une période où les Ju/'hoansi «ont évité de justesse un état de quasi-esclavage». Néanmoins les problèmes perdurent, le plus important étant relatif à la détermination du gouvernement à maintenir les !Kung à l'état d'« espèce sauvage protégée».

John reconnaît que ses premiers films, à l'instar des comédies de Jaime Uys et des représentations véhiculées par d'autres media, ont créé une image de Bochimans fiers et isolés qui se nourrissent de chasse et cueillette. Cette image stéréotypée de chasseurs-cueilleurs, malheureusement, ne séduit pas seulement les touristes internationaux, mais aussi le gouvernement et les organisations non gouvernementales officielles. Cette représentation est néfaste aux Ju/'hoansi à l'époque contemporaine ${ }^{219}$. Suite à la division de la terre et à l'oubli de techniques ancestrales par les nouvelles générations, le peuple !Kung m’a plus été en mesure de survivre de la chasse et la cueillette dans les années i99o. Ils sont «condamnés à mort par le mythe», s'ils ne s'adaptent pas aux
218 Les scènes où figure John sont bien évidemment filmées par un autre opérateur. Les crédits de la cinquième partie indiquent huit opérateurs, en sus de John (ibid.).

219 Par exemple, People of the Great Sandface (1985), réalisé et commenté par Paul John Myburgh, qui a été diffusé en I986 sur Channel 4 en Grande-Bretagne sous forme d'une série de quatre épisodes, a été virulemment critiqué par John en 1990 lors d'une réunion de la Northeastern Anthropological Association, ce film perpétuant selon lui le mythe des Bochimans en tant que bons sauvages. 
exigences d'une économie plurielle et à de nouvelles façons de subvenir à leurs besoins. Un autocrate allemand a repris la direction de la Fondation, s'écartant de la mission première qui consistait à établir des fermes. Il a été remplacé par un Hollandais plus jeune et mieux disposé mais qui croit encore au mythe, comme le font les représentants de l'Agence des États-Unis pour le développement international (avec un budget de ı6 millions de dollars) qui recommandent la création de «zones tampons dans des parcs nationaux» pour les !Kung. Même Tsamko est devenu un partisan de la Préservation de la Nature, convaincu que les Ju/'hoansi profiteront de l'activité des chasseurs, des cinéastes et d'autres «touristes culturels». Plus loin dans le film, nous voyons un faux village Bochiman, où des !Kung habillés en habits traditionnels prétendent vivre «selon les coutumes ancestrales» pour répondre aux demandes de touristes «intéressés par le savoir-faire des San».

Un espoir demeure quant à la capacité à diriger des Ju/'hoansi, désormais transmise à une nouvelle génération. Le petit-fils de $\neq$ Toma, Moses, est un fonctionnaire qui parle anglais et qui a été élu directeur de la Coopérative des fermiers, incluant jusqu'à 35 communautés. Et John Marshall poursuit ses activités déterminées de lobbying. À une réunion de la Fondation pour le développement en 1994, John a ignoré la requête qui lui ai faite de ne pas filmer et laisse tourner sa caméra de guérilla. On tente de l'expulser de la réunion, mais il s'y oppose, soulignant non seulement qu'il est l'un des fondateurs de la Fondation, mais encore qu'il «en connaît plus que quiconque ici». John pense que le but initial de la Fondation - «aider les gens à s'aider eux-mêmes»- a été perdu de vue, alors que les membres de l'équipe ont augmenté (désormais 32) et que l'argent (totalisant 3,5 millions de dollars) a été dépensé en construisant des bureaux, en achetant des véhicules et en constituant des rapports et des études, plutôt qu'en formant et éduquant les Ju/'hoansi ou qu'en les aidant à protéger leurs ressources en eau.

Un épilogue montre John qui revient en 2000 à Nyae Nyae pour sa quinzième (et dernière) visite. Les fermes redémarrent; cinq écoles de village ont été inaugurées; Tsamko règle les différends; sa sœur Bao est devenue agent de santé; !U, la veuve de $\neq$ Toma, fabrique et vend des colliers aux touristes. Nombreux sont ceux qui veulent relancer l'activité des fermes, mais la plupart d'entre eux survivent grâce aux rations de farine de maïs distribuées par le gouvernement. En 200I, six 
membres résolus de la famille de ₹Toma continuent à vivre à /Gautscha. La série se clôt sur le rappel que la mémoire de ₹Toma survivra, mais le futur de sa famille est loin d'être assuré, tandis que ce film émouvant touche à sa fin.

Marshall et ses collègues ont travaillé sur A Kalahari Family pendant quatorze ans ${ }^{220}$. Immergée dans une masse de documents visuels et sonores accumulés pendant plus de cinq décennies, l'équipe devait relever le défi de présenter le parcours complexe d'une famille Ju'hoan et de tout un peuple à un public qui n'est pas du tout familier (on peut facilement le comprendre) de l'histoire des Bochimans et de la Namibie contemporaine ${ }^{221}$. La série ne se limite ainsi pas à l'histoire d'une famille africaine lointaine qui a lutté contre la dépossession, la délocalisation et les défis de l'adaptation, mais devient aussi l'histoire d'une famille américaine intrépide qui s'est consacrée à l'étude attentive et à la documentation d'une famille Ju'hoan et, ce qui est le plus important, à apprendre à la connaître. À travers les comptes rendus de John (et de Lorna), les commentaires et les souvenirs de $\neq$ Toma et de sa famille, la profondeur et la longévité des liens entre ces deux familles sont révélées, à tel point que le titre de la série revêt une nouvelle signification. Comme Scott McDonald l'a suggéré, le titre au singulier encourage les spectateurs à appréhender les Marshall et les familles Ju/'hoansi comme unies ${ }^{222}$ - et à considérer ce film comme l'odyssée personnelle de John en tant que cinéaste et membre d'une famille. Son plaidoyer pour les !Kung traverse la série jusque dans les derniers épisodes. Selon Elizabeth,

Au moment du décès de John en 2005, il était en train de monter A Kalahari Family en vue de sa présentation sur PBS [American Public Broadcasting System] pour propager plus largement son message. Il consacra ses dernières forces à aider son peuple d'adoption, comme il l'avait fait pendant cinquante-cinq ans suite à leur première rencontre. ${ }^{223}$

Aujourd'hui, en 20I9, la série n’a toujours pas été diffusée sur les chaînes américaines, mais elle a été présentée sur la télévision namibienne à la fréquence de 30 minutes par semaine, pendant douze semaines ${ }^{224}$.

\section{Par-delà le cinéma ethnographique}

Ce qui avait débuté comme une aventure familiale pour les Marshall devint une entreprise ethnographique sérieuse, qui témoigne finalement
220 John a réalisé ou coréalisé les cinq épisodes; Claire Ritchie a coréalisé les parties deux et trois. Au début du projet, John l'a décrit comme «le film de Claire; ce qu'elle veut faire, c'est une sorte d'histoire, de synthèse [...] à partir du témoignage des gens, comme dans N!ai, avec plusieurs personnages qui se font les porte-paroles de différentes périodes et de différents aspects» (John Marshall, «Filming and Learning», op. cit., p. 157).

221 La série intègre des matériaux (pour certains jamais montrés auparavant) extraits des archives des Bochimans Ju/'hoansi, qui comprennent plus d'un million de pieds de films I6mm et des centaines d'heures de vidéo, ainsi que des dizaines de milliers de photographies, une collection ethnographique sans égal. DER avance ces chiffres dans son matériel promotionnel.

222 Scott MacDonald, American Ethnographic Film and Personal Documentary, op. cit., p. 55 .

223 E. M. Thomas, The Old Way, op.cit., p. 289 .

224 E-mail de Frank Aveni, DER, à l'auteure, le 28 juin 20 I 8 . 
225 Paul Theroux, «Foreward: Families in the Field», dans Ilisa Barbash, Where the Roads All End, op. cit., p. XVI.

226 Lorna avait Ior ans quand elle publia Nyae Nyae !Kung: Beliefs and Rituals, Cambridge, Mass., Peabody $\mathrm{Mu}$ seum of Archeology and Ethnology/ Harvard University, I999. Elle est décédée en 2002. Elizabeth publia The Old Way (op. cit.) en 2006 et Dreaming of Lions (op. cit.) en 2013 (réédité en 20ı6).

227 Ce portrait de I6 minutes (2006) a été réalisé par Alice Apley et David Tamès; le court métrage documentaire présente des extraits de films de John et les souvenirs de sa famille, de ses collègues et amis. d'un rare alliage de ressources financières, d'opportunités, de dévouement et de compétences. Comme Paul Theroux l'écrit, «[] es Marshall - pleins de ressources, rapides et efficaces, curieux, audacieux, humains - ont présenté leurs sujets comme un reflet de leur propre image en miroir ${ }^{225}$. Malgré le décès de Laurence en 1980 , le projet de la famille s'est poursuivi et élargi. Lorna et Elizabeth ont toutes deux publié de nouveaux ouvrages sur les!Kung, et Elizabeth est retournée à deux reprises à Nyae Nyae dans les années I980; cependant, c'est John qui reste physiquement en contact avec sa famille Kalahari durant les années i980 et 1990 à travers son engagement pour le développement ${ }^{226}$.

Juste avant son décès, la contribution de John au cinéma ethnographique a été reconnue à travers le Lifetime Achievement Award de la Society for Visual Anthropology et par l'intégration de The Hunters au National Film Registry de la Library of Congress. Par la suite, la Ju/'hoan Bushmen Film and Video Collection a été intégrée au Registre de la mémoire du monde de l'UNESCO; un John Marshall Award for Contemporary Ethnomedia a été créé; le Musée des beauxarts de Boston a organisé un «Hommage à John Marshall»; Anthology Film Archives à New York a organisé une rétrospective des films de John; et en hommage, DER a produit un court métrage, Remembering John Marshall ${ }^{227}$.

Les films de John Marshall portent le flanc à la critique; avec le temps, leur analyse a alimenté des débats cruciaux portant sur l'éthique et la politique du cinéma interculturel. Ces débats se poursuivent. La documentation ethnographique du peuple !Kung que John Marshall a laissée est inégalée (près de deux millions de pieds de films $16 \mathrm{~mm}$; 40 heures de vidéo); sa valeur s'accroîtra avec les années. Mais peu avant son décès, ce qui comptait le plus aux yeux de John Kennedy Marshall, c'était son travail se situant au-delà du cinéma ethnographique: son rôle dans le développement et la défense de ses amis Ju/'hoansi, en collaboration avec eux, pendant une période de crise. La loyauté de John tout au long de sa vie envers $¥$ Toma et sa famille a conduit Marshall à consacrer les dernières décennies de sa vie à travailler pour et avec les Ju/'hoansi dans leur combat pour l'autodétermination. John ne considérait pas $A$ Kalahari Family comme un film important parce qu'il constituait un tour de force cinématographique, parce qu'il retraçait le projet de la famille Marshall ou parce qu’il résumait et concluait sa carrière cinéma- 
tographique, mais parce qu'il constituait un outil de soutien en faveur des Ju/'hoansi dépossédés. Elizabeth Marshall se souvient d'une amie anthropologue, «venue visiter [s]on frère alors qu'il était au chevet de la mort; et il lui avait demandé de poursuivre son travail avec les fermiers. Elle a dit qu'elle le ferait. ${ }^{228}$
228 E. M. Thomas, The Old Way, op. cit., p. 3ı. L'amie de John et Elizabeth, Polly Wiessner, vendit les terrains qu'elle avait au Vermont et remit cet argent aux Ju/'hoansi pour la construction de puits, de pompes à eau et de barrière contre les éléphants en hommage à John. Wiessner a conduit des études démographiques à Nyae Nyae et créé le Tradition and Transition Fund. Id., pp. 3Io-3II. 